\title{
VARIAÇÃO GENÉTICA EM PROGÊNIES DE UMA POPULAÇÃO DE Eucalyptus Grandis (HILL) MAIDEN
}

PAULO YOSHIO KAGEYAMA

Orientador: PROF. DR. ROLAND VENCOVSKY

Tese apresentada à Escola Superior de Agricultura "Luiz de Queiroz", da Universidade de São Paulo, para obtenção do título de Doutor em Genética e Melhoramento de Plantas.

P I R A C I C A B A

Estado de São Paulo - Brasil

Outubro - 1980 


\section{CURRICULUM VITAE}

O autor, engenheiro agrónomo silvicultor Pau10 Yoshio Kageyama, nasceu a 03 de dezembro de 1945 em Santo Anastācio-SP. Concluiu o curso de engenharia agronômica na Escola Superior de Agricultura "Luiz de queiroz", em Piracicaba-SP, em dezembro de 1969. Atuou como engenheiro agrônomo silvicultor em companhias florestais de janeiro de 1970 até novembro de 1972, quando então iniciou-se no campo da pesquisa florestal, tendo sido contratado pelo Instituto de Pesquisas e Estudos Florestais - IPEF, em Piracicaba-SP, onde atuou até setembro de 1977. Obteve o seu grau de Mestre em Genética e Melhoramento de Plantas, pelo Departamento de Genética da ESALQ/USP, em Piracicaba, apresentando sua dissertação em 12 de junho de 1977. Iniciou sua carreira como docente em 20 de setembro de 1977, tendo sido contratado pelo Departamento de Silvicultura da ESALQ/USP, em Piracicaba, onde continua até a presente data.

Nesse Departamento, $\bar{e}$ responsāvel pelo setor de Produção e Tecnologia de Sementes Florestais, desenvolven do atividades de ensino e pesquisa nos campos de melhoramento blorestal e produção e tecnologia de sementes florestais. $E$ assessor para assuntos de melhoramento genētico e produção de sementes florestais do Instituto de Pesquisas. e Estudos Florestais - IPEF, em Piracicaba, desde novembro de 1977. 0 principal enfoque que vem dando na sua atividade de pesquisa é o da aplicação da genética quantitativa no melhoramento blorestal. 
.iii.

\section{AGRADECIMENTOS}

Este trabalho é fruto da pesquisa que venho desenvolvendo no campo do melhoramento florestal e que repre senta, sem dūvida, os conhecimentos e experiências adquiridos junto aos professores, principalmente do Departamento de Genética da ESALQ, junto aos colegas do Departamento de Silvicultura da ESALQ e do Instituto de Pesquisas e Estudos Flo restais - IPEF e junto aos meus alunos do Curso de Engenharia Florestal da ESALQ, aos quais sou muito grato.

Os meus agradecimentos sinceros ao meu orientador neste trabalho, Professor Roland Vencovsky, pela sua dedicação e interesse em adentrar no campo do. melhoramento florestal, e que sem dūvida enriqueceu ainda mais o traba1 ho.

Quero também agradecer aos meus colegas Fátima C. M. Märques, Sebastião Machado da Fonseca, Admir Lopes Mora, Edson Antonio Balloni e Walter de Paula Lima, pelas contínuas discussões acerca do trabalho desenvolvido e que, juntamente com as valiosas sugestões dos professores José Branco de Miranda Filho e Isaias 0. Geraldi, auxiliaram, sobremaneira no desenvolvimento do mesmo.

Não poderia também deixar de agradecer ao Dí lei W. Senne, à Sueli Penteado e à Sônia Novaes Rasera, pela colaboração na organização e computação dos dados e nos trabalhos de datilografia.

Finalmente, os meus agradecimentos ao IPEF, através das companhias associadas que conduziram os ensaios, e ao Conselho Nacional de Desenvolvimento Científico e Tecno 
lógico - CNPq, que forneceram condições para a realização a contento deste trabalho.

Uma deferência muito especial à Angela e à Cạ roline que me incentivaram e participaram em todos os momentos, principalmente nos maus pedaços, dessa importante fase da minha vida profissional. 
1. RESUMO

2. INTRODU ÇÃO $\ldots \ldots \ldots \ldots \ldots \ldots \ldots \ldots \ldots \ldots \ldots \ldots \ldots \ldots \ldots \ldots \ldots$

3. REvisão de literatura $\ldots \ldots \ldots \ldots \ldots \ldots \ldots \ldots \ldots \ldots \ldots \ldots \ldots$

3.1. Ensaios de progênies em espécies florestais 7

3.2. Estimação de parâmetros genéticos em espé-

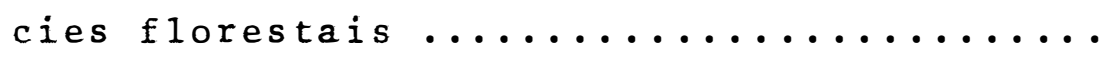

3.3. Estimativas de herdabilidade para as princí pais caracteristicas das ärvores ...........

3.4. Ganhos genéticos para seleção entre e den-

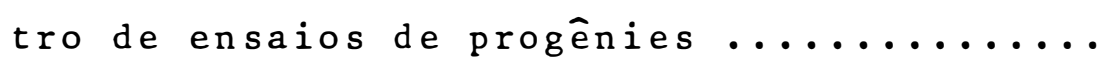

4. MAterial e métodos $\ldots \ldots \ldots \ldots \ldots \ldots \ldots \ldots$

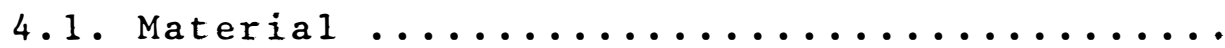

4.1.1. Caracterização da população que deu origem às progênies ...............

4.1.2. Especificação dos materiais nos 1ocais de experimentação .......... 36

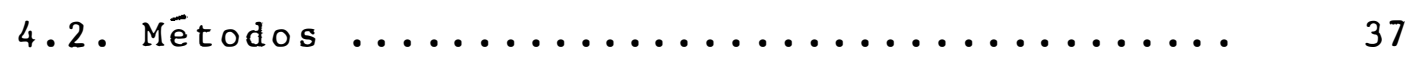

4.2.1. Instalação dos ensaios ......... 37

4.2.2. Coleta de dados dos ensaios ....... 39

4.2.3. Anälise estatística .......... 41

4.2.3.1. Análise de variância indivi dual para cada local .....

4.2.3.2. Anālise de variância conjun ta para os cinco locais ...

4.2.3.3. Análise de covariância ... 45

4.2.4. Estimação de parâmetros genéticos .. 48 4.2.4.1. Estimą̧ão de variâncias genéticas ................. 
. vi.

pāgina.

4.2.4.2. Estimativas de covariâncias genéticas e de correlações genéticas entre pares de ca racterísticas ...........

4.2.4.3. Estimativas de progressos genéticos na seleção ......

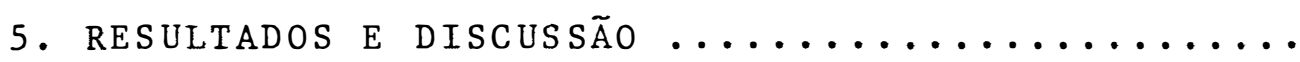

5.1. Crescimento em altura e sobrevivência das plantas aos 12 meses de idade ..........

5.2. Resultados da avaliação de altura, DAP, volume cilíndrico, sobrevivência e forma do tronco das árvores, aos dois anos de idade.

5.3. Resultados das análises da variância indivi duais e conjuntas para as cinco caracteristicas, aos dois anos de idade ...........

5.4. Estimação de variâncias genéticas e de coeficientes de herdabilidade para a altura, o DAP e a forma do tronco das àrvores nos cin co locais de ensaios, aos dois anos de ida-

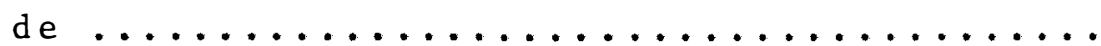

5.5. Estimação de ganhos genéticos com a seleção entre e dentro de progênies para a altura, o DAP e a forma do tronco das árvores, nos cinco locais de ensaios, aos dois anos de

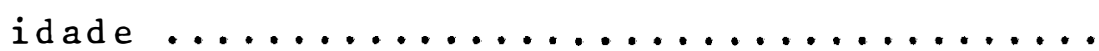

5.6. Coeficientes de correlações genéticas e fenotipicas entre as características de altura, DAP, volume cilíndrico e forma do tronco das árvores, nos cinco locais de ensaios,

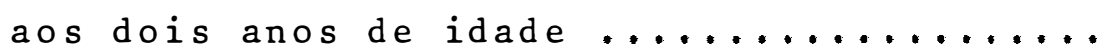


.vii.

pāgina.

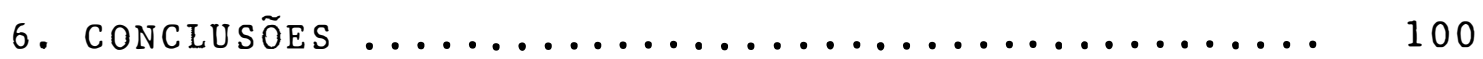

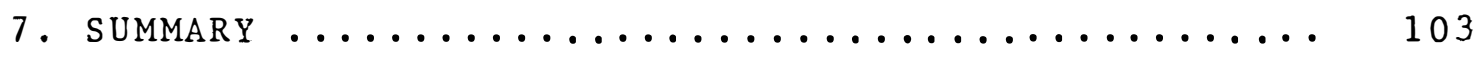

8. Literatura citada $\ldots \ldots \ldots \ldots \ldots \ldots \ldots \ldots \ldots \ldots \ldots$

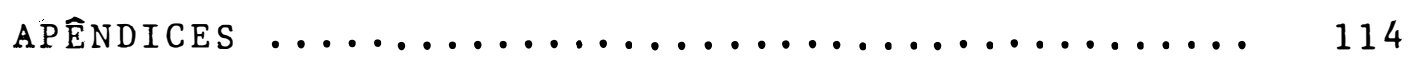




\section{RESUMO}

0 presente trabalho é um estudo da variação genētica em progênies de polinização livre de Eucalyptus grandis (Hil1) Maiden de árvores selecionadas fenotipicamente em população-base origināria de Coff's Harbour - Autrália.

Os ensaios foram instalados em cinco locais: Agudos, Anhembi, Brotas, Lençóis Paulista e Resende, em novembro e dezembro de 1976. O delineamento utilizado foi o látice triplo com 64 ( $8 \times 8$ ) tratamentos, envolvendo as progênies de ärvores selecionadas da população-base, progênies de outras populações, testemunha comercial e amostra de popu 1 ação-base sem seleção.

Os resultados obtidos no primeiro ano revelaram um crescimento médio em altura, nos cinco locais de en saio, de 5,27 metros, variando de 4,24 (Brotas) a 6,11 metros (Resende), mostrando o potencial do material genético nas condições estudadas. A população-base de E. grandis estudada apresentou, nessa idade, considerável variação genéti ca para a altura de plantas em todos os locais estudados, mostrando a possibilidade de seleção e melhoramento. A va- 
riação genética para a sobrevivência de plantas nas parcelas, por sua vez, foi menos expressiva, e variável de local para local.

As estimativas de ganhos realizados na seleção fenotípica das ärvores que geraram as progênies foram em média de 5,65\% para a altura de plantas, nos cinco locais., com um ano de idade, mostrando a variação entre materiais com e sem seleção desde as idades iniciais.

Os dados de crescimento em altura aos dois anos de idade, com média de 12,08 metros nos cinco locais, confirmam o potencial de crescimento do material genético testado. As estimativas de ganhos realizados na seleçãofenotípica, aos dois anos de idade, foram similares às obtidas no primeiro ano para a altura de plantas e equivalentes a $6,22 \%$. Essas estimativas foram de $24,3 \%, 13,43 \%, 8,41 \%$ e $1,59 \%$ para a sobrevivência, a forma do tronco, o volume cilindrico e o DAP, respectivamente, indicando os avanços gené ticos obtidos pela utilização de um ciclo de seleção fenotípica na população em estudo.

Ao nível de locais individuais, aos dois anos de idade, foram detectadas variações genéticas diferenciais entre progênies para todas as caracteristicas estudadas, embora tenham sido constatadas variações significativas para a maioria das características nos diversos locais. Os valores de eficiências dos lätices encontrados justificaram a instalação dos experimentos nesse tipo de delineamento.

Ao nivel de locais em conjunto, aos dois anos de idade, foram detectadas variações genéticas entre progênies para todas as características estudadas, exceto para a sobrevivência das plantas. 0 efeito de locais mostrou-sesig nificativo e bastante expressivo para todas as caracteristi- 
cas estudadas. 0 efeito da interação de progênies por 1ocais mostrou-se também significativo para todas as características, refletindo-se na redução das herdabilidades e, por tanto, na seleção para locais em conjunto.

As variâncias genéticas entre progênies, estí madas para altura, DAP e forma do tronco, mostraram boas pre cisões, a julgar pelos baixos desvios padrões encontrados. As herdabilidades no sentido restrito estimadas ao nível de plantas foram similares às obtidas entre plantas dentro de progênies, e que, por sua vez, foram bem inferiores às obtidas ao nível de média de progênies para as características estudadas. As estimativas dos diferentes tipos de herdabili dades foram de maiores magnitudes para a forma do tronco,vin do a seguir a altura e o DAP, mostrando as perspectivas de resposta à seleção dessas características.

As estimativas de ganhos genéticos com a sele ção entre e dentro de progênies nos locais individuais mostraram razoáveis avanços genéticos para as três característi cas estudadas, revelando a possibilidade de sucesso da seleção dentro de cada ensaio. Em função dos avanços verificados na seleção fenotípica para a forma do tronco, da correla ção positiva e alta entre as características de crescimento (altura, DAP e volume cilíndrico) e da ausência de correlação entre a forma do tronco e o crescimento, a seleção dentro dos ensaios deverá ser centrada nas características de crescimento mais do que na forma do tronco. 
o eucalipto, pela sua extensa área plantada no Brasil, e pelo seu potencial de utilização como matériaprima para as indústrias madeireiras, representa, sem dúvida, o nosso mais importante gênero de espécie florestal exótica.

Desde a introdução do eucalipto no Brasil por Edmundo Navarro de Andrade, no início do século, extensas plantações têm sido efetuadas, principalmente a partir de 1966, através dos incentivos fiscais governamentais concedidos ao reflorestamento, e que deram grande impulso ao plantio de florestas em nosso país.

Segundo as estimativas feitas pelo Instituto Brasileiro de Desenvolvimento Florestal, a área total reflorestada no Brasil através dos incentivos fiscais, no período de 1966 a 1976, foi de 2.300 .000 ha, sendo que desse total um percentual de $60,0 \%$ se refere às plantações efetuadas com espécies do gênero Eucalyptus. A área anual reflorestada com eucaliptos, atualmente, é da ordem de 200.000 ha, que mostra a importância dos mesmos para nossa industria madeireira.

Dentre as espécies de eucaliptos mais usualmente utilizadas no Brasil destacam-se: $E$. grandis 
Maiden, E. saligna Smith e E. urophylla, sendo que a madeira dessas espécies destina-se principalmente à indústria de celulose e papel, chapas duras e para a produção de carvão. Grande ênfase vem sendo dada atualmente para sua utilização em indústria de serraria.

0 E. grandis, pelas suas características silviculturais e tecnológicas favoráveis, aliadas ao seu bom comportamento em amplas condições ecológicas, vem tomando ca da vez mais importância tanto no Brasil como em outros países com clima tropical, merecendo cada vez mais importância em termos de melhoramento genético.

A grande facilidade de cruzamento entre espécies do gênero Eucalyptus, associada à falta de cuidados no isolamento dos talhões inicialmente implantados, provocou uma hibridação desregrada entre espécies e que revela, para a maioria das plantaşões existentes em nosso meio, uma mistu ra de híbridos em diversos graus e entre diversas espécies, dificultando sobremaneira a utilização dessas populações em programas de melhoramento genético, já que é recomendāvel umá certa uniformidade para a população e uma manutenção das características da espécie.

Em função dessa realidade existente, os programas de melhoramento com eucaliptos, que vêm sendo conduzi dos no Brasil, vêm se utilizando da reintrodução de novos ma teriais genéticos, provenientes de coleta de sementes nas re giões de origem, feitas principalmente por órgãos oficiais da Austrália.

Os esquemas adotados para o melhoramento genetico e produção de sementes melhoradas de espécies exóticas, generalizadamente, podem ser resumidos nas seguintes etapas:

a. introdução de espécies, 
b. ensaio de procedências dentro de espécies,

c. seleção dentro de populações-base.

A seleção fenotípica individual dentro de populações-base adequadas e sua utilização para a produção de sementes melhoradas através dos "Pomares de Sementes", tanto por clones como por mudas, constitui-se num dos métodos mais correntes no melhoramento florestal.

Os testes de progênies, instalados tanto a partir de sementes de polinizaçöes livres como de cruzamentos controlados, representam uma das mais úteis ferramentas para o melhorista florestal. A sua utilização tem sido importante para a determinação do valor reprodutivo dos indiví duos selecionados, na estimativa de parâmetros genéticos, pa ra a seleção de novos indivíduos superiores e como fonte de produção de sementes atravēs de sua transformação em pomar de sementes por mudas.

o presente trabalho tem por objetivo:

a. Estudar o comportamento de progênies de ár vores superiores de E. grandis selecionadas em populações de origem australiana.

b. Obter informações sobre o potencial das progênies em diferentes localidades e as possíveis interações de progênies por locais.

c. Estimar os parâmetros genéticos da população em estudo, para as principais características silvicultu rais.

d. Prover. uma fonte de material para a continuidade de programa de melhoramento genético com a espécie. 


\section{REVISÃO DE LITERATURA}

\subsection{Ensaios de progēnies em espēcies florestais}

Os ensaios de progênies, instalados tanto a partir de sementes de polinizações livres como de cruzamentos controlados, representam uma das mais úteis ferramentas para o melhorista florestal.

Segundo colocam SHELBOURNE e COCKREM e KEIDING (1974), os principais objetivos dos testes de progênies utilizados em programas de melhoramento florestal poderiam ser assim relacionados:

a. Estimar a capacidade geral de combinação de clones com o objetivo de ordenā-los e reselecionar os melhores.

b. Estimar a capacidade específica de combina ção e identificar cruzamentos particulares entre dois pais que mostrem alta especificidade nos cruzamentos.

c. Estimar os parâmetros genéticos tais como variâncias aditivas e dominantes, coeficientes de herdabilidade, correlações genéticas, etc. 
d. Prover uma fonte de material genético para futuras seleções.

e. Predizer os ganhos a serem obtidos.

Diversos são os esquemas para geração de progênies que vêm sendo utilizados em espécies florestais, tanto para a avaliação do valor genotípico dos progenitores como para a determinação de parâmetros genéticos das populações. SHELBOURNE e COCKREM (1969) enfatizam a necessidade de se estabelecerem prioridades, já que esses dois principais objetivos dos testes de progênies geralmente não são compatíveis, havendo a necessidade de delineamentos adequados para os diferentes aspectos.

Dentre os esquemas para geração de progênies mais utilizados em espécies florestais podem-se citar:

a. Teste de progênié clonaz

Esse método de teste de progênie, obtido a partir de propagação vegetativa, tem sido bastante utilizado em espécies florestais apesar de fornecer informações genéti cas restritas. O aproveitamento dos "Pomares de Sementes clonais" instalados a partir de enxertia ou estaquia como teste de progênie clonal tem sido bastante comum. Também, pạ ra espécies florestais em que as plantações são efetuadas a partir de estacas enraizadas, tal como em Populus spp., esse tipo de teste de progênie tem sido útil (MOHN e RANDALL, 1971 ).

Através desse método foram obtidas estimati vas de herdabilidade no sentido amplo para densidade da madeira de Pinus radiata por FIELDING e BROWN (1960); para den sidade, comprimento de traqueídeos e desvio da grã da madei- 
em Pinus radiata por NICHOLLS (1967); para comprimento de traqueídeo da madeira de $P$. elliottii var. elliottii e $P$. radia ta por SMITH (1967); para altura, diâmetro, fator de forma, diâmetro da copa e espessura da casca em Criptomeria japonica por TODA (1972); para a altura e diâmetro em Populus deltoides por MOHN e RANDALL (1971); para frutificação em P.elliot tii var. elliottii por VARNELL et alii (1967); dentre outros.

b. Progénies de polinizacão aberta

Esse método de produzir progênies e obtenção de estimativas de parâmetros genéticos é o que mais vem sendo utilizado em espécies florestais. Isso se justifica pela sua facilidade de instalação em relação aos ensaios de progê nies que exigem polinização controlada. No entanto, o que se verifica é um aproveitamento dos ensaios de progênies,que prioritariamente têm o objetivo de testar ärvores mães para um programa de "Pomar de Sementes", para a obtenção de estimativas de parâmetros genéticos da população.

Dessa forma, o que se verifica nos ensaios de progênies é a inclusão de indivấduos selecionados na população e não uma amostra tomada ao acaso da mesma, condição essencial para que as estimativas dos parâmetros sejam genera1 izadas para essa população. Contudo, TODA (1972) 1evanta essa questão, mostrando que a seleção de indivíduos na popu1 ação reduzirá os valores da variância total e variância entre familias na mesma taxa, mantendo mais ou menos constante a estimativa da herdabilidade.

Ensaios específicos para determinação de parâa metros genéticos têm sido pouco comuns em espécies florestais, porém, informações bäsicas sobre componentes da variação genética entre e dentro de populações foram e vêm sendo 
conduzidos, tal como o trabalho de SHELBOURNE e STONECYPHER (1971), onde os autores tomam 280 árvores ao acaso de uma po pulação, num estudo de progênies de polinização livre, especificamente para a determinação de parâmetros genéticos. Po rém, a maioria dos ensaios envolvendo progênies de polinização aberta revela um nūmero relativamente pequeno de famí1ias, normalmente bem abaixo de 50, e comärvores não tomadas ao acaso da população.

Segundo SHELBOURNE e COCKREM (1969), o teste de progênie de polinização aberta é o método mais barato e atrativo, apesar das desvantagens e restrições que o mesmo apresenta em relação aos testes de progênie de polinização controlada.

Como jà salientado, a estimativa de parâmetros genéticos através de progênies de polinização aberta, apesar das restrições apresentadas, vem sendo a metodologia mais utilizada em espécies florestais. Dentre os inūmeros trabalhos podem-se citar o de SMITH (1967), para diversas ca racteristicas da madeira em $P$. elliottii var. elliottii e $P$. taeda; VARNELL et alii (1967), para frutificação em P. elliottii var. elliottii; HOLST e TEICH(1969) para caracteristicas de crescimento e forma do tronco em Picea glauca; SHELBOURNE et alii (1969), para características de crescimento e qualidade da madeira em P. taeda; ELDRIDGE (1972), para caracteristicas de crescimento e forma do tronco em Eucalyptus regnans; SHELBOURNE e STONECYPHER (1971), para características e forma do tronco em $P$. taeda; MATZIRIS e ZOBEL para caracteristicas de crescimento, forma do tronco, qualidade da madeira e infecção por Cronartium fusiforme em $P$. taeda; MORGENSTERN (1974) para altura de árvores em Picea ma riana; SQUILLACE et alii (1975), para altura e resistência a Lophodermium pinastri em $P$. sylvestris; NAMKOONG e CONKLE (1976), para altura de plantas em $P$. ponderosa; dentre ou- 
tros.

Esse métodoé, sem dūvida, o que mais vem merecendo a atenção da maioria dos programas de melhoramento, justamente devido a sua facilidade de instalação e condução, além de atender os objetivos tanto da determinação da capaci dade geral de combinação como de parâmetros genéticos.

c. Progênies obtidas por policruzamentos

O teste de "top-cross" utilizado em culturas anuais, onde 1 inhas endogâmicas são cruzadas como machos com uma uniforme população de fêmeas, foi adaptado em espécies florestais para testar a capacidade geral de combinação (CGC) de ärvores de "Pomares de Sementes", através do teste denomina do de policruzamento ("poli-cross"). Por esse método, cada clone é polinizado artificialmente com uma mistura de pólen de uma amostra de clones do pomar, podendo-se tomar os que produzem maior quantidade de pólen, os que iniciam o florescimento mais precocemente, ou simplesmente clones tomados ao acaso (BURLEY et alii, 1966).

Esse tipo de teste de progênie é equivalente ao de polinização livre, considerando portanto o parentesco de meios-irmãos para as progênies. 0 delineamento de policruzamento leva vantagem, no entanto, pois a amostra de pólen nesse caso é mais representativa da população de pólen. Isso se torna mais flagrante quando temos uma variabilidade muito grande na produção de pōlen entre as ärvores, existindo o risco de que haja a predominância de pólen de uma ou poucas ärvores.

Esse método, como implica em cruzamentos controlados e não fornece informações além da capacidade geral de combinação, tem sido bem pouco utilizado nos programas de 
melhoramento florestal. A partir de polinização controlada, outros delineamentos que fornecem também a capacidade especi fica de combinação (CEC) têm sido utilizados.

\section{d. Delineamento I da Carolina do Norte}

Esse método de produzir progênies, que envolve a polinização controlada entre indivíduos, fornece maiores informações sobre a capacidade de combinação dos pais., permitindo,.. portanto, a obtenção de maior quantidade de parâa metros genéticos da população. Por envolver a polinização controlada, bastante trabalhosa e onerosa em espécies flores tais, esse método tem sido pouco utilizado no campo da silvi cultura.

Através desse delineamento, um grupo de márvores tomadas como machos é cruzada com $\underline{n}$ grupos de $\underline{f}$ fềmeas, de modo que cada um dos machos é cruzado com um diferente grupo de fêmeas, produzindo nff famílias no total. Nes se caso, a variância entre progênies pode ser partida em variância entre machos e variância de fêmeas dentro de machos (COCKERHAM, 1963).

Esse tipo de delineamento é pouco comum na $1 \underline{i}$ teratura florestal, provavelmente devido ao grande número de cruzamentos exigidos. SHELBOURNE e STONECYPHER (1971) utilizaram-se dessa metodologia para determinações de parâmetros genéticos em população de $P$. taeda, utilizando-se de 65 árvores consideradas como machos, cruzando-as com árvores fê meas em grupos de 5, tótalizando portanto 325 famílias. 
e. Delineamento de testadores (Delineamento II - da Carolina do Norte)

Nesse tipo de delineamento para produção de progênies, cada macho, aqui chamado de "testador", é cruzado com $\underline{f}$ fêmeas, denominadas candidatas, para produzir (m $x$ ) familias. Os testadores podem ser ärvores geneticamente com provadas ou mesmo indivíduos tomados ao acaso da população.

A variância entre progênies, nesse caso, pode ser partida em variância entre machos, variância entre fêmeas e variância da interação machos $x$ fêmeas (COCKERHAM, 1963 ; BURLEY, et alii, 1966).

Esse método de obtenção de progênies vem sendo bastante utilizado em espécies florestais, em virtude da sua maleabilidade dé obtenção de estimativas da herdabilidade, da capacidade geral e da capacidade específica de combinação.

o grande problema enfrentado é que, conforme o número de testadores aumenta, o número total de cruzamentos, e portanto de familias, torna o esquema muito trabalhoso ou restritivo. Dessa forma, o número de testadores que vem sendo utilizado é o de 4 a 5 indivíduos, conforme recomendado por Zobel e Kellison (1963), citado por BURLEY et alii (1966). BELL e FERET (1972) analisam o número de testadores quanto aos aspectos genéticos e economicos, concluin do sobre a conveniência de que o número de testadores fique em torno de 4 a 5 , variando, sob o aspecto economico, de 1 a 8 .

0 método de testadores foi utilizado por BINGHAM et alii (1969), para determinação de parâmetros genéti cos quanto à resistência de Pinus monticola à Cronartium ribicola, utilizando-se de 4 testadores. KRAUS (1973), a par- 
tir do mesmo método, utilizou-se de 5 testadores para a determinação de CGC e CEC em Pinus elliottii para as características de altura e resistência ao Cronartium fusíforme, HA NOVER e BARNES (1969), com 4 testadores, estimou parâmetros genéticos para altura de plantas em $P$. menticola, dentre outros.

f. Delineamento de cruzamentos dialélicos

Esse tipo de delineamento, que permite informações bastante completas tanto sobre a CGC e CEC como quanto as estimativas de herdabilidade, apesar de ser bastante restritivo em relação ao custo e às dificuldades de realização, vem sendo regularmente utilizado em espécies florestais. Os autores têm enfatizado bastante esse método, principalmente em termos académicos, para testar ou comprovar a validade dos métodos mais simples e mais correntes, tal como o de poI inização aberta.

Nos cruzamentos dialélicos os n pais são cruzados em todas as combinações possíveis, incluindo os cruzamentos rëcíprocos, produzindo $n^{2}$ famỉlias. Nesse caso, a va riância entre progênies pode ser partida em variância devida à capacidade geral, variância devida à capacidade específica, variância devida ao efeito materno e variância devida aos efeitos recíprocos.

A grande restrição dessa metodologia para espécies florestais é o grande nümero de cruzamentos exigidos e que a torna bastante difícil e onerosa, limitando sobremaneira a sua aplicação corrente. No entanto, muitos autores têm-se utilizado dos cruzamentos dialélicos para produzir progênies, porém, a maioria utilizando-se de poucos indivíduos paternais. Dessa forma, os resultados obtidos são, no 
geral, pouco precisos.

Dentre os autores que se utilizaram desse método podem-se citar SQUILLACE et alii (1967), utilizando-se de altura de plantas em Pinus monticola, KRIEBEL, NAMKOONG e USANIS (1972), trabalhando com características de crescimento e de dimensão da copa em Eucalyptus grandis, dentre outros.

3.2. Estimação de parāmetros genēticos em espēcies flores tais

o total desconhecimento sobre a resposta à se leção praticada para as diversas características, a grande responsabilidade da, seleção em espécies florestais e a impos sibilidade de se pensar, a curto prazo, emmuitos ciclos recorrentes de seleção, fez com que um esforço bastante grande venha sendo despendido nos estudos de determinação de parâme tros genéticos para as espécies florestais mais importantes.

Os parâmetros genéticos que interessam ao me1horista e que são frequentemente visados nos estudos envolvendo progênies se referem, segundo ROBINSON e COCKERHAM (1965), às variâncias genéticas em suas componentes aditivas e não aditivas, ao coeficiente de herdabilidade tanto no sen tido amplo como restrito, às interações dos efeitos genéticos e ambientais e, finalmente, às correlações genéticas entre características.

Segundo VENCOVSKY (1969), as estimativas dos parâmetros genéticos se prestam para: a. obterem-se informações sobre o tipo de ação dos genes em caracteres quantitati vos, b. orientação sobre o esquema mais adequado de seleção a ser adotado e c. estimação do progresso esperado na seleção. 
Após COMSTOCK e ROBINSON (1948) terem desenvolvido os conceitos inicialmente enunciados por Fisher em 1918 e Wright em 1935, em termos de obtenção dos componentes de variância genética a partir de familias de irmãos germanos e de meios-irmãos, um grande avanço foi observado na estimação dos parâmetros genéticos de populações.

Conforme coloca FALCONER (1964), a variância genética aditiva, ou a variância dos valores reprodutivos, é o componente mais importante, já que é a principal causa da semelhança entre parentes e, portanto, o principal determinante das propriedades genéticas observadas da população e da resposta desta à seleção. A herdabilidade de um caráter quantitativo, que se define como o quociente da variância ge nética aditiva e a variância fenotípica, é uma de suas propriedades mais impoxtantes, pelo seu papel preditivo, expres sando a confiabilidade do valor fenotípico como indicação do seu valor reprodutivo.

Segundo SQUILLACE et alii (1967), as estimati vas de herdabilidade são ajudas valiosas no planejamento de programas de melhoramento florestal que envolvem seleção, au xiliando no julgamento sobre a quantidade de esforço relativo que deve ser despendido em cada uma das características que se está melhorando. Isso tem particular interesse para a seleção em espécies florestais. onde, em função do seu lon go ciclo e de suas características específicas, o enfoque é mais para a sofisticação nos métodos de: seleção do que nos métodos de melhoramento.

$\bar{E}$ importante dar-se conta de que a herdabilidade não é uma propriedadede umcaráter unicamente, mas sim tam bém da população e das circunstâncias ambientais a que estão sujeitos os individuos que compõem a mesma (FALCONER, 1964). ZOBEL (1961) mostra a importância desse fato em espécies flo restais, sugerindo que as herdabilidades sejam obtidas para 
ärvores em idade de corte, servindo as estimativas obtidas em idades anteriores somente como indicativas.

Quando se trata de obter informações experimentais com relação às variâncias genéticas, tanto os genótí pos como os ambientes se convertem em amostras de ambas as categorias de população. Segundo VENCOVSKY (1969), tendo si do definida a população-base de genōtipos, a amostragem consiste em dela se obterem indivíduos com um certo grau de paren tesco e da covariância entre esses indivíduos aparentados são estimadas as variâncias genéticas da população-base. Des sa forma, conforme FALCONER (1964), qualquer componente de variância entre grupos de individuos aparentados é igual à covariância dos membros desse grupo. A variância entre médias de familias de meios-irmãos estima, portanto, a covariância genotípica de meios-irmãos, a qual equivale aproxima damente a um quarto da variância aditiva.

As estimativas de variância genética aditiva obtidas dessa forma não são livres das variâncias epistāti cas. Segundo VENCOVSKY (1969), as variâncias epistáticas têm provavelmente valores muito menores do que a variância aditiva em populações panmỉticas, costumando-se desprezā-las em experimentos nos quais elas não podem ser estimadas. Assim, segundo FALCONER (1964), qualquer estimativa da variância aditiva obtida dessa forma conterā também $1 / 16$ da variân cia epistática aditiva por aditiva mais $1 / 64$ da variância aditiva por aditiva por aditiva, e assim por diante.

$\widehat{E}$ de grande importância o conhecimento dos re quisitos feitos para as interpretaçoes genéticas dos componentes de variância. COMSTOCK e ROBINSON (1948) têm relacio nado os seguintes requisitos básicos para essa interpretação:

a. pareamento de individuos tomados ao acaso na produção de progênies experimentais. 
b. distribuição ao acaso dos genótipos nos distintos ambientes.

c. ausência de efeitos maternos.

d. herança regular diplóide.

e. equilíbrio de ligação nas progênies amostradas.

f. ausência de epistasia.

Para uma estimação ampla e sem restrições dos componentes da variância genética, conforme coloca VENCovsKY (1969), uma condição é essencial: tanto os indivíduos aparen tados que constituem o material experimental, como os da população-base, devem ser não endocruzados. Nesse sentido, NAMKOONG (1966), discorrendo sobre os problemas de ocorrência de endogamia e sua influência nos testes de progênies, le vanta restrições sobre a estimativa de variâncias genéticas aditivas da população através da utilização de sementes de polinização livre. Se a endogamia prevalece, o teste de pro gênie de polinização aberta inflaria as estimativas da variância genética. Segundo ELDRIDGE (1977), existem evidências de que tanto autofecundações como cruzamentos ocorrem nos eucaliptos, porém, com predominância da alogamia.

$\bar{E}$ bem conhecido que o fenótipo reflete influências ambientais e genéticas e, além disso, que os genótipos respondem distintamente às variações ambientais. Essa resposta diferencial dos efeitos genotípicos e ambientais no desenvolvimento dos organismos dá origem ao importante grupo de parâmetros conhecido com o nome de interação de genótipo e ambiente. ROBINSON E COCKERHAM (1965) colocam que os parâa metros genéticos estimados devem ser independentes dos efeitos ambientais, condição que se satisfaz somente quando não 
existem interações com ambientes. Para contornar essa dificuldade é necessārio testar os genótipos em uma série de ambientes, de maneira que se possam separar as variâncias gené ticas da variância devida às interações de genótipos e ambientes. Desde que a maioria das estimativas de variâncias genéticas em espécies florestais são baseadas em experimentos em um só ambiente, essas estimativas, segundo RINKe THOR (1976), podem estar infladas pela presença de uma interação de genótipos por ambientes.

Na estimação da variância devida à interação de genótipos e ambientes, VENCOVSKY (1978) levanta que esse componente é composto de 2 partes, a saber: a. uma devida à diferença na variabilidade genética do material dentro dos ambientes e b. uma segunda advinda da falta de correlação en tre o material de um ambiente para o outro.

Segundo NAMKOONG et alii (1966), os efeitos de interação de genótipos e ambientes não têm sido considera dos na maioria dos trabalhos, sendo normalmente incluidos no componente genético. O componente devido a interações de ge nótipos e ambientes tem, particularmente, alta importância em espécies florestais, principalmente porque o zoneamento ecológico para as espécies/procedências envolve regiões muito extensas, englobando ambientes bastante diversos, já que as plantações têm caminhado a cada ano para novas äreas.

Desde que a maioria dos caracteres de importância econômica, tal como a produção, são complexos quanto à sua herança e podem envolver diversos caracteres relaciona dos, o grau de correlação genotípica e fenotípica dos caracteres é um parâmetro também bastante importante (ROBINSON et alii, 1951).

Os caracteres correlacionados, conforme FALC NER (1964), são de interesse por duas razões principais: a. 
em conexão com as causas genéticas de correlação através da ação pleiotrópica dos genes e b. em conexão com as mudanças produzidas pela seleção, ou como o melhoramento de um caráter pode causar mudanças simultâneas em outros caracteres.

Nos estudos genéticos, é necessärio distinguir duas causas de correlação entre os caracteres: a causa genética e a causa ambiental. Segundo VEncovsky (1978), a correlação devida a causas genéticas, e que mede a associação genética entre as duas características, interfere ou par ticipa na seleção, sendo causada por efeitos pleiotrópicos dos genes ou então por falta de equilíbrio de ligação. 0 am Diente é uma causa de correlação nos casos em que dois carac teres estejam sendo influenciados pelas mesmas diferenças de condições ambientais.

A estimação de correlações genéticas se baseia, conforme FALCONER (1964), na semelhança entre individuos aparentados, de forma anāloga à obtenção das variâncias genéticas. Dessa forma, na anālise de famỉlias de meios irmãos, o componente de covariância entre progênies estima um quarto de covariância aditiva, ou seja, um quarto da covariância dos valores reprodutivos dos dois caracteres. A corre lação genética entre caracteres assume grande importância quando se pratica a seleção num dado caráter e se quer predizer a resposta em outro carāter correlacionado ao primeiro.

Afora os métodos descritos para obtenção de parâmetros genéticos da população, o método proposto por sAKAI e HATAKEYAMA (1963), sem a utilização de progênies, tem sido utilizado para espécies florestais por inúmeros autores. Segundo esse método, a partir da estimativa de variâncias entre parcelas de um talhão e a medida de mudanças na variância média da parcela quando o tamanho da parcela é variado, calcula-se a variância genética e ambiental da popula ção em questão. O efeito de variabilidade ambiental é espe- 
rado que reflita na taxa em que as variâncias de parcelas va riam com as mudanças no tamanho da parcela no talhão.

Segundo NAMKOONG e SQUILLACE (1970), esse método tem se revelado satisfatório para inūmeras espécies,mos trando que as características analisadas por esse método têm que ter variâncias de parcelas que variam de acordo com uma função logarítmica de mudanças no tamanho da parcela. SAKAI e MUKAIDE (1967), acrescentam na fórmula de SAKAI e HATAKEYA MA (1963) o componente de variância competicional além da genética e ambiental.

0 método de SAKAI e HATAKEYAMA (1963) permite também a obtenção de estimativas de correlações genéticas en tre características, muito embora tenha sido pouco comum na literatura. 0 coeficiente de correlação nesse caso não se refere à parte aditiva, mas sim no sentido amplo. SAKAI e MUKAIDE (1967) empregam o método, acrescido da componente competicional, para a correlação entre altura e diâmetro em Cryptomeria japonica.

Os estudos de parâmetros genéticos das popula ções para as diferentes características das árvores, conforme já enfatizado, tem-se concentrado principalmente na deter minação das variâncias e covariâncias genéticas,principalmente quanto às suas partes aditivas, visando as estimativas de herdabilidade no sentido amplo e restrito, assim como de cor relações genéticas.

A estimativa do erro associado aos componentes de variância, bastante importante para a visualização do grau de confiança de estimativa do parâmetro, não tem sido cal culada para a maioria dos casos em espécies florestais. Nos casos onde a mesma foi obtida, a estimativa foi feita através das informações obtidas da anālise de variância dos testes de progênies, conforme as expressões apresentadas por VE 
LO e VENCOVSKY (1974). As estimativas do erro associado à variâncias genéticas foram obtidas em espécies florestais por SMITH (1967), BINGHAM et a $i$ i (1969), SHELBOURNE, ZOBEL e STONECYPHER (1969), ELDRIDGE (1972), MATZIRIS e ZOBEL (1973), RINK e THOR (1976), dentre outros.

Segundo colocam VELO e VENCOVSKY (1974), o ex ro associado à variância genética obtido da anālise de variância é inversamente proporcional aos graus de liberdade para progênies e resíduo, e ao nümero de repetições e de plan tas por parcela. O número aproximado de observações requerido, segundo BOGYO (1964), para uma herdabilidade em torno de 0,20 e um erro padrão de $20 \%$, seria de 4000 indivíduos, o que mostra o grau de confiabilidade dessas estimativas. Esses fatores tiveram, provavelmente, grandes efeitos na infla ção dos erros obtidos pelos autores em espécies florestais.

3.3. Estimativas de herdabilidades para as principais características das ārvores

As características das árvores, consideradas como importantes no melhoramento florestal, poderiam ser agrupadas em: a. características de crescimento, b. caracte rísticas de forma das árvores, c. características de qualida de da madeira e d. outras.

Serão discutidas a seguir as estimativas de herdabilidade e de correlações genéticas obtidas, por grupo de características e para as diferentes espécies, segundo as diversas metodologias utilizadas. Essas estimativas representam uma amostra das obtidas, podendo mostrar a tendência existente para as diversas características. 
a. Caracteristicas de crescimento

As caracteristicas associadas ao crescimento, tais como a altura total, o diâmetro (DAP) e o volume de madeira, foram e vêm sendo consideradas como as mais importantes, em função do seu alto valor econômico (Tabela I).

A partir da amostra de trabalhos apresentados, onde foram obtidas estimativas de herdabilidade, pode- se observar uma grande variação nos resultados obtidos para as diferentes espécies e métodos empregados. Existe uma pre dominância para os métodos mais simples, tal como o de polinização livre, relativamente aos mais complexos e trabalho sos, e que exigem polinizações controladas e um grande número de progênies.

De um modo geral, os autores se utilizaram de pequeno número de pais e, portanto, de poucas famílias para a determinação da herdabilidade, com exceção de alguns poucos casos com um número razoável de progenitores. Isso se deve, provavelmente, à grande dificuldade para a instalação e condução de ensaios dessa natureza em espécies florestais.

Um outro aspecto importante verificado é o que diz respeito à idade das plantas avaliadas. Muito embora tenha sido bastante realçada a restrição para estimativas de parâmetros genéticos em idades precoces nas espécies florestais, o que se verifica, na maioria dos casos, são avalia ções em ensaios muito jovens. O acompanhamento da evolução desses dados, em idades mais adultas, será bastante importan te para se ter maior segurança dessas estimativas. 


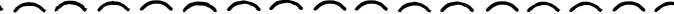

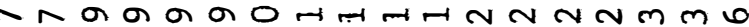

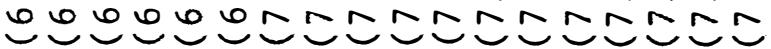

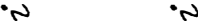

.4 $\quad$ ine

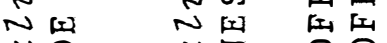

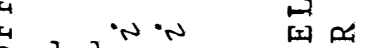
四

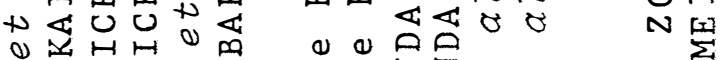

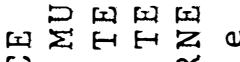
U

z

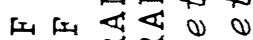

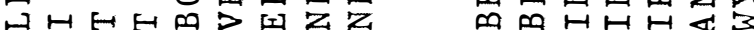

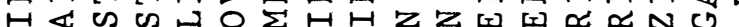

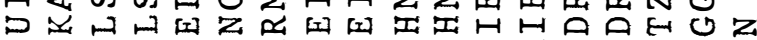
О४

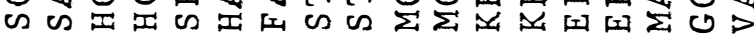

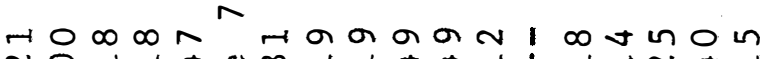

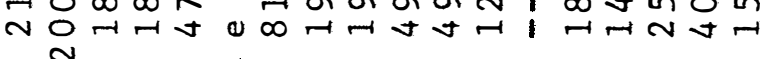

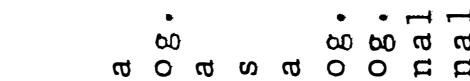

त

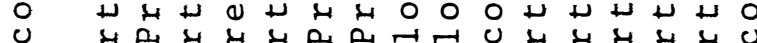

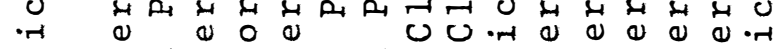
光

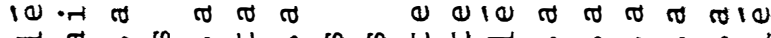

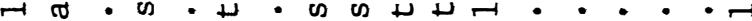

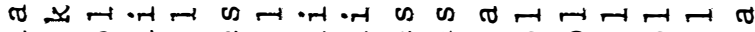

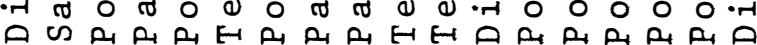
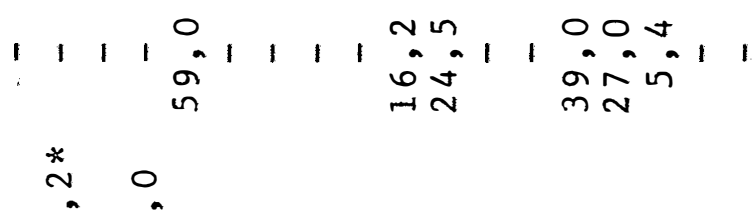

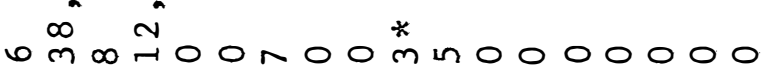
0'

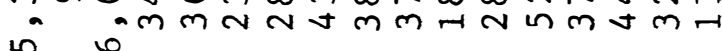
$\sim$

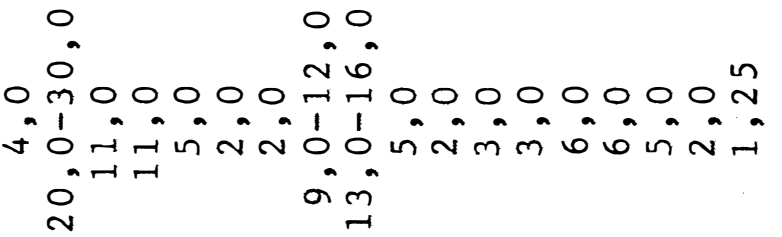

శَ

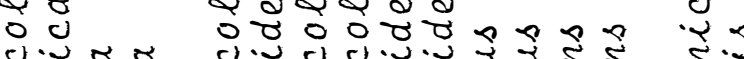

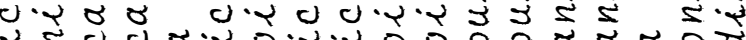

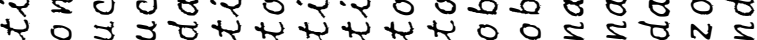

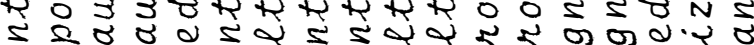

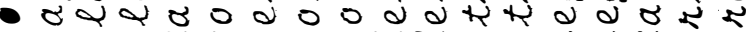
हनाणस ádáa 

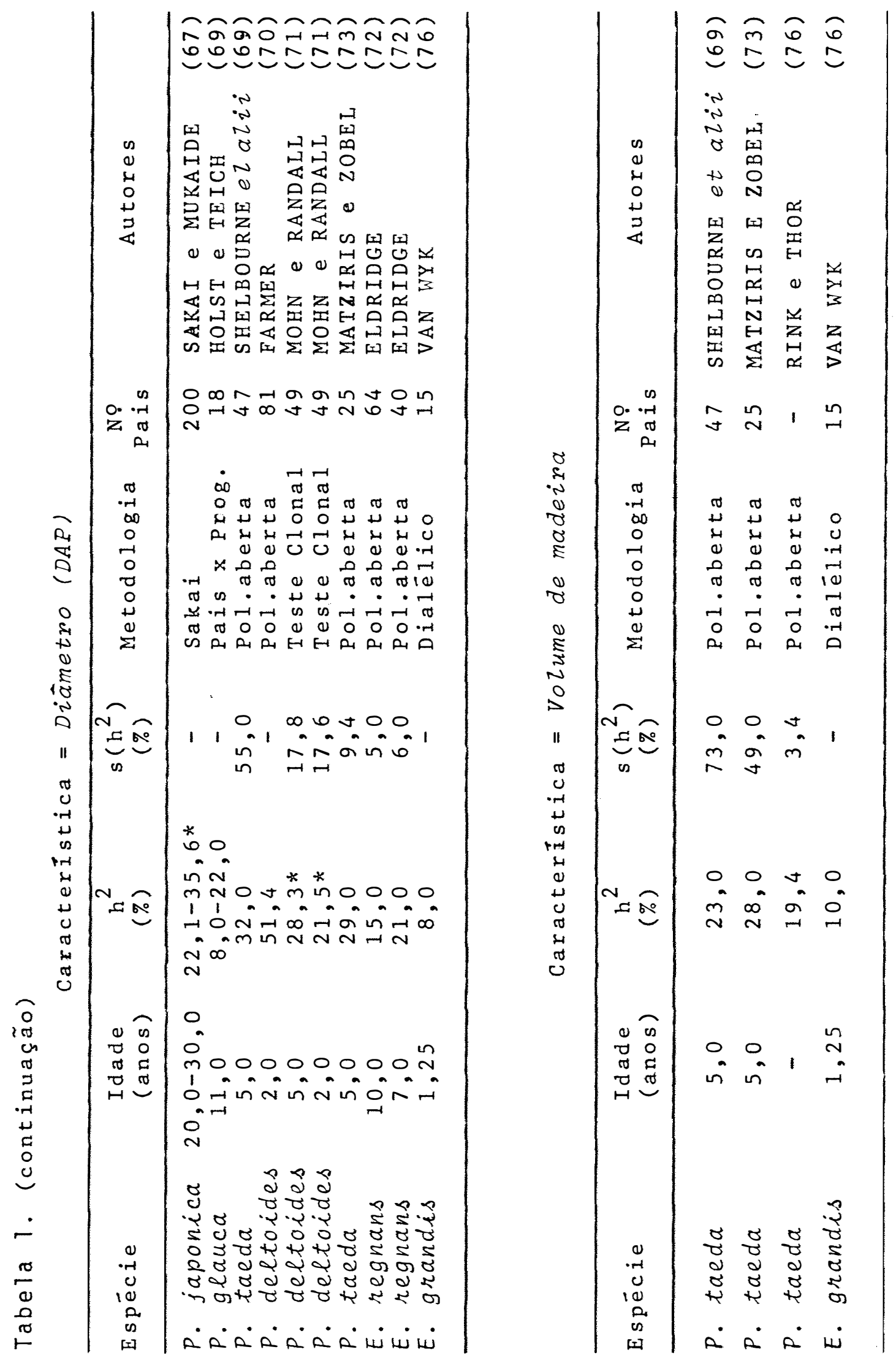
Relativamente às estimativas de herdabilidade obtidas, apesar das restrições levantadas, pode-se, de uma maneira geral, especular sobre as tendências que vêm sendo observadas. Um ponto que deve ser levantado é soḅre qual se ria a magnitude da herdabilidade para as três características de crescimento analisadas. De maneira geral, os dados revelam uma tendência, em média, para maior herdabilidade para altura do que para diâmetro e volume, confirmando a con clusão da maioria dos autores.

b. Caracteristicas de forma das árvores

As características de forma das ärvores estão associadas à forma do tronco (encrocamento, curvatura, bifurcação) e forma da copa (diâmetro, comprimento de ramos, ângulo de ramos) (Tabela 2 ).

As características de forma geral das ärvores mostram, no geral, as estimativas para a herdabilidade com maior magnitude do que para as características de crescimento, confirmando a tendência relatada pelos autores.

As restrições levantadas quanto à precisãodas estimativas para as características de crescimento também se aplicam para as de forma das árvores, muito embora, no segun do caso, o número de pais tenha sido no geral bem maior. os erros das estimativas, para os casos calculados, mostram tam bém uma grande magnitude para os mesmos. 
.27

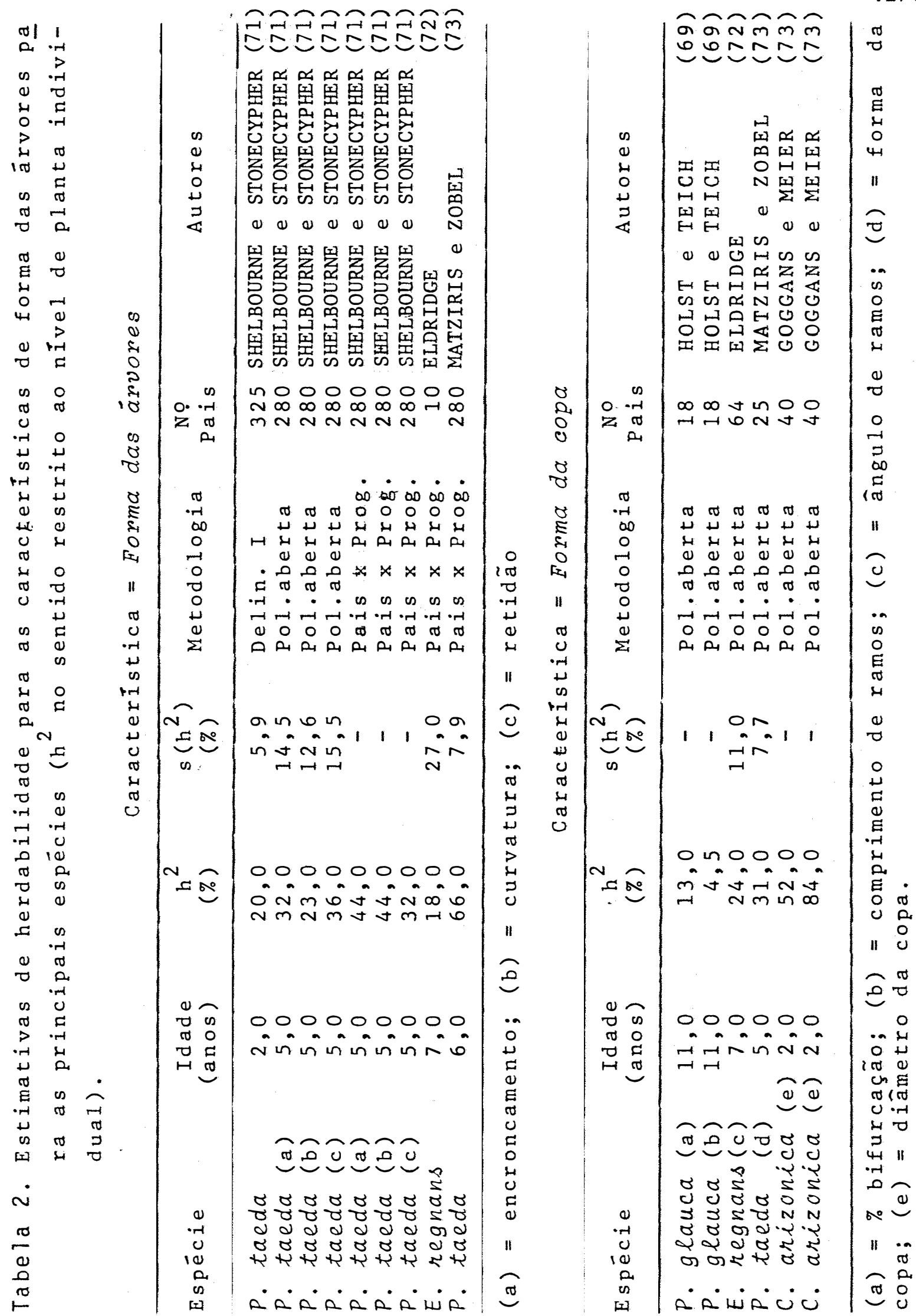


Essas características, por serem no geral ava liadas subjetivamente, apresentam maior imprecisão na coleta de dados, provocando provavelmente um erro adicional, inflan do mais o erro das estimativas. Porém, de uma maneira geral, tem sido citado que as características de forma das ārvores têm respondido bastante à seleçãofenotípica, mostrando serem de alta herdabilidade.

TODA (1972) mostra que a classificação das características em de alta e baixa herdabilidade pode definir a estratégia do melhoramento para as espécies florestais. O melhoramento das árvores para as primeiras características pode efetivamente ser efetuada pela propagação massal dos in dividuos selecionados com alta intensidade (Pomares de Semen tes Clonais), enquanto a melhoria de características de baixa herdabilidade poderia ser feita pela seleção de muitos in divíduos com menor intensidade, acompanhada com a re-seleção de familias e indivíduos em testes de progênies (Pomar de Se mentes por Mudas).

c. Coeficientes de correlagões entre caracteristicas das ärvores

As correlações genéticas e ambientais entre pares de características das árvores têm sido estimadas por diversos autores, através das covariâncias obtidas nas anāli ses de covariâncias, assim como por outros métodos anteriormente descritos.

Os estudos de correlações têm envolvido principalmente as características de crescimento, de forma do tronco e de qualidade da madeira. Uma série de estudos de correlação é discutida a seguir. 


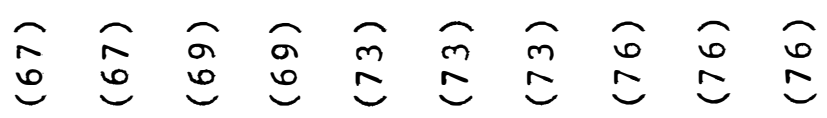

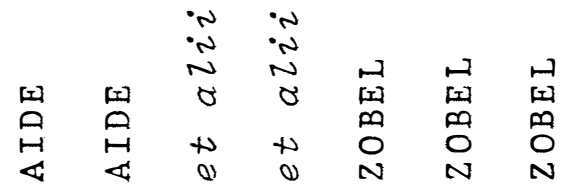

ชั

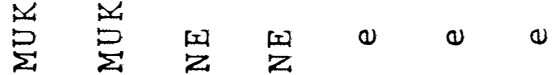

$\pi$

2 出

- ब

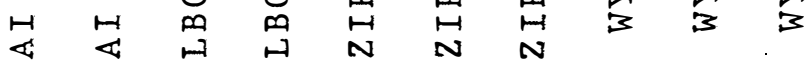

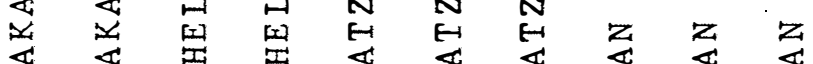

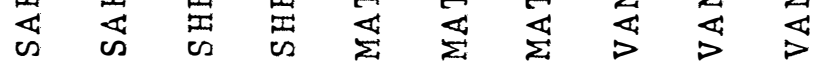

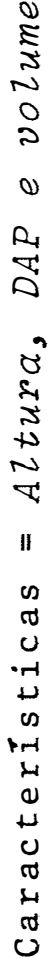
(2)

0
0
0
$\stackrel{0}{10}$
$\Sigma$
$\Sigma$

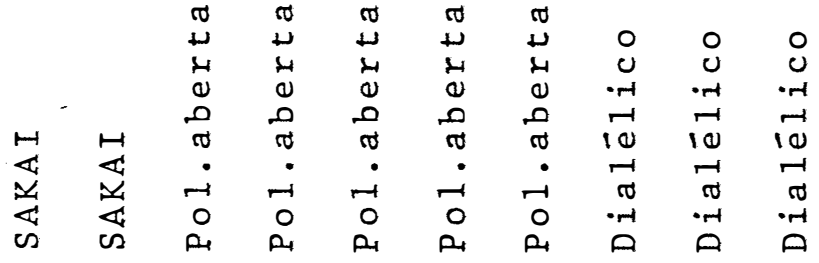

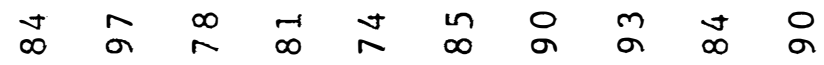

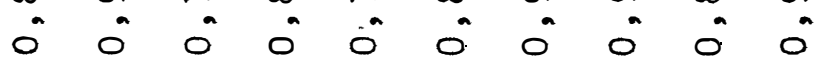

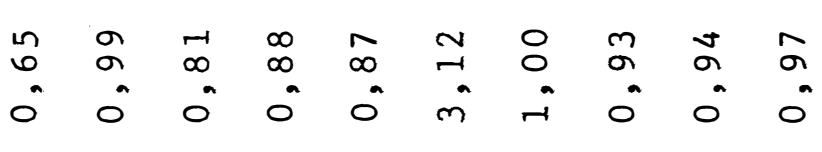

(1)

4 E

0

is

$\infty$

U

म 0

(a) $\cdot 4$

(1)

$\infty 2$

$\infty$

in

$\pi 0$

$\pi$

H

$\begin{array}{lll}4 & 1 \\ 0 & 0 \\ 0 & 4-1\end{array}$

$\dot{m}$

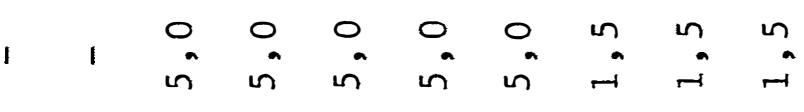

$\begin{array}{cc}0 & 0 \\ 0 & 0 \\ 0 & 0 \\ 0 & 0 \\ 0 & 0\end{array}$

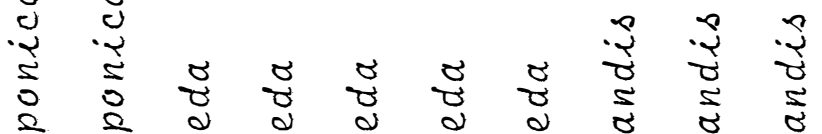

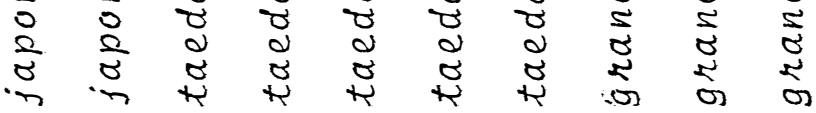

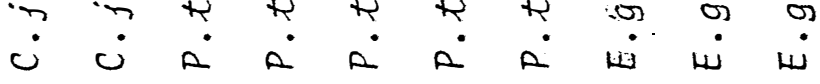

崖䍃崖

$x \neq x x \neq x x x x$

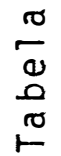

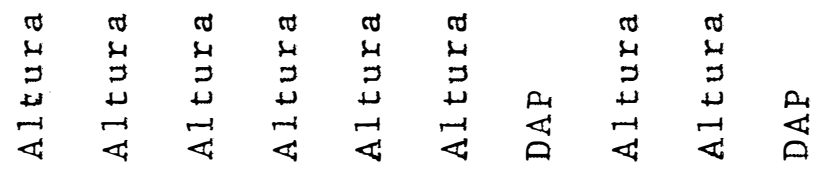




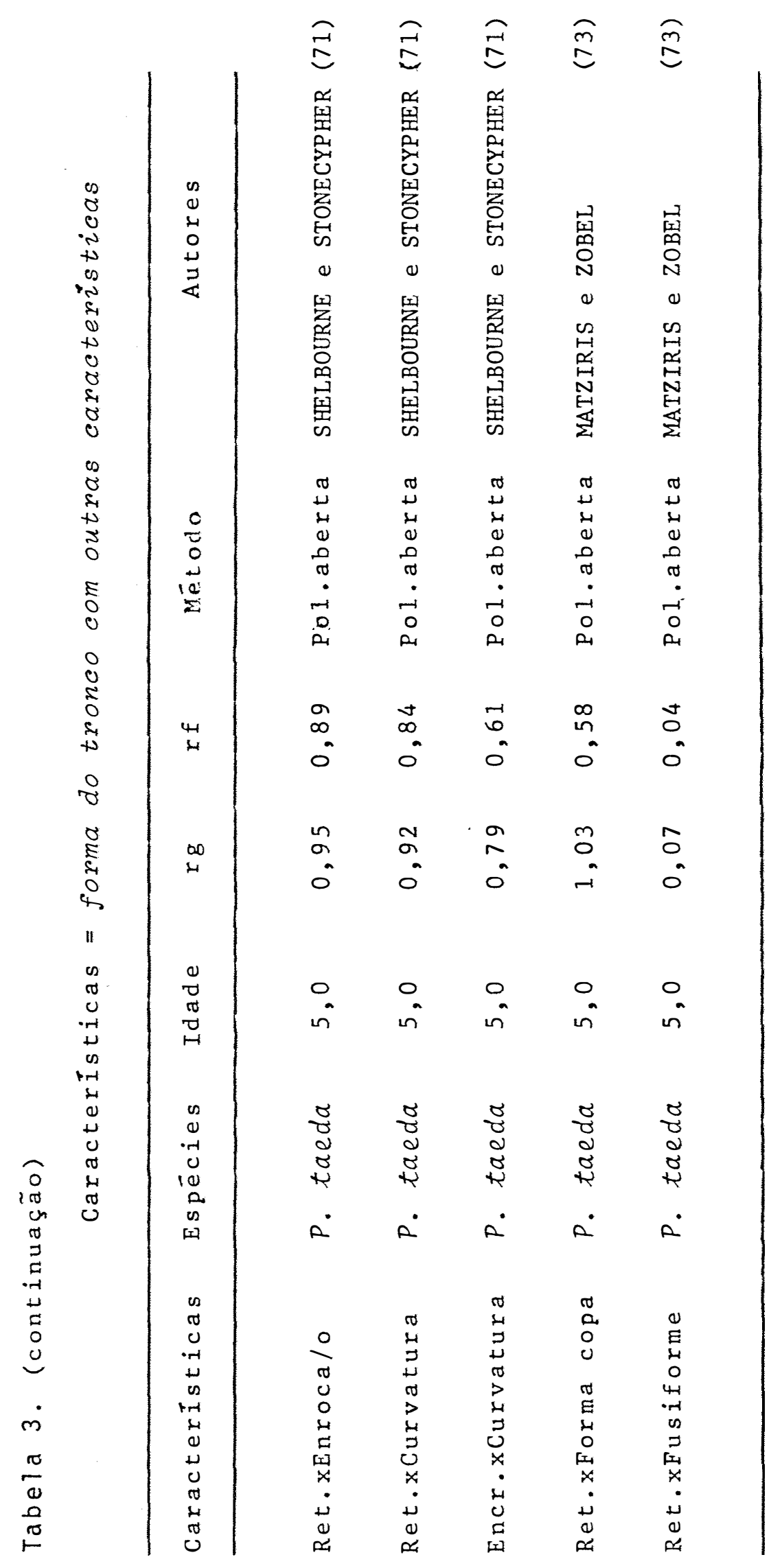


A correlação tanto genética como fenotípica entre as características de crescimento são bastante fortes e próximas à unidade, mostrando provavelmente a existência de pleiotropia para o controle genético dessas características. As correlações genéticas são no geral maiores do que as fenotípicas, indicando que os efeitos ambientais têm diminuído o efeito das primeiras.

As correlações entre as características de crescimento e de densidade da madeira apresentam resultados às vezes opostos (correlação negativa e positiva), para espé cies diferentes e mesmo para uma mesma espécie, o que se deve provavelmente a erros de determinação.

Uma correlação positiva entre altura e DAP com comprimento de fibras, altamente favorável, é verificada tanto para $P$. taeda como para $P$. deltoides. As característi cas de forma do tronco apresentam-se fortemente correlaciona das.

Essas correlações, embora não muito conclusivas, mostram fatores importantes e que devem ser considera dos na seleção, principalmente quando a mesma envolve múltiplas características simultaneamente. Correlações genéticas positivas entre características e de alta magnitude mostram que as mesmas podem ser consideradas como uma única na seleção. Correlações não significativas indicam a independência entre elas. Correlações negativas fortes merecem cuidado es pecial na seleção, pois prejudicam sobremaneira a seleção si multânea.

As correlações entre fase juvenil e fase adul ta, de alta importância e bem pouco estudada em espécies flo restais deve merecer um enfoque especial, já que a validade das estimativas em idades precoces é função da magnitude des sas correlações. SHELBOURNE e STONECYPHER (1971) relatam 
que a retidão do tronco é uma característica que tem sua her dabilidade aumentada com o aumento da idade das árvores.

3.4. Ganhos genēticos para seleção entre e dentro de ensaios de progēnies

Os testes de progênies em espécies florestais têm também sido utilizados como material básico para a produ ção de sementes melhoradas, após seleção dentro das mesmas.

NAMKOONG (1966), descrevendo os métodos de me1horamento em espécies florestais, relata a alternativa do "Pomar de Sementes por Mudas de Polinização Aberta". Por es se método, árvores são primeiro selecionadas com base em seu prōprio fenótipo e sementes coletadas das mesmas são plantadas em esquema de teste de progênie em locais representati vos do programa. A seleção das melhores familias e de indivíduos dentro dessas famílias no próprio material teste será utilizada para a produção de sementes melhoradas, não se vol tando, portanto, às árvores matrizes originais. Para a formação final do pomar de sementes, tem sido relatada na 1 iteratura uma percentagem de seleção de $25 \%$ entre famílias e de $20 \%$ dentro das famílias.

FRANKLIN e MESKIMEN (1973), em programa de melhoramento com E. robusta no sul dos EUA, relatam que a1tos ganhos genéticos podem ser obtidos pela seleção entre e dentro de famílias de polinização livre. Segundo MORGENSTERN (1974), a seleção por famỉlias apresenta maior eficiência e é mais ütil para características de baixa herdabilidade, tais como as de crescimento de plantas.

SLUDER (1975), em predição de ganhos a partir de teste de progênie de Pinus elliottii, relata que a se leção de ärvores individuais, seguida por seleção entre e 
.34 .

dentro de familias, poderia produzir pelo menos o dobro de ganho em volume de madeira, comparativamente a seleção individual somente. Snyder (1969), citado por MORGENSTERN (1974), encontrou ganhos para crescimento em altura, em seleção por familias em Pinus palustris, quase que três vezes maiores que os obtidos por seleção de árvores individuais.

Enfatizando a importância dos "Pomares de Sementes por Mudas", SHELbOURne (1969a) relata que os mesmos são de alta relevância para os casos em que a propagaço vegetativa apresenta dificuldades, ou ainda quando a espécie tem ciclo reprodutivo curto. 


\section{MATERIAL E METODOS}

\subsection{Material}

\subsubsection{Caracterização da população que deu origem às progènies}

As progênies de polinização livre, para insta lação dos ensaios, foram obtidas de árvores selecionadas fenotipicamente em uma população (população-base) de E. grandis, estabelecida com sementes provenientes de Coffs Harbour - N.S.W. Austrália (população original). Essa população base foi implantada em dois locais do Estado de são Paulo (Mogi Guaçu - SP e Salto - SP) em 1969, tendo sido efetuada, em 1975, a seleção das árvores e coleta das sementes para o estabelecimento dos ensaios.

A seleção fenotípica das ārvores foi efetuada segundo o método de estratificação da população, com uma intensidade geral em torno de 1:5000, utilizando-se nesse critério principalmente as características de crescimento em al tura e diâmetro e de forma do tronco das árvores. Foram coletadas, na população-base, sementes de polinização livre de 
55 árvores, e que foram utilizadas para instalação dos testes de progênies.

Foram incluídas nos ensaios, além dessas progênies, uma testemunha referente à população-base sem: seleção, uma testemunha comercial (África do sul) e pequenas amostras de progênies da Austrália e de Rio Claro-SP.

4.1.2. Especificação dos materiais nos locais de experimentação

Em cada um dos cinco locais de experimentação foi instalado um ensaio envolvendo progênies das árvores selecionadas, demais testemunhas e outras progênies, totalizan do 64 tratamentos. A maior parte do número de progênies (49) e das testemunhas, referentes à população-base e ao material comercial, foram comuns a todos os locais e experimentação. As amostras de progênies de outras populações, embora não sendo as mesmas, foram também colocadas nos cinco locais.

A caracterização dos locais de origem das sementes (população original), dos locais de estabelecimentoda população-base que deu origemàs progênies e dos locais de experimentação é especificada na Tabela 4. 
Tabela 4. Características do local da população original, dos locais de instalação da população base e dos 1ocais de experimentação.

\section{Localidade}

a. População original

Coffs Harbour - NSW

- Austrālia

b. População base $22^{\circ} 11^{\prime} \mathrm{S}$

Salto - SP
Latitude

$30^{\circ} 00^{\prime} \mathrm{s}$

$152^{\circ} 55^{\prime} \mathrm{E}$
Longitude Altitude $47^{\circ} 07^{\prime} \mathrm{W}$

600

$47^{\circ} 03^{\prime} \mathrm{W}$

700

c. Experimentação

Agudos - SP

$22^{\circ} 19^{\prime} \mathrm{s}$

$49^{\circ} 04^{\prime} \mathrm{W}$

Anhembi - SP

$22^{\circ} 40^{\prime} \mathrm{s}$

$48^{\circ} 10^{\prime} \mathrm{W}$

Brotas - SP

$22^{\circ} 20^{\prime} \mathrm{s}$

$48^{\circ} 10^{\prime} \mathrm{W}$

800

Lençois Paulista - SP

$22^{\circ} 40^{\prime} \mathrm{S}$

$48^{\circ} 25^{\prime} \mathrm{W}$

600

Resende - RJ

$22^{\circ} 30^{\prime} \mathrm{s}$

$44^{\circ} 30^{\prime} \mathrm{W}$

500

\subsubsection{Instalação dos ensaios}

Os ensaios foram instalados nos cinco locais em novembro e dezembro de 1976, com mudas formadas em um só local (Brotas-SP). Na fase de formação de mudas praticou-se um raleamento, na fase de repicagem, eliminando-se as que não tivessem alcançado o porte para tal operação. 
o delineamento utilizado para os cinco locais foi o látice $8 \times 8$ triplo, cujos 64 tratamentos incluíam pro gênies da população-base, testemunhas e progênies de outras populações. A especificação dos tratamentos nos cinco 10cais de experimentação é dada na Tabela 5.

Tabela 5. Número de tratamentos e sua especificação nos cinco locais de experimentação.

Especificação dos

Tratamentos

\begin{tabular}{|c|c|c|c|c|}
\hline \multicolumn{5}{|c|}{ Locais } \\
\hline Agu & $\begin{array}{c}\text { Anhem } \\
\text { bi }\end{array}$ & $\operatorname{Bro}$ & $\begin{array}{l}\text { Len- } \\
\text { çóis }\end{array}$ & $\operatorname{des}^{\operatorname{Res}}$ \\
\hline
\end{tabular}

Total de Tratamentos

$\begin{array}{lllll}64 & 64 & 64 & 64 & 64\end{array}$

Total de Progênies

52

52

56

54

52

Progênies comuns

Total de Testemunhas A

Testemunhas A comuns

Total de Testemunhas $B$

Testemunha $B$ comum

Total de outras Progênies

outras Progênies comuns

49

49

49

49

49

44

22

2

2

4

4

2

2

2

11

1

1

4

44

2

Testemunha $A=$ população base sem seleção; Testemunha $B=$ tes temunha comercial; Outras Progênies = Progênies de Rio Claro (SP) e Austrāila.

As parcelas dos experimentos foram lineares e constituidas de 10 plantas, ao espaçamento de $3 \times 2$ metros, nos locais Agudos e Resende, e retangulares com 25 plantas $(5 \times 5)$, ao mesmo espaçamento, com 9 plantas mensuráveis (3 $x$ 3), nos locais Anhembi, Brotas e Lençóis.

A diferença básica entre os dois esquemas uti Iizados se refere mais à existência de bordadura e o conse quente aumento da área experimental nas parcelas retangula- 
res do que à variação do nümero de plantas efetivas por parcela, jā que a diferença no nūmero efetivo de plantas; por parcela é bastante pequena (10 para 9 plantas).

\subsubsection{Coleta de dados dos ensaios}

Os ensaios foram avaliados no campo aos 12 me ses de idade, coletando-se dados de crescimento em altura e de sobrevivência de plantas, e aos 24 meses de idade, acrescentando-se, além dessas duas características, as de DAP (diâmetro à altura do peito) e de forma do tronco. o volume cilindrico por parcela, uma característica obtida através dos dados combinados de altura, DAP, e sobrevivência, foi inclui do como parâmetro medidor de produção de madeira.

A coleta de dados para as características altura, DAP e forma do tronco das ärvores foi efetuada ao nível de plantas individuais, enquanto que para as características de sobrevivência e volume cilíndrico a obtenção dos da. dos foi ao nível de médias de parcelas. Isso tem implicações no tipo de unidade para os dados das diferentes caracte risticas: para as primeiras foram gerados dados de médias de parcelas por planta, ao passo que para as segundas obtiveram -se dados de totais por parcela. Essa forma de obtenção dos dados implicou também a possibilidade ou não de estimativas de variâncias e covariâncias entre plantas dentro de parce 1 as.

A avaliação das características foi efetuada segundo os esquemas usuais para altura e DAP, utilizando-se de dendrometro marca "Blume-leiss" para a primeira e compasso florestal para a segunda. Para forma do tronco utilizou-se de um critério subjetivo, a partir de notas visuais de 1 a 5 , segundo o esquema: 
Nota 1: tronco com defeito muito grave; tronco muito tortuoso.

Nota 2: tronco com defeito grave; tronco com tortuosidade acima da média.

Nota 3: tronco com defeito bastante visível; tronco com tortuosidade média.

Nota 4: tronco com defeito pouco visível;tron co com tortuosidade abaixo da média.

Nota 5: tronco sem defeito; tronco tendendo à retidão ou reto.

Considerou-se como defeito de forma do tronco - seu grau de curvatura e/ou de encrocamento, analisando-se todo o comprimento do mesmo. Para minimização do problema de subjetividade na atribuição de notas, antes da avaliação definitiva para essa característica, procurou-se estabelecer bem os padrões de cada classe de notas, cuidando-se para que a distância qualitativa entre as classes fosse de mesma magnitude. Adicionalmente, levou-se em conta a opinião de dois julgadores para a avaliação do tronco de cada àrvore, utilizando-se a média das duas observações como representativa da mesma.

Esse esquema de avaliação subjetiva, apesar de discutível, é uma das possibilidades viáveis de realização de coleta de dados para características tais como forma do tronco. Inúmeros autores têm-se utilizado desse sistema, podendo-se citar os trabalhos de SHELBOURNE (1969b), ELDRIDGE (1972) e NIKLES (1973), dentre outros. 


\subsubsection{Anālise de variāncia individual para cada local}

A análise de variância individual para os dados de cada local foi a usual, segundo o esquema em látice proposto por COCHRAN e COX (1957). O modelo matemático para esse tipo de análise fica:

$$
Y_{i j k m}=\mu+t_{i}+b_{j(k)}+r_{k}+e_{i j(k)}+d_{m(i j k)}
$$

onde: $Y_{i j k m} \bar{e}$ a observação feita no individuo m, do tratamen to $i$, no bloco $j$ e da repetição $k ; \mu$ é a média geral; $t_{i}$ é o efeito do tratamento; $b_{j(k)}$ é o efeito de blocos dentro de repetições; $r_{k}$ é o efeito de repetições; e ${ }_{i j(k)}$ é o efeito do erro intrabloco; $d_{m(i j k)}$ é o efeito dentro de parcelas.

O ajuste de totais de tratamentos e o quadrado médio do erro efetivo foram utilizados nos casos em que a eficiência do látice foi superior a $110 \%$, segundo recomendam SNYDER(1966) e MIRANDA FILHO (1978). Nos casos de eficiência do látice inferiores a $110 \%$ foram utilizados para análise os totais de tratamentos não ajustados, juntamente com o erro da análise de variância segundo o esquema de blocos ao acaso.

Com a utilização de tratamentos ajustados ou não ajustados, com as análises em látice ou em blocos ao aca so, aos níveis de médias de parcelas, por planta ou de totais de parcelas, as estruturas das análises de variâncias indivi duais ficam: 


\begin{tabular}{|c|c|c|c|c|}
\hline \multirow{2}{*}{ F.V. } & \multirow{2}{*}{ G.L. } & \multirow{2}{*}{ QM } & $\begin{array}{l}\text { Ao nível de médias } \\
\text { de parcelas }\end{array}$ & $\begin{array}{l}\text { Ao nível de to- } \\
\text { tais de parcelas }\end{array}$ \\
\hline & & & $E(Q M)$ & $E(Q M)$ \\
\hline $\begin{array}{l}\text { Tratamentos } \\
\text { ajustados }\end{array}$ & $k-1$ & $\mathrm{Q}_{1}$ & $(I / \bar{n}) \sigma_{d}^{2}+\sigma_{e}^{2}+r \sigma^{2} t_{1}$ & $\sigma_{e}^{2 !}+r \sigma^{2} t_{2}$ \\
\hline Erro efetivo & $(k-1)(x-(-1)$ & $\mathrm{Q}_{2}$ & $(1 / \bar{n}) \sigma_{\mathrm{d}}^{2}+\sigma_{\mathrm{e}}^{2}$ & $\sigma_{\mathrm{e}}^{2^{\prime}}$ \\
\hline $\begin{array}{l}\text { Tratamentos } \\
\text { não ajustados }\end{array}$ & $t-1$ & $\mathrm{Q}_{1}$ & $(1 / \bar{n}) \sigma_{d}^{2}+\sigma_{e}^{2}+r \sigma^{2} t_{1}$ & $\sigma_{e}^{2}+r \sigma^{2} t_{2}$ \\
\hline Erro (BAA) & $(r-1)(t-1)$ & $Q_{2}$ & $(1 / \bar{n}) \sigma_{d}^{2}+\sigma_{e}^{2}$ & $\sigma_{e}^{2}$ \\
\hline $\begin{array}{l}\text { Dentro de } \\
\text { parcelas }\end{array}$ & $r t(n-1)$ & $Q_{3}$ & $\sigma_{\mathrm{d}}^{2}$ & - \\
\hline
\end{tabular}

$Q M=$ quadrado médio; $E(Q M)$ = esperança do quadrado médio: ; $\sigma^{2} t_{1}$ e $\sigma^{2} t_{2}=$ variância entre tratamentos ao nível de plantas e ao nivel de totais de parcelas, respectivamente; $\sigma_{e}^{2}=$ variância entre parcelas ao nível de plantas; $\sigma_{e}^{2^{\prime}}=$ variância entre totais de parcelas; $\sigma_{\mathrm{d}}^{2}=$ variância dentro de parce las; $\bar{n}=$ número de plantas por parcela (média harmônica).

A variância dentro de parcelas foi estimada independentemente da anālise de variância, através da média ponderada dos quadrados médios dentro de parcelas, conside rando-se as variações de número de plantas nas mesmas.

0 esquema ao nível de plantas individuais só é vảilo para as características altura, DAP e forma do tron co, onde a coleta de dados foi ao nível de árvores individuais. Para as caracteristicas sobrevivência e volume cilín drico, cuja obtenção dos dados foi ao nível de totais de par celas, o esquema da análise de variância foi considerado tam 
bém a este nível.

\subsubsection{Anālise de variāncia conjunta para os cinco locais}

A análise de variância conjunta para locais foi efetuada a partir de médias de tratamentos ajustados ou não ajustados, conforme o critério já estabelecido referente aos valores obtidos de eficiência dos látices. O erroutili zado nessa análise foi o erro médio entre os erros efetivos e os erros de blocos ao acaso, correspondentes aos tratamen tos ajustados ou não ajustados, respectivamente.

O modelo matemático referente à anālise conjunta para locais fíca:

$$
\bar{Y}_{i j \ell m}=\mu+t_{i}^{\prime}+a_{\ell}+(t a)_{i \ell}+\bar{e}_{i j \ell}+\bar{d}_{i j \ell m}
$$

com tratamento e locais considerados como efeitos aleatórios, onde: $\overline{\mathrm{Y}}_{i j \ell m} \bar{e}$ a observação feita no individuo m, do tratamen to $i$, no bloco j do local $\ell ; \mu$ é a média geral; t'i é o efeito de tratamento; $a_{\ell}$ é o efeito de local; ta il $_{\ell}$ é o efeito da interação de tratamento por local; $\bar{e}_{i j l} \bar{e}$ o efeito do erro experimental; $\overline{\mathrm{d}}_{i j \ell m} \bar{e}$ o efeito dentro de parcelas.

A anālise de variância conjunta envolveu somente os tratamentos comuns a todos os locais, englobando 49 progenies e 5 outros tratamentos, e tendo as seguintes estru turas de análises: 
a. Anälise com médias de parcelas por planta

F. V.

G.L.

QM

$E(Q M)$

Locais

Tratamentos

$t-1$
$Q_{1}$

$\mathrm{Q}_{2}(1 / \overline{\mathrm{n}}) \sigma_{\mathrm{d}}^{2}+\sigma_{\mathrm{e}}^{2}+\mathrm{r} \sigma^{2} \mathrm{t}_{1} l+\mathrm{rs} \sigma^{2} \mathrm{t}_{1}$

Locais $x$ Tratamentos $(p-1)(t-1)$

$\mathrm{Q}_{3}(1 / \overline{\mathrm{n}}) \sigma_{\mathrm{d}}^{2}+\sigma_{\mathrm{e}}^{2}+\mathrm{r} \sigma^{2} \mathrm{t}_{1} l$

Erro médio

$\left[N I_{1}\right.$

$\mathrm{Q}_{4}(1 / \overline{\mathrm{n}}) \sigma_{\mathrm{d}}^{2}+\sigma_{\mathrm{e}}^{2}$

Dentro

$\sum \mathrm{NI}_{2}$

$Q_{5}$

$\sigma_{d}^{2}$

$\sigma^{2} t_{1}=$ variância entre tratamentos ao nível de

p1 antas;

$\sigma^{2} t_{1} l=$ variância da interação de tratamentos por locais; $\sigma_{\mathrm{e}}^{2}=$ variância entre parcelas; $\sigma_{\mathrm{d}}^{2}=$ variância dentro de parcelas; $\bar{n}=$ nümero de plantas por parcela (média harmônica); $\sum N l_{1}=$ somatória do número de graus de liberdade para os ex ros das anālises individuais; $\sum \mathrm{NI}_{2}=$ somatōria do nümero de graus de liberdade dentro de parcelas. 
b. Análisescom totais de parcelas por parcela

F.V.

G.L.

QM

E (QM)

Locais

Tratamentos

Locais $\mathrm{x}$ Tratamentos

Erro médio $(s-1)$

$(t-1)$

$(p-1)(t-1) \quad Q_{3}$

$\sum N 1$ $-\sigma_{e}^{2}+r \sigma^{2} t_{2} l$

$\mathrm{Q}_{1}$

$\mathrm{Q}_{2}$

$\sigma_{e}^{2^{\prime}}+r \sigma^{2} t_{2} l+r s \sigma^{2} t_{2}$

$\sigma_{e}^{2}$

$\sigma^{2} t_{2}=$ variância entre tratamentos ao nivel de totais de par celas; $\sigma^{2} t_{2} l=$ variância da interação de tratamentos por 1ocais; $\sigma_{\mathrm{e}}^{2^{\prime}}=$ variância entre totais de parcelas; $\sum \mathrm{N} 1=$ somatória do número de graus de liberdade para os erros das análises individuais.

\subsubsection{Anāilise de covariāncia}

a. Anălise de covariância individual para cada local

As anālises de covariâncias individuais, envolvendo pares das características avaliadas, foram realizadas segundo o método de Kempthorne (1966), citado por GERALDI (1977), com as progênies comuns aos cinco 1ocais de experimentação. 
Através desse método, os produtos mëdios foram obtidos através dos quadrados médios provenientes das análises de variância em blocos ao acaso, a partir das somató rias dos valores das duas características em estudo, e dessas caracteristicas individualmente, ou:

$\mathrm{x} \quad \mathrm{y} \quad \mathrm{u} \quad \mathrm{x}, \mathrm{y}$

Progênies $\quad{ }^{Q} P_{x} \quad Q_{y} P_{u} P_{x} P_{x}=1 / 2\left(Q M P_{u}-Q M P_{x}-Q M P_{y}\right)$

Erro

$$
Q_{x} \quad Q M E_{y} \quad Q M E_{u} \quad P M E_{x, y}=1 / 2\left(Q M E_{u}-Q M E_{x}-Q M E_{y}\right)
$$

sendo: $\mathrm{x} \cdot \mathrm{e} \mathrm{y}=$ características em estudo; $\mathrm{u}=(\mathrm{x}+\mathrm{y}) ; \mathrm{QMP}=$ quadrado médio de progênies; $Q M E$ = quadrado médio do erro en tre parcelas; $P M P=$ produto médio entre progênies; $P M E$ = pro duto médio do erro entre parcelas.

Os quadrados médios para as caracteristicas in dividuais ( $M_{x}$ e $\left.Q M_{y}\right)$ utilizados para o cálculo dos produtos médios foram os correspondentes das anälises de variâncias in dividuais já discutidas. A anālise em látice para a somatória das duas características não seria a mais recomendada,já que a covariância dentro de parcelas não foi possível de ser determinada, pela grande quantidade de cálculos envolvidos. Isso se justifica, já que o produto médio do erro efetivo, a partir de 64 tratamentos, proveniente do látice, conteria a covariância dentro de parcelas não só das progênies como tam bém das testemunhas, o que não seria coerente, como pode-se 
constatar pelo conteūdo das esperanças dos produtos médios. Dessa forma, para minimizar tal problema, a análise mais ade quada foi considerada a de blocos ao acaso, somente com as progênies comuns.

A estrutura da anāilse de covariância para cá da par de característica num local fica, no esquema em blocos ao acaso, da seguinte forma:
F. V .
G.L .
PM
$E(P M)$

$\begin{array}{lccc}\text { Progênies } & p-1 & \mathrm{PM}_{1} & (1 / \overline{\mathrm{n}}) \operatorname{Cov}_{\mathrm{d}}+\operatorname{Cov}_{\mathrm{e}}+\mathrm{C}_{\mathrm{p}}^{\prime} \\ \text { Erro } & (\mathrm{r}-1)(\mathrm{p}-1) & \mathrm{PM}_{2} & (1 / \overline{\mathrm{n}}) \operatorname{Cov}_{\mathrm{d}}+\operatorname{Cov}_{\mathrm{e}}\end{array}$

$P M=$ produto médio; $E(P M)$ = esperança do produto médio; Cov' = covariância entre progênies ; Cove = covariância entre parcelas; Cov ${ }_{\mathrm{d}}=$ covariância dentro de parcelas; $\bar{n}=$ número de plantas por parcela (média harmônica).

b. Anälise de covariância conjunta para os cinco locais

As anālises de covariâncias conjuntas entre caracteristicas para locais foram realizadas a partir dos to tais das anālises em blocos ao acaso, juntamente com o erro médio das cinco anālises de covariâncias individuais, considerando os respectivos graus de $1 i^{5}$ erdade. A estrutura da anālise, dessa forma, fica: 

F.V.
G.L.
PM
$E(P M)$

$\begin{array}{lccc}\text { Locais } & \mathrm{s}-1 & \mathrm{P}_{1} & \\ \text { Progênies } & \mathrm{p}-1 & \mathrm{P}_{2} & (1 / \overline{\mathrm{n}}) \operatorname{Cov}_{\mathrm{d}}+\operatorname{Cov}_{\mathrm{e}}+\mathrm{rCov}_{\mathrm{p} 1}+\mathrm{r} \operatorname{Cov}_{\mathrm{p}} \\ \text { Prog. x Locais } & (\mathrm{p}-\mathrm{I})(\mathrm{s}-1) & \mathrm{P}_{3} & (1 / \overline{\mathrm{n}}) \operatorname{Cov}_{\mathrm{d}}+\operatorname{Cov}_{\mathrm{e}}+\mathrm{rCov}_{\mathrm{pl}} \\ \text { Erro médio } & {[\mathrm{Nl}} & \mathrm{P}_{4} & (1 / \overline{\mathrm{n}}) \operatorname{Cov}_{\mathrm{d}}+\operatorname{Cov}_{\mathrm{e}}\end{array}$

$\operatorname{Cov}_{\mathrm{p}}=$ covariância entre progênies; Cov $=$ covariância entre parcelas ao nivel de plantas; $\operatorname{Cov}_{d}=$ covariância dentro de parcelas; $\bar{n}=$ número de plantas por parcela (média harmôni ca); $\sum N I$ = somatória do número de graus de liberdade para os erros das anālises individuais; $\mathrm{Cov}_{\mathrm{pl}}=$ coyariância da in teração de progênies por locais.

\subsubsection{Estimação de parāmetros genēticos}

As estimativas de variâncias genéticas e não genéticas, de coeficientes de herdabilidade, de correlações genéticas, de ganhos genéticos e de outros parâmetros afins foram obtidas a partir das anālises anteriormente descritas, e com o detalhamento discutido a seguir.

4.2.4.1. Estimação de variãncias genēticas

As estimativas de variâncias genéticas e não genéticas e de parâmetros afins para as características altu 
ra, DAP e forma do tronco foram extraídas das esperanças dos quadrados médios das análises de variâncias, em látice ou em blocos ao acaso que, segundo VENCOVSKY (1978), se as semelham no que concerne à estimação dos componentes de variação.

a. Estimação de variâncias genéticas por caracteristicas e Zocal

Para a estimação de variâncias genéticas, no caso de utilização do látice, o quadrado médio de progênies foi obtido através de totais de tratamentos ajustados, incluindo somente as 49 progênies comuns aos cinco locais. 0 quadrado médio do erro utilizado foi o de erro efetivo, a partir da anālise original do látice com 64 tratamentos, supondo a homogeneidade do erro experimental.

Dessa forma, para a estimativa da variância do erro, a partir de 64 tratamentos, foi necessārio se dispor também da estimativa da variância dentro de parcelas para os 64 tratamentos. Assim, a estrutura da análise de variância e suas respectivas esperanças dos quadrados médios, com base em médias de parcelas por planta, fica: 
F. V.

G.L.

$\mathrm{p}-1$

$Q_{1}$

$(1 / \bar{n}) \sigma_{d}^{2}+\sigma_{e}^{2}+r \sigma_{p}^{2}$

Progênies

Ajustadas

$(k-1)(r-k-1)$

$\mathrm{Q}_{2}$

$(1 / \overline{\mathrm{n}}) \sigma_{\mathrm{d}}^{2}+\sigma_{\mathrm{e}}^{2}$

$\begin{array}{llll}\text { Dentro } & {\left[\mathrm{N}_{1}\right.} & Q_{3} & \sigma_{\mathrm{d}}^{2} \\ \text { Dentro' } & {\left[\mathrm{NI}_{2}\right.} & Q_{3}^{\prime} & \sigma_{\mathrm{d}}^{2}\end{array}$

$\sigma_{\mathrm{p}}^{2}=$ variância entre progênies; $\sigma_{\mathrm{e}}^{2}=$ variância entre parceças; $\sigma_{d}^{2}$ e $\sigma_{d}^{2}{ }^{\prime}=$ variancia dentro de parcelas com 49 e 64 tratamentos, respectivamente; $\left[\mathrm{Nl}_{1}\right.$ e $\left[\mathrm{Nl}_{2}=\right.$ somatórias dos núme ros de graus de 1 iberdade dentro de parcelas para as 49 progênies comuns e para os 64 tratamentos, respectivamente; $\bar{n}=$ número de plantas por parcela (média harmônica).

Com a substituição de $\sigma_{\mathrm{d}}^{2}$ e $\sigma_{\mathrm{d}}^{2}$ ' nas esperanças dos quadrados médios de tratamentos ajustados e do erro efetivo, respectivamente, obtêm-se as estimativas de $\sigma_{\mathrm{p}}^{2}$ e $\sigma_{\mathrm{e}}^{2}$.

No caso da análise em blocos ao acaso a questão fica mais simplificada, pois a análise com as 49 progênies comuns é adequada para a estimação dos componentes de variância, ficando a estrutura da análise da seguinte forma: 


\begin{tabular}{lccc}
\hline F.V. & G.L. & QM & E (QM) \\
\hline Progênies & $(p-1)$ & $Q_{1}$ & $(1 / \bar{n}) \sigma_{d}^{2}+\sigma_{e}^{2}+r \sigma_{p}^{2}$ \\
Erro & $(r-1)(p-1)$ & $Q_{2}$ & $(1 / \bar{n}) \sigma_{d}^{2}+\sigma_{e}^{2}$ \\
Dentro & {$[N 1$} & $Q_{3}$ & $\sigma_{d}^{2}$ \\
\hline
\end{tabular}

$\sigma_{\mathrm{p}}^{2^{\prime}}=$ variância entre progênies; $\sigma_{\mathrm{e}}^{2}=$ variância entre parcelas; $\sigma_{\mathrm{d}}^{2}=$ variância dentro de parcelas com 49 progênies comuns; $\quad \sum N 1$ = somatória do número de graus de liberdade dentro de parcelas; $\bar{n}=$ nümero de plantas por parcela (média har mônica).

Isto posto, as estimativas das variâncias entre progênies $\left(\sigma_{p}^{2}\right)$, do erro $\left(\sigma_{e}^{2}\right)$ e dentro de parcelas $\left(\sigma_{\mathrm{d}}^{2}\right)$, para cada característica e local, tornam-se facilmente deter mināveis a partir das esperanças dos quadrados médios, tanto na anālise em 1 átice como em blocos ao acaso, já que as mesmas têm iguais componentes.

As estimativas dos erros associados às variân cias entre progênies foram obtidas a partir da anālise de va riância, segundo VELO e VENCOVSKY (1974), por:

$$
s\left(\sigma_{p}^{2}\right)=\sqrt{\frac{2}{\mathrm{n}^{2} \mathrm{r}^{2}}\left(\frac{\mathrm{Q}_{1}^{2}}{\mathrm{~g}_{1}+2}+\frac{\mathrm{Q}_{2}^{2}}{\mathrm{~g}_{2}+2}\right)}
$$

sendo: $s\left(\sigma_{\mathrm{p}}^{2}\right)=$ estimativa do erro da variância entre progênies de meios-irmãos; $\bar{n}=$ número médio de plantas por parce1a; $r=$ número de repetições; $Q_{1}$ e $Q_{2}=$ quadrado médio para progênies e para o erro experimental, respectivamente; $g_{1}$ e 
$g_{2}=$ nümero de graus de liberdade para progênies e para o ex ro experimental, respectivamente.

0 coeficiente de herdabilidade ao nível de plantas individuais, referente à seleção entre plantas em ca da ensaio, fica então:

$$
h_{1}^{2}=\frac{4 \sigma_{p}^{2}}{\sigma_{d}^{2}+\sigma_{e}^{2}+\sigma_{p}^{2}}
$$

Essa estimativa de $\sigma_{\mathrm{p}}^{2}$ contém, na verdade, con forme colocam ROBINSON e COCKERHAM (1965), um componente ad cional devido à interação $\left(\sigma_{\mathrm{pl}}^{2}\right)$, não sendo adequada para a estimativa do coeficiente de herdabilidade envolvendo todos os locais.

0 coeficiente de herdabilidade para a seleção massal dentro de famílias de meios-irmãos, para cada local de ensaio, foi obtido por:

$$
h_{d}^{2}=\frac{3 \sigma_{p}^{2}}{\sigma_{d}^{2}}
$$

considerando-se que dentro das progênies de meios-irmãos existem só $3 / 4$ da variância genética aditiva.

O coeficiente de herdabilidade para seleção entre médias de famílias de meios-irmãos, dentro de cada ensaio, foi obtido a partir da seguinte expressão: 


$$
h_{m 1}^{2}=\frac{\sigma_{p}^{2}}{\frac{\sigma_{d}^{2}}{r \tilde{n}}+\frac{\sigma_{e}^{2}}{r}+\sigma_{p}^{2}}
$$

b. Estimąão de variâncias genéticas por caracteristicas em vários locais

As estimativas de variâncias a partir da análise conjunta nos cinco locais, visando principalmente a extrair da variância entre progênies o componente da interação progênies por locais, foram obtidas através da esperança dos quadrados médios da análise de variância conjunta, com a seguinte estrutura:

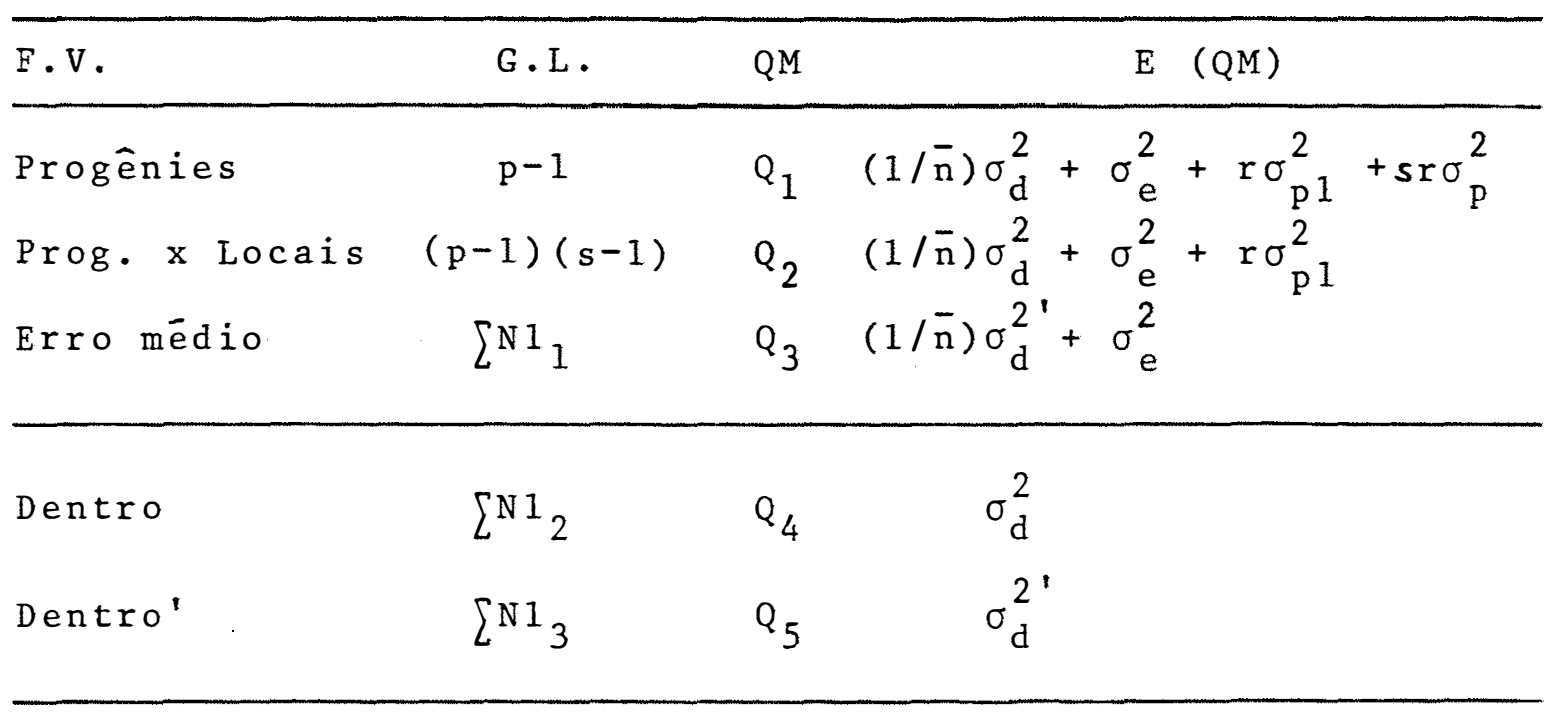

$\sigma_{\mathrm{p}}^{2}=$ variância entre progênies ao nível de plantas; $\sigma_{\mathrm{p} 1}^{2}=$ va riância da interação de progênies por locais; $\sigma_{e}^{2}=$ variância entre parcelas ao nível de plantas; $\sigma_{d}^{2}=$ variância dentro de parcelas com 49 progênies; $\sigma_{d}^{2}=$ variância dentro de parcelas com 64 tratamentos; $\left[N 1_{1}=\right.$ somatória do número de graus de $1 \underline{i}$ berdade para os erros das análises individuais; $\left[\mathrm{NI}_{2}\right.$ e $\left[\mathrm{Nl}_{3}=\right.$ 
somatória dos números de graus de liberdade dentro de parce1 as para 49 e 64 tratamentos, respectivamente.

Da mesma forma que foi descrito para a anālise individual, o quadrado médio para tratamentos na análise conjunta para locais foi obtido através de tratamentos ajustados (om 1átice) e de não ajustados (em blocos ao acaso), a partir das 49 progênies comuns aos cinco locais. 0 quadrado médio da interação de progênies por locais foi igualmente ob tido de totais de tratamentos ajustados com 49 progênies em cinco locais. Para o erro médio, o cálculo do quadrado médio teve como base os erros efetivos da análise em látice e os erros da análise em blocos ao acaso, considerando-se nos dois casos os 64 tratamentos.

0 quadrado médio dentro de parcelas, com base em 64 tratamentos, foi necessärio somente para estimar a variância entre parcelas $\left(\sigma_{\mathrm{e}}^{2}\right)$, a partir da esperança do quadra do médio do erro médio. O quadrado médio dentro de parcelas, com base em 49 progênies, estimou a variância dentro $\left(\sigma_{\mathrm{d}}^{2}\right)$ de् sejada, além de ter sido necessário para a obtenção da variância entre progênies $\left(\sigma_{\mathrm{p}}^{2}\right)$ e da variância da interação de progênies por locais $\left(\sigma_{\mathrm{p} 1}^{2}\right)$.

As estimativas de coeficientes de herdabilida de a diferentes níveis de unidade de seleção foram obtidas através das expressões de VEncovsky (1978).

0 coeficiente de herdabilidade, ao nível de plantas individuais, para seleção entre plantas nos locais em conjunto, foi obtido por:

$$
h_{2}^{2}=\frac{4 \sigma_{p}^{2}}{\sigma_{d}^{2}+\sigma_{e}^{2}+\sigma_{p 1}^{2}+\sigma_{p}^{2}}
$$


o coeficiente de herdabilidade para seleção entre médias de famílias de meios-irmãos para locais em conjunto fica:

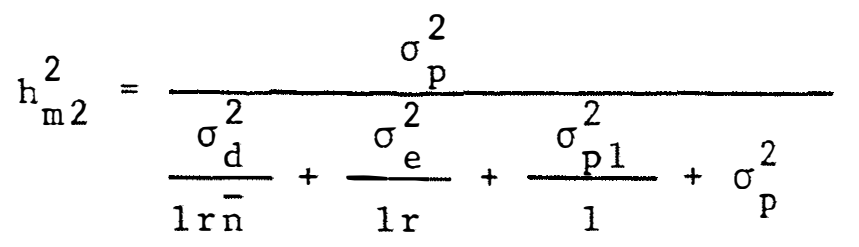

o coeficiente de variação genética $\left(\mathrm{CV}_{\mathrm{g}}\right)$ tanto ao nível de ensaio individual como ao nível de locais em conjunto foi obtido, ainda segundo VENCOVSKY (1978), por:

$$
\mathrm{CV}_{\mathrm{g}}(\%)=\frac{\sigma_{\mathrm{p}}}{\overline{\mathrm{x}}} \cdot 100
$$

4.2.4.2. Estimativas de covariäncias genēticas e de correlações genēticas entre pares de características

As estimativas de covariâncias genéticas e não genéticas e de parâmetros afins, entre pares de características, foram extraídas das esperanças dos produtos médios das análises de covariâncias, em látices ou em blocos ao aca so, segundo VENCOVSKY (1978).

a. Estimativas por par de caracteristicas num local

A estimativa da covariância entre progênies $\left(\operatorname{Cov}_{p}\right.$ ) para duas características, em cada local, foi obtida através da anālise de covariância, cuja estrutura já foi apresentada anteriormente. Através das esperanças dos produ- 
tos médios, relativas a progênies e ao erro, pode ser calculada a covariância entre progênies, que juntamente com as va riâncias entre progênies para as duas características indivi duais $\left(\sigma_{\mathrm{p}(\mathrm{x})}^{2^{\prime}}\right.$ e $\left.\sigma_{\mathrm{p}(\mathrm{y})}^{2^{\prime}}\right)$ permite estimar o coeficiente de corre Iação genética aditiva entre essas duas características, para um local, segundo FALCONER (1964), através de:

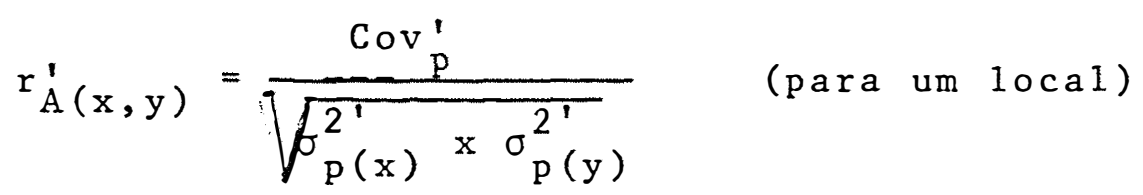

sendo $\mathrm{r}_{\mathrm{A}(\mathrm{x}, \mathrm{y})}=$ coeficiente de correlação genética aditiva pa ra as caracteristicas $x$ e $y$ e considerando que a Cov' contém $1 / 4$ da covariância aditiva; igualmente como na variância entre progênies, a covariância entre progênies determinada para um local contém também a covariância da interação de progênies por locais.

A correlação fenotípica ao nível de médias de progênies, entre pares de caracteristicas, foi obtida, segun do QUEIROZ (1969), por:

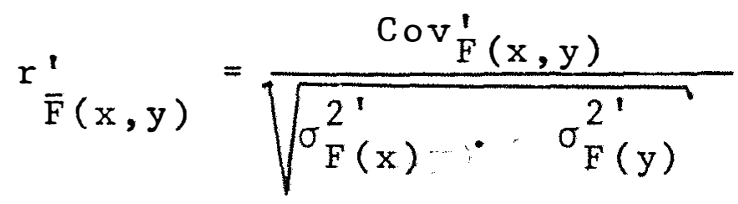

sendo: $\operatorname{Cov}_{F(x, y)}^{\prime} \operatorname{Cov}_{p}^{\prime}+\frac{\operatorname{Cov}_{e}}{r}+\frac{\operatorname{Cov}_{d}}{\bar{n} r}$

$$
\sigma_{F(x)}^{2}=\sigma_{p(x)}^{2^{\prime}}+\frac{\sigma_{e(x)}^{2}}{r}+\frac{\sigma_{d(x)}^{2}}{\bar{n} r}
$$




$$
\sigma_{F(y)}^{2}=\sigma_{p(y)}^{2}+\frac{\sigma_{e(y)}^{2}}{r}+\frac{\sigma_{d(y)}^{2}}{\bar{n} r}
$$

b. Estimativas por par de caracteristicas em vários locais

As estimativas das covariâncias entre progênies, da interação de progênies por locais e do erro entre parcelas foram obtidas através da esperança dos produtos médios da análise de covariância conjunta, para o par da carac terísticas em estudo, nos värios locais.

A covariância entre progênies obtida dessa for ma, e que se apresenta livre da covariância da interação de progênies por locais, juntamente com as variâncias entre pro gênies para as duas caracteristicas individuais, e uobtidas das respectivas análises de variâncias conjuntas para locais, permite obter a estimativa de correlação genética entre essas duas características, para os diversos locais, através de :

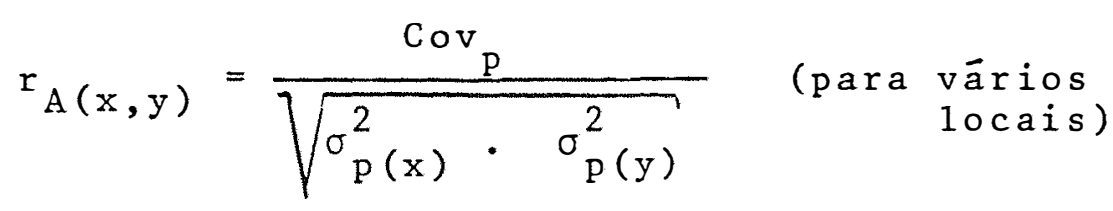

A diferença dessa expressão para a anterior diz respeito à abrangência dos parâmetros; no primeiro caso refere-se a um local somente e no segundo a vários locais.

Da mesma forma, a correlação fenotípica entre médias de progênies, considerando os diversos locais, foi ob tida por: 


$$
r_{\bar{F}(x, y)}=\frac{\operatorname{Cov}_{F(x, y)}}{\sqrt{\sigma_{F(x)}^{2} \cdot \sigma_{F(y)}^{2}}}
$$

sendo:

$$
\begin{aligned}
& \operatorname{Cov}_{F(x, y)}=\operatorname{Cov}_{p}+\frac{C_{p 1}}{1}+\frac{\operatorname{Cov}_{e}}{1 r}+\frac{\operatorname{Cov}_{d}}{1 r \bar{n}} \\
& \sigma_{F(x)}^{2}=\sigma_{p(x)}^{2}+\frac{\sigma_{p l(x)}^{2}}{1}+\frac{\sigma_{e(x)}^{2}}{1 r}+\frac{\sigma_{d(x)}^{2}}{1 r \bar{n}} \\
& \sigma_{F(y)}^{2}=\sigma_{p(y)}^{2}+\frac{\sigma_{p}^{2}(y)}{1}+\frac{\sigma_{e}^{2}(y)}{1 r}+\frac{\sigma_{d(y)}^{2}}{1 r \bar{n}}
\end{aligned}
$$

4.2.4.3. Estimativas de progressos genēticos na seleção

As estimativas de progressos genéticos para seleção nos ensaios foram obtidas através das expressões apresentadas por VENCOVSKY (1978).

Para cada característica e local, o progresso esperado na seleção entre e dentro de famílias de meios-irmãos, com seleção em ambos os sexos, através da transforma ção dos testes de progênies em "Pomar de Sementes por Mudas", foi obtido por: 


$$
G_{s}=\frac{K_{1}(1 / 4) \sigma_{A}^{2}}{\sqrt{\frac{\sigma_{d}^{2}}{\bar{n} r}+\frac{\sigma_{e}^{2}}{r}+\sigma_{p}^{2}}}+\frac{K_{2}(3 / 4) \sigma_{A}^{2}}{\sqrt{\sigma_{d}^{2}}}
$$

sendo: $G_{S}=$ progresso esperado na seleção; $K_{1}$ e $k_{2}=$ intensidades de seleção entre e dentro de progênies, respectiva mente; $\sigma_{\mathrm{A}}^{2}=$ variância genética aditiva; $\sigma_{\mathrm{p}}^{2}=$ variância entre progênies; $\sigma_{\mathrm{e}}^{2}=$ variância entre parcelas; $\sigma_{\underline{\mathrm{d}}}^{2}=$ variância den

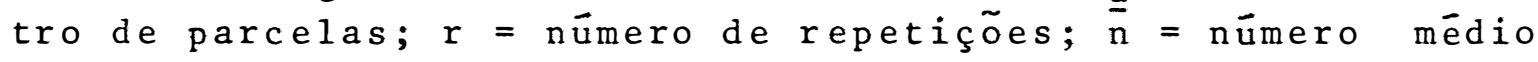
de plantas por parcela.

A seleção nos dois sexos, tanto.entre como dentro de progênies, é possível nas plantas perenes, tais co mo as espécies florestais, devido à possibilidade de seleção num ano e recombinação em anos subsequentes, conforme relata do por NAMKOONG (1966). Essa é uma vantagem apresentada pelas plantas perenes em relação às plantas anuais, principalmente na seleção dentro de progênies, onde a mesma pode ser mais evidenciada.

O efeito da interação de genótipos por locais na seleção foi avaliado através da comparação entre a seleção de famílias para locais individuais e para locais em con junto (seleção marginal). A perda devida à seleção marginal, relativamente à.seleção maximizada, foi avaliada através da relação ȳb/ỹa, sendo: ýa a média dos diversos locais para as melhores famílias em cada local e $\bar{y}$ a médias das melhores familias para todos os locais em conjunto.

A estimativa de ganhos realizados para as diversas características, na seleção fenotípica das árvores que originaram as progênies, foi obtida pela diferença entre 
.60 .

a média das progênies de árvores selecionadas e a média da população-base sem seleção utilizada como testemunha. Essas estimativas dão indicações das magnitudes de intensidades de seleção utilizadas para cada característica na seleção fenotípica, além de ser um aferidor das estimativas de herdabil $\underline{i}$ dades encontradas. 


\section{RESULTADOS E DISCUSSÃO}

\subsection{Crescimento em altura e sobrevivenncia das plantas aos 12 meses de idade}

Os resultados de crescimento em altura e sobrevivência das plantas aos 12 meses de idade, nos cinco $10-$ cais de ensaio, são apresentados e discutidos a seguir. Esses resultados são de importância justificada, pelas informa ções que fornecem sobre a evolução do ensaio, de idade mais jovem para mais avançada, permitindo melhores conclusões sobre o material em estudo.

Os resultados dos ensaios, aos 12 meses de idade no campo, mostram comportamentos expressivos para as progênies, notadamente para crescimento em altura de plantas. As médias dos ensaios nos locais Rezende, Agudos, Lençóis Paulista, Anhembi e Brotas foram, respectivamente, de 6,11 m, $5,61 \mathrm{~m}, 5,28 \mathrm{~m}, 5,12 \mathrm{~m}$ e $4,24 \mathrm{~m}$ para altura de plantas, mostrando o rápido crescimento inicial do material e a magnitude da variação devidá a locais. A variação verificada entre locais parece estar associada mais à variação nas caracterís ticas edáficas, já que as diferenças entre as latitudes dos 
locais de experimentação não é superior a $21^{\prime}$, e as variações de longitude não têm sido consideradas como importantes climaticamente. A variação de altitude é mais acentuada somente entre Brotas ( 800 metros) e os outros quatro locais (em torno de 550 metros), que pode ser também um dos determi nantes do crescimento diferencial entre locais.

A variação genética entre progênies para a a 1 tura das plantas dentro de cada local foi mais expressiva em Brotas, vindo a seguir os locais Lençóis, Agudos, Rezende e Anhembi, a julgar pelos valores de $F$ das análises da variância. Deve-se considerar ainda que os coeficientes de variação experimentais foram bastante homogêneos e de baixa magni tude para os cinco locais ensaiados, variando de $6,1 \%$ a $9,1 \%$ As eficiências dos látices foram bastante variáveis entre lo cais para essa característica, com quatro valores acima de $110 \%$, justificando plenamente a utilização desse delineamento experimental (SNYDER, 1966).

Para a sobrevivência de plantas nas parcelas, a variação entre tratamento foi, de modo geral, menos acentuada que para a altura de plantas, considerando-se os valores de $F$ da análise de variância, muito embora os coeficientes de variação experimentais tenhám sido de alta magnitude, variando de $50,8 \%$ a $72,8 \%$. Esses altos coeficientes de variação experimentais, por outro lado, revelam a ocorrênciade mortalidade de plantas por causas fortuitas. As eficiências dos látices para essa característica foram bem inferiores às encontradas para a altura das plantas, não mostrando correspondência entre as eficiências para as duas características nos: diferentes locais. Isso se deve, provavelmente, a efeitos fortuitos que contribuíram para a variação entre blocos em relação à sobrevivência e não à altura das plantas, e vice-versa. 
.63.

\begin{tabular}{|c|c|c|c|c|c|c|c|c|c|c|c|c|c|c|c|c|c|c|c|c|c|c|c|}
\hline $\begin{array}{l}w \\
0\end{array}$ & $\stackrel{\infty}{\infty}$ & & $\stackrel{\infty}{\infty}$ & $\underset{\nu}{\pi}$ & & & & & $\begin{array}{l}* \\
*\end{array}$ & $\begin{array}{l}* \\
*\end{array}$ & & & $\begin{array}{l}* \\
-*\end{array}$ & & & & & & & & ol & in & \\
\hline$\infty$ & is & & $\mathbb{0}$ & $\Xi$ & & $\Delta$ & $n$ & 0 & $\hat{\sim}$ & $\tilde{m}$ & & $\checkmark$ & in & $\therefore$ & & & & & & 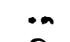 & & G & \\
\hline$\ddot{r}$ & $\mathbb{E}$ & & 0 & ח & & n & n. & 0 & 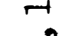 & $n_{a}$ & 1 & $a$ & $a$ & 0 & & $t$ & 1 & $t$ & 1 & 20 & $w$ & & \\
\hline 100 & & & $-r$ & $E$ & & in & in & in & $N$ & $\rightarrow$ & & $n$ & 0 & - & & 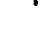 & . & 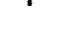 & 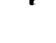 & in & $\mu$ & 0 & \\
\hline 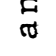 & $\underset{-1}{N}$ & & $\ln$ & 0 & & & & & & & & & & & & & & & & $\stackrel{a}{\rightarrow}$ & $\stackrel{0}{>}$ & $\pi$ & \\
\hline$\infty$ & $\infty$ & & & & & & & & & & & & & & & & & & & $\begin{array}{l}0 \\
\text { is }\end{array}$ & 崖 &.$\pi$ & \\
\hline$\underset{0}{\pi}$ & م) & & & & & & & & $*$ & & & & & & & & & & & $\mathbf{E}$ & 0 & $\underset{Z}{0}$ & \\
\hline$\infty$ & $\infty$ & & & $\stackrel{0}{\sigma}$ & & $\Gamma$ & & & * & $\stackrel{*}{n}$ & $\sim$ & $N$ & & & & 0 & $\stackrel{*}{\sim}$ & 0 & & 0 & $\sigma$ & $1 \pi$ & \\
\hline 0 & $\pi$ & & & G & & 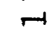 & $\sim$ & $a$ & 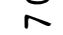 & 6 & 6 & 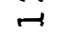 & & & & $=$ & in & $\sim$ & $m$ & & $\infty$ &.$-\mathrm{H}$ & \\
\hline $\overrightarrow{0}$ & 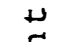 & & & 0 & & 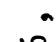 & $\therefore$ & $a$ & a & a & 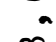 & $\therefore$ & 1 & 1 & & a & a & $a$ & $\therefore$ & 0 & 0 & 4 & \\
\hline+ & $\tilde{\sigma}$ & & & 0 & & & & & & & $\stackrel{\infty}{\sim}$ & & & & & -1 & - & : & 6 & $\infty$ & $\vec{A}$ & $\vec{r}$ & \\
\hline $\overrightarrow{7}$ & $\overrightarrow{0}$ & & & 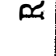 & & & & & & & -1 & & & & & & & $r$ & & $\overrightarrow{1}$ & $r_{\infty}^{10}$ & t- & \\
\hline $\begin{array}{l}w \\
0\end{array}$ & 0 & & & & & & & & $*$ & * & & & & & & & $*$ & & & 300 & О & $\infty$ & \\
\hline$\mu$ & $\nabla$ & & & $\infty$ & & & & & $*$ & $*$ & & & & & & & $*$ & & & on & a & $*$ & \\
\hline 0 & $\sigma$ & & & 10 & & $\sim$ & $m$ & 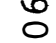 & $\vec{\sim}$ & $\overrightarrow{\vec{r}}$ & $\hat{m}$ & ָ & & & & in & in & $\stackrel{-}{\sim}$ & 5 & $\stackrel{\pi}{\pi}$ & 0 & $*$ & \\
\hline 0 & $\cdot-1$ & & & 4 & & in & a & a & a & a & $\because$ & a & 1 & 1 & & ! & a & a & . & $=$ & $\pi$ & 0 & \\
\hline $\begin{array}{l}\omega \\
0\end{array}$ & U & & & 吕 & & in & in & $n$ & $N$ & $N$ & $\stackrel{\infty}{\infty}$ & $\infty$ & & & & 6 & 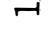 & ก & in & م. & $\pi$ & * & \\
\hline$\cdot \pi$ & $\stackrel{10}{>}$ & & & 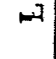 & & & & & & & -1 & & & & & & & $r$ & & $D_{1}$ & $\underset{\sigma}{\infty}$ & an & \\
\hline$\stackrel{\infty}{\square}$ & $\stackrel{-r}{>}$ & & ๘ा & & & & & & $*$ & & & & & & & & & & & $\widehat{\approx}$ & D. & $\vec{\sigma}$ & \\
\hline $\overrightarrow{0}$ & 0 & & $\cdot-1$ & o) & & & & & $\ddot{*}$ & $\tilde{*}$ & & & & & & & & & & 2 & $\sqrt{4}$ & $\omega$ & \\
\hline$\infty$ & مـ & & 0 & $\stackrel{\sigma}{+}$ & & $\stackrel{\sim}{\sim}$ & $\stackrel{\infty}{\sim}$ & $\begin{array}{l}\infty \\
0 \\
0\end{array}$ & مू & $\tilde{0}$ & $\vec{a}$ & nn & & & & $\stackrel{\vec{m}}{\mathrm{~m}}$ & $\stackrel{0}{-}$ & 신 & $\infty$ & $\because a$ & 0 & ָָ & \\
\hline$\circ$ & 0 & & 이 & 0 & & a & a & a & a & $\therefore$ & a & $\therefore$ & 1 & 1 & & a & a & $a$ & 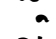 & $\infty$ & + & E & \\
\hline$\nabla$ & $\infty$ & & & $\stackrel{H}{n}$ & & $\checkmark$ & $\checkmark$ & $\checkmark$ & $m$ & $N$ & $\underset{-1}{N}$ & $\infty$ & & & & in & -1 & 응 & $N$ & $\pi$ & $\infty$ & $\cdot-1$ & \\
\hline$\infty$ & 0 & & & & & & & & & & -1 & & & & & & & $\rightarrow$ & & $\pi$ & $E$ & $a$ & \\
\hline 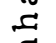 & $\sigma$ & & & & & & & & * & & & & & & & & & & & 0 & $\frown$ & $\bar{x}$ & \\
\hline$\underset{\Xi}{\Xi}$ & 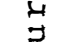 & & & 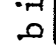 & & $N$ & $\infty$ & $n$ & * & $\stackrel{*}{m}$ & 0 & -1 & & & & 0 & & 0 & & - & $\Xi$ & 0 & \\
\hline $\boldsymbol{E}$ & $\pi$ & & & E & & 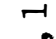 & $\vec{r}$ & $\infty$ & 6 & in & $\vec{r}$ & -1 & & & & 6 & $\sim$ & $m$ & $\sim$ & c) & & 0 & \\
\hline$\stackrel{\sim}{\sim}$ & $\sqrt{\pi}$ & & & $\stackrel{0}{]}$ & & in & in & ga & $\vec{n}$ & $\vec{r}$ & $\hat{g}$ & 0 & 1 & 1 & & in & 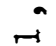 & $0^{\circ}$ & 0 & $\vec{\alpha}$ & $\ddot{\sigma}$ & $i \pi$ & \\
\hline $\begin{array}{l}\infty \\
0 \\
0\end{array}$ & & & & $\bar{G}$ & & & & & & & 0 & & & & & & & $m$ & in & is & $P$ & $\pi$ & \\
\hline$\omega$ & 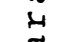 & $\because$ & & & & & & & & & & & & & & & & & & $\omega$ & $\widetilde{G}$ & 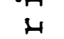 & \\
\hline 0 & $\stackrel{\pi}{2}$ & $\pi$ & & () & & & & & $\ddot{*}$ & $*$ & & & & & & & $\begin{array}{r}* \\
*\end{array}$ & & & $\stackrel{4}{2}$ & $\pi$ & $\int^{\pi}$ & \\
\hline & & 0 & & 이 & & $\sqrt{0}$ & $\vec{r}$ & 0 & 6 & $m$ & 0 & $\checkmark$ & & & & 0 & $\checkmark$ & $n$ & & 0 & $\pi$ & & \\
\hline 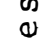 & $\widetilde{\sigma}$ & $\neg$ & & $\vec{y}$ & & a & $n_{0}$ & $\stackrel{+}{a}$ & a & o & m & $\infty$ & 1 & 1 & & 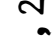 & $\infty$ & $\tilde{n}_{0}$ & 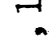 & ? & $\sigma$ & 0 & \\
\hline$\cdot \vec{a}$ & $\vec{\theta}$ & 0 & & $\frac{a}{4}$ & & $n$ & & in & $r$ & $r$ & $m$ & $\infty$ & & & & 윽 & $r$ & $m$ & $\circ$ & 100 & $\begin{array}{l}\infty \\
0\end{array}$ & 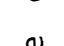 & \\
\hline${ }_{\infty}^{10}$ & $\frac{E}{4}$ & $\underset{. T}{I-1}$ & & & & & & & & & -1 & & & & & & & -1 & & $\underset{-1}{0}$ & \pm & \pm & \\
\hline 안 & $\smile$ & $u$ & & & & & & & & & & & & & & & & & & . & 0 & c్ & \\
\hline D & $\pi$ & $\infty$ & & & & & $\frown$ & $\frown$ & $\frown$ & $\frown$ & & $\frown$ & & & & & & & & 0 & స్ & 0 & \\
\hline$\infty$ & •-t & $E$ & & & & & $\vec{c}$ & 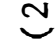 & $\stackrel{n}{\smile}$ & $\Xi$ & a) & $\stackrel{\simeq}{0}$ & & & & & & & & $\because$ & $\stackrel{\Delta}{ }$ & - & \\
\hline$\pi_{0}^{\pi}$ & $E$ & & & & & & & & & & $u$ & & & & & & & 0 & & 10 & 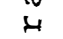 & 0 & \\
\hline 0 & $\begin{array}{l}.4 \\
100\end{array}$ & 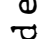 & & & & & in & & & & $\cdot-4$ & & & & & & & r & & $\infty$ & $\downarrow$ & 0 & \\
\hline$\infty$ & 4 & $\pi$ & & & & & a & & & & $1 \pi$ & & & $\omega$ & & & & 10 & & 4 & $\pi$ & & \\
\hline$\pi$ & $\pi$ & $\tau$ & 車 & & & & $\overrightarrow{0}$ & 0 & & & $\rightarrow$ & & & $\therefore-1$ & & & & $H$ & & مص & $\mu$ & $\frown$ & \\
\hline ד & $p$ & •rt & & & & & $\infty$ & $\infty$ & $\infty$ & & ○ & & & 0 & & & & Q & & $\infty$ & $\pi$ & in & \\
\hline 10 & $\pi$ & 0 & & 0 & & & & $\infty$ & 0 & & $\nabla$ & $\frown$ & & 0 & & & & $\nabla$ & $\therefore$ & $\pi$ & H & - & \\
\hline$\Sigma$ & $\nabla$ & $\tau$ & & 4 & & $\approx$ & $\dot{\sim}$ & & \pm & $\infty$ & $\pi$ & $\cong 0$ & & -1 & & $\vec{r}$ & \pm & & $\smile$ & $\nabla$ & 5 & $\ddot{a n}$ & 0 \\
\hline$\dot{\circ}$ & & & & 0 & $\xi$ & 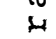 & 0 & $\dot{a}$ & $\omega$ & 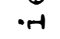 &.-4 & • & & $x$ & sొ & - & 崩 & . & $\bullet$ & $\pi$ & 0 & $\pi$ & \\
\hline 6 & & & & $E$ & $\approx$ & $\underset{\infty}{0}$ & 4 & 0 & $E$ & I & 0 & 2 & $\infty$ & & - & 0 & $\Xi$ & 0 & a & $\cdot r-1$ & \pm & 0 & in \\
\hline rర & & & 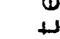 & 4 & 8 & $\infty$ & & & 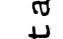 & ${ }_{\infty}^{10}$ & ( & $\stackrel{x}{\alpha}$ & $\vec{r}$ & in & & $\infty$ & त & (1) & $x$ & 10 & os & $\pi$ & 0 \\
\hline - & & & & $\pi$ & $f_{f}$ & $\pi$ & $\pi$ & $\therefore$ & $\pi$ & 0 & $\cdot-4$ & & 0 & 0 & 0 & $\pi$ & $\pi$ & $\cdot \because$ & & $\Sigma$ & $E$ & 0 & 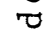 \\
\hline مد & & & 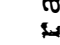 & & $\underset{+}{\mathbb{N}}$ & ס & $\stackrel{\theta}{-\pi}$ & in & 点 & $\mu_{1}^{H}$ & $\underset{.-1}{u}$ & $\dot{>}$ & $\stackrel{0}{\rightarrow}$ & 虫 & $\frac{n}{2}$ & 年 & $\stackrel{M}{H}$ & . & $\dot{>}$ & $\frown$ & & •rt & \\
\hline 10 & & & $\pi$ & & $\sim$ & 10 & 10 & 0 & & & 4 & . & 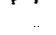 & & & 10 & & 4 & $\because$ & $\pi$ & $m$ & o & ه \\
\hline 5 & & & 5 & & $\digamma$ & $\Sigma$ & $\Sigma$ & $\in$ & {$\left[\begin{array}{ll}1 \\
1\end{array}\right.$} & L4 & [도] & 0 & [as & 15 & $E_{1}$ & $\Sigma$ & 出 & 되 & 0 & $\smile$ & $\smile$ & -1 & $>$ \\
\hline
\end{tabular}


A comparação entre as médias das progênies das árvores selecionadas com a média da testemunha referente à população original de onde foram extraídas as progênies, mostra a resposta à seleção fenotípica efetuada. Uma superioridade em média de $5,65 \%$ em favor das progênies de árvores selecionadas, com uma resposta mais ou menos semelhante para os cinco 1 ocais $(5,74 \%, 6,80 \%, 4,90 \%, 5,73 \%$ e $5,07 \%)$, re vela a consistência dos resultados.

A estimativa de ganhos médios realizados para a seleção somente do lado feminino (progênies de polinização 1 ivre), e correspondentes a 5,68\% para altura de plantas, de monstram que com a seleção também do lado masculino, através da instalação dos "Pomares de Sementes clonais", pode-se pre ver o dobro do ganho obtido, o que equivale a $11,36 \%$, representando, sem dúvida, um valor bastante significativo e de conformidade com o obtido por VAN WYK (1976).

5.2. Resultados da avaliação de altura, DAP, volume cilin drico, sobrevivência e forma do tronco das ārvores, aos dois anos de idade

Os resultados de médias de altura, DAP, sobre vivência, volume cilíndrico e forma do tronco dos ensaios nos cinco locais, para os diferentes tipos de progênies e testemunhas, são apresentados na Tabela 7 .

Os dados de médias de crescimento em alturade plantas aos dois anos confirmam o comportamento observado no primeiro ano de crescimento, mostrando o valor do material para as condições ensaiadas. Foi observado um crescimento médio nos cinco $10 \mathrm{cais}$ de 12,08 metros na altura das plantas, com amplitude de 10,38 metros (Agudos) a 14,32 metros 
(Resende). 0 incremento em altura no segundo ano de crescimento foi diferencial nos vários locais, mostrando que o rit mo de crescimento em função do estágio de desenvolvimento po de variar em função das condições locais. 0 maior incremento no segundo ano foi observado para Anhembi (8,43 m), vindo a seguir Resende $(8,21 \mathrm{~m})$, Brotas $(7,35 \mathrm{~m})$, Lençöis $(5,27 \mathrm{~m})$ e por último Agudos $(4,77 \mathrm{~m})$. Esse fato indica a necessidade de que haja precauções nas extrapolações de crescimentos de idades juvenis para idades mais avançadas, o que é bem en fatizado por VAN WYK (1976), KAGEYAMA (1977), dentre outros.

Os resultados obtidos, de médias de sobrevivência nas parcelas aos dois anos de idade, não revelam dife renças flagrantes comparativamente ao primeiro ano, mostran do que as falhas existentes foram devidas a fatores existentes, predominantemente na instalação do ensaio e no primeiro ano de crescimento. Os dados médios de DAP de plantas e vo- lume cilíndrico de parcelas seguem as mesmas tendências que as observadas para altura de plantas; a forma do tronco, que ser $\bar{a}$ discutida mais detalhadamente, apresenta um comportamen to geral diferente do obtido para as características de cre cimento.

A comparação das médias das progênies das ārvores selecionadas com as das testemunhas, incluídas no ensaio, permite a visualização do valor dessas progênies em re 1 ação a materiais comerciais existentes, assim como possibilita, através da sua comparação com a população-base sem seleção, avaliar os ganhos realizados.

As médias obtidas da população-base de onde foram extraídas as progênies, quando comparadas com as médias das progênies de outras populações e da testemunha comercial da África do Sul, mostram-se sempre superiores a es- 
sas para todas as características avaliadas, exceto para a forma de tronco. Esse fato reforça o valor que a população de Coff's Harbour, escolhida como população-base, tem para fins de seleção intrapopulacional. Os materiais utilizados como testemunhas, para avaliação do programa de melhoramento, a partir de comparação com a população-base originada de Coff's Harbour, eram os existentes na época de instalação dos ensaios. Para que se possa ter um programa de melhoramento dinâmico, uma verificação constante deve ser efetuada, incluindo-se periodicamente nas comparações com o material melhorado, outras populações que se tornem disponíveis.

A superioridade das progênies das ärvores selecionadas, relativamente à população-base sem seleção, foi variāvel para as diferentes características estudadas. A su perioridade média para os cinco locais foi maior para a sobrevivência $(24,37 \%)$, vindo a seguir a forma do tronco $(13,43 \%)$, o volume cilíndrico $(8,41 \%)$, a altura $(6,22 \%)$ e por último o $\operatorname{DAP}(1,59 \%)$. Esses valores encontrados, e que refletem a resposta à seleção fenotípica efetuada, são devidos às diferentes pressões impostas na seleção para as características e/ou às herdabilidades diferenciais para as mesmas.

Ao se compararem as estimativas de ganhos rea lizados para a altura de plantas aos dois anos, de idade $(6,22 \%)$ com as obtidas no primeiro ano $(5,65 \%)$, observa-se uma similaridade de resultados, e que mostra uma certa constância na diferença genética entre os materiais testados no decorrer do tempo. 
.67.

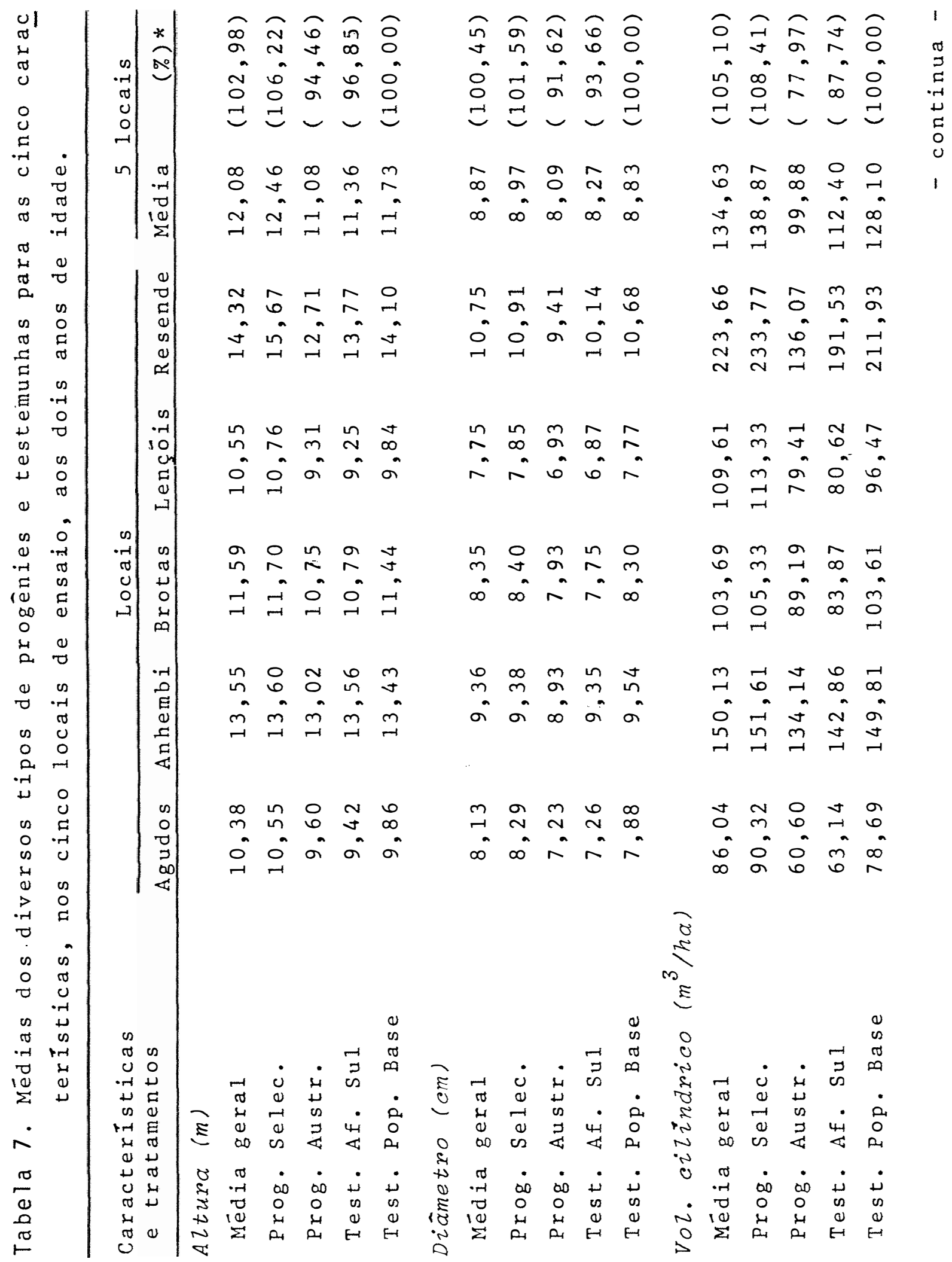


.68.

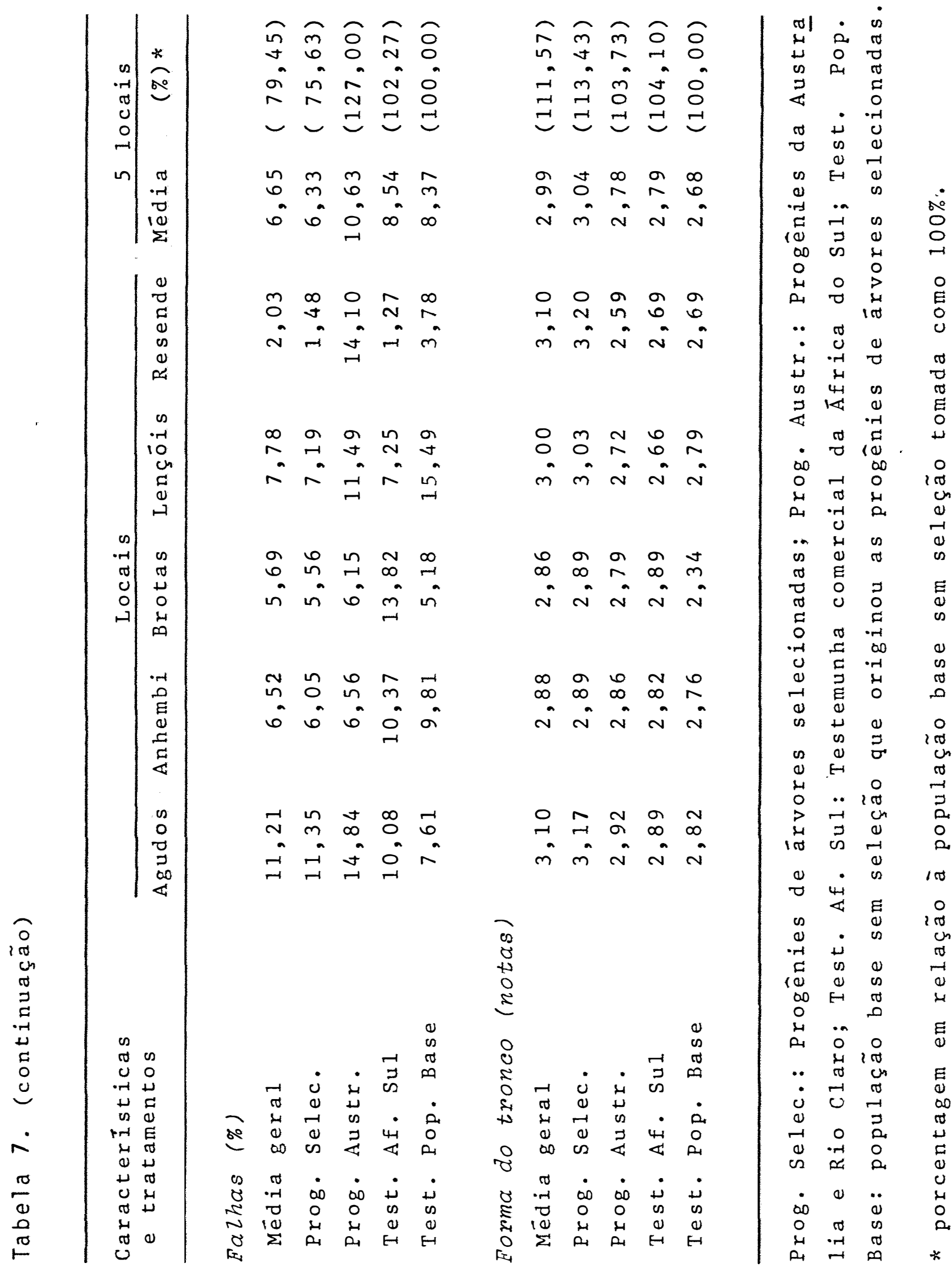


A partir dessas estimativas de ganhos realiza dos, com a utilização de progênies de polinização livre, podem-se prever ganhos significativos quando se extrapolam esses valores para a seleção em ambos os sexos. Essa situação, que seria obtida através da instalação dos "Pomares de semen tes Clonais", permitiria a predição de um ganho genético em torno de $26,86 \%$ para a forma do tronco, $16,82 \%$ para o volume de madeira, $12,44 \%$ para a altura das plantas e $3,18 \%$ para o DAP de plantas, o que representaria um avanço significativo para essas características, considerando que somente um ciclo de seleção foi envolvido. Essas predições de ganhos genéticos estão de acordo com as estimativas efetuadas por SHELBOURNE (1969a) e ELDRIDGE (1977).

5.3. Resultados das anālises da variāncia individuais e conjuntas para as cinco características, aos dois anos de idade

Os resultados obtidos das anālises da variância individuais para as características altura, DAP, formado tronco, volume cilíndrico e sobrevivência das plantas, nos cinco locais de ensaios, são apresentados na Tabela 8 .

As variações genéticas entre tratamentos foram detectadas para todas as características em todos os 1ocais, muito embora os valores tenham variado tanto entre locais como entre características. Nos locais Agudos e Resenle foram constatadas variações genéticas significativas para todas as cinco características. Nos locais Anhembi e Len çóis foram detectadas variações genéticas para quatro das cinco características, sendo que no primeiro local não se mostraram significativas as variações entre tratamentos para 
a sobrevivência nas parcelas e no segundo local para o DAP de plantas. O local Brotas apresentou variações genéticas somente para três características, sendo que isso não ocorreu para volume cilindrico e sobrevivência de parcelas. Con siderando-se as caracteristicas estudadas, a forma do tronco e a altura de plantas foram as que mostraram variações genéticas em todos os cinco locais, vindo a seguir o volume cilindrico de parcelas e o DAP de plantas, em que as variações genéticas foram detectadas em quatro locais, e por ūltimo a sobrevivência nas parcelas em três locais somente.

Os diferentes comportamentos dos tratamentos nos diversos locais podem ser interpretados como uma expressão diferencial dos materiais genéticos de local para local, e que refletiria na interação de tratamentos por locais (VEN COVSKY, 1978), ou mesmo em função da variação do erro experi mental entre locais. De fato, os coeficientes de variação experimentais foram mais baixos e pouco variáveis para a for ma do tronco e a altura de plantas, intermediários e mais va riáveis para o volume cilíndrico e o DAP de plantas, e extre mamente altos e também variáveis para a sobrevivência de plantas. Surpreendentemente, a forma do tronco, avaliada subjetivamente, foi a caracteristica que revelou os valores mais baixos para os coeficientes de variação das análises de variāncia, mostrando portanto maior precisão experimental. I so indica que a forma do tronco, do modo como foi avaliada, apresentou uma boa eficiência experimental dentro de cada lo cal de ensaio.

Muito embora os ensaios dos diferentes locais tenham sido instalados em condições ambientais diferentes, a parentemente, a utilização de parcelas com e sem bordadura nos ensaios não afetou a eficiência dos ensaios. Os ensaios nos locais Anhembi, Brotas e Lençóis com parcelas de 25 (5 x 
5) plantas, e bordadura simples, não apresentaram coeficientes de variação experimentais menores do que os instaladosem Resende e Agudos, com parcelas lineares de 10 plantas e sem bordaduras. Em idade mais avançada, à medida que haja maior efeito de competição entre parcelas, esses resultados poderão se alterar.

Os valores de $F$ da análise de variância para as 49 progênies comuns aos cinco locais foram, no geral, mais baixos que os observados para os 64 tratamentos, e que incluem as testemunhas. Isso se deve ao fato de que a inclusão das testemunhas no ensaio, que foram invariavelmente inferiores às progênies de árvores selecionadas, aumentou a va riabilidade entre tratamentos. Deve-se considerar que, mesmo com a variação diminuída, entre progênies, o resultado geral pouco se alterou em termos de detecção de variabilidade genética, para as cinco caracteristicas e os cinco locais.

Os valores encontrados para as eficiências dos 1átices, considerando-se um 1 imite de $110 \%$ (SNYDER, 1966 e MIRANDA FILHO, 1978), mostraram-se variáveis tanto entre 1ocais como entre características dentro de locais. Das 25 eficiências encontradas, 11 se mostraram acima de $110 \%$ e 14 abaixo desse limite, confirmando a justificativa da instalação dos experimentos em 1átice. Em Agudos, quatro características apresentaram eficiências acima do limite estipulado; em Anhembi, Brotas e Resende, o mesmo ocorreu para três características; em Lençóis, somente uma característica ultrapassou esse limite. Igualmente como no primeiro ano, den tro de um ensaio, diferentes caracteristicas apresentaram di ferentes eficiências de látice, mostrando maior influência da variação entre blocos para umas do que para outras. 
Tabela 8. Resultados das anālises da variāncia individuais para as cinco características nos cinco locais de ensaio, envolvendo os 64 tratamentos e as 49 progê nies comuns aos locais, aos dois anos de idade.

\begin{tabular}{|c|c|c|c|c|c|c|c|}
\hline \multirow[t]{2}{*}{ Locais } & \multirow{2}{*}{ Características } & \multirow{2}{*}{$\begin{array}{l}\text { Média } \\
\text { do } \\
\text { ensaio }\end{array}$} & \multicolumn{3}{|c|}{ F tratamentos } & \multirow{2}{*}{$\begin{array}{c}\text { Ef. } \\
\text { Lätice } \\
(\%)\end{array}$} & \multirow{2}{*}{$\begin{array}{l}\text { C.V. } \\
\text { exp. } \\
(\%)\end{array}$} \\
\hline & & & 64 & tratos. & 49 prog. & & \\
\hline \multirow{5}{*}{ Agudos } & Altura (m) & 10,38 & & $1 ; 65 *$ & $1,45 *$ & 176,71 & 9,3 \\
\hline & DAP $(\mathrm{cm})$ & 8,13 & & $1,84 * *$ & $1,90 * *$ & 135,11 & 12,9 \\
\hline & Forma (nota) & 3,10 & & $2,96 * *$ & $2,74 * *$ & 102,30 & 5,0 \\
\hline & Vol.Cil. ( $\left.\mathrm{m}^{3} / \mathrm{ha}\right)$ & 86,04 & & $2,33 * *$ & $1,95 * *$ & 128,74 & 26,7 \\
\hline & Falha (\%) & 11,21 & & $1,81 * *$ & $2,22 * *$ & 113,42 & 56,7 \\
\hline \multirow{5}{*}{ Anhembi } & Altura (m) & 13,55 & & $1,84 * *$ & $2,09 * *$ & 188,13 & 5,9 \\
\hline & DAP $(\mathrm{cm})$ & 9,36 & & $1,53 *$ & 1,33 & 106,12 & 8,0 \\
\hline & Forma (nota) & 2,88 & & $2,87 * *$ & $3,11 * *$ & 103,80 & 5,1 \\
\hline & Vol.Cil. (m $3 / \mathrm{ha})$ & 150,13 & & $1,70 * *$ & $1,63 *$ & 105,04 & 19,5 \\
\hline & Falha $(\%)$ & 6,52 & & 1,34 & 1,25 & 125,82 & 64,3 \\
\hline \multirow{5}{*}{ Brotas } & Altura (m) & 11,60 & & $1,68 * *$ & 1,32 & 103,67 & 8,7 \\
\hline & DAP $(\mathrm{cm})$ & 8,35 & & $1,48 *$ & 1,31 & 109,24 & 11,5 \\
\hline & Forma (nota) & 2,86 & & $2,53 * *$ & $2,33 * *$ & 124,05 & 6,4 \\
\hline & Vol.Cil. ( $\left.\mathrm{m}^{3} / \mathrm{ha}\right)$ & 103,69 & & 1,07 & 1,01 & 112,59 & 27,3 \\
\hline & Falha (\%) & 5,69 & & 1,12 & 1,01 & 100,84 & 82,3 \\
\hline \multirow{5}{*}{ Lençöis } & Altura (m) & 10,55 & & $2,19 * \star$ & $2,11 * *$ & 109,07 & 9,9 \\
\hline & $\operatorname{DAP}(\mathrm{cm})$ & 7,75 & & 1,33 & 1,32 & 100,51 & 12,8 \\
\hline & Forma (nota) & 3,00 & & $2,42 * *$ & $2,30 * *$ & 113,37 & 4,9 \\
\hline & Vol.Cil. (m $\left.\mathrm{m}^{3} / \mathrm{ha}\right)$ & 109,08 & & $2,45 * \dot{x}$ & $2,14 * *$ & 103,01 & 29,2 \\
\hline & Falha (\%) & 7,78 & & $3,64 * *$ & $3,06 * *$ & 109,63 & 61,9 \\
\hline \multirow{5}{*}{ Resende } & Altura (m) & 14,32 & & $2,20 * *$ & $1,86 * *$ & 119,82 & 7,3 \\
\hline & $\mathrm{DAP}(\mathrm{cm})$ & 10,75 & & $2,19 * *$ & $1,83 * *$ & 101,36 & 8,8 \\
\hline & Forma (nota) & 3,10 & & $3,33 * *$ & $2,30 * *$ & 127,66 & 5,9 \\
\hline & Vol.Cil. ( $\left.\mathrm{m}^{3} / \mathrm{ha}\right)$ & 223,66 & & $2,78 * *$ & $1,95 * *$ & 107,11 & 19,7 \\
\hline & Falha $(\%)$ & 2,03 & & $3,17 * *$ & $1,69 * *$ & 103,36 & 73,7 \\
\hline
\end{tabular}

F.tratamento: teste $F$ para tratamento da Anava para 64 trata mentos e as 49 progênies comuns aos 5 locais; Ef. Látice: eficiência do látice; C.V. exp.: coeficiente de variação expe rimental; Vol. Cil.: volume cilindrico.

* significância ao nível de $5 \%$, ** significância ao nível de $1 \%$. 
A avaliação do efeito de progênies, de locais e da interação entre estes dois fatores pode ser melhor compreendida através dos resultados da anāilse conjunta para lo cais, envolvendo as cinco características, e que são expressas na Tabela 9 .

Tabela 9. Resultados das anālises da variância conjuntas para as cinco características envolvendo as 49 progê nies comuns aos cinco locais, aos dois anos de ida de.

\begin{tabular}{llllll}
\hline Caracteristicas & $\begin{array}{l}\text { Médias } \\
\text { Gerais }\end{array}$ & $\begin{array}{l}\text { progê } \\
\text { nies }\end{array}$ & F locais & Frog. & C.V. \\
locais & $(\%)$
\end{tabular}

$\begin{array}{lrlrrr}\text { Altura (m) } & 12,23 & 2,03 * * & 316,98 * * & 1,46 * * & 8,1 \\ \text { DAP (cm) } & 8,97 & 1,65 * * & 173,72 * * & 1,37 * * & 10,6 \\ \text { Forma (notas) } & 3,04 & 3,84 * * & 20,53 * * & 1,60 * * & 5,5 \\ \left.\text { Vol.Cil. (m }{ }^{3} / \text { ha }\right) & 139,26 & 2,07 * * & 280,13 * * & 1,47 * * & 24,8 \\ \text { Falhas (\%) } & 6,65 & 1,33 & 18,05 * * & 1,77 * * & 71,9\end{array}$

C.V. exp. (\%): coeficiente de variação experimental em : porcentagem; Vol. Cil. ( $\left.\mathrm{m}^{3} / \mathrm{ha}\right)$ : volume cilindrico em metros c $\vec{u}-$ bicos por hectare; ** significância ao nível de $1 \%$.

Das cinco características analisadas, a altura, o DAP de plantas, a forma do tronco e o volume cilindrico das ārvores apresentaram variações genéticas significativas entre progênies, detectadas pelos respectivos valores de F das anāilses de variância conjuntas. Somente para a sobre vivência de plantas nas parcelas não foram detectadas tais variações ao nível de progênies. A variação entre médias de progênies, para as três principais características, altura 
de plantas, DAP de plantas e forma de tronco, pode ser visua lizada na Figura 1 . Essas variações mostram boas perspectivas para seleção entre progênies e continuidade do melhora mento, o que será discutido posteriormente.

As variações verificadas para a sobrevivência de plantas, apesar de expressivas, não se mostraram significativas, provavelmente devido ao erro experimental expresso pelo alto coeficiente de variação de análise de variância.Na anālise de variância conjunta para locais constatou-se a me ma tendência para os coeficientes de variação verificada nas anālises individuais, com esses valores muito altos para sobrevivência $(71,9 \%)$, e menores para o volume cilindrico $(24,8 \%), \operatorname{DAP}(10,6 \%)$, altura $(8,1 \%)$ e forma do tronco $(5,5 \%)$. Esses diferentes erros experimentais expressam, por um lado, propriedades intrinsecas das características e, por outro, a falhas casuais na instalação dos ensaios, como é o caso de sobrevivência nas parcelas. As três características simples, ou avaliadas por árvore individual, apresentaram erros experimentais considerados baixos para ensaios de campo, de acor do com PIMENTEL gOMES (1973), mostrando boas precisões para as anālises estatísticas. O volume cilíndrico a nível de parcelas, por ser uma característica composta, formada por altura, DAP e sobrevivência, apresenta tendência para maior erro experimental. Esse fato, aliado ao fato da sobrevivência e o volume cilíndrico serem difíceis de avaliação ao nível de árvore individual, justifica a escolha das caracterís ticas altura, DAP e forma do tronco como as principais para obtenção de estimativas de parâmetros genéticos.

Os efeitos de locais, a julgar pelos valores respectivos dos $F$ das anālises de variância, foram os que se mostraram mais altos para todas as caracteristicas estudadas. A variação devida a locais foi mais expressiva para as carac 

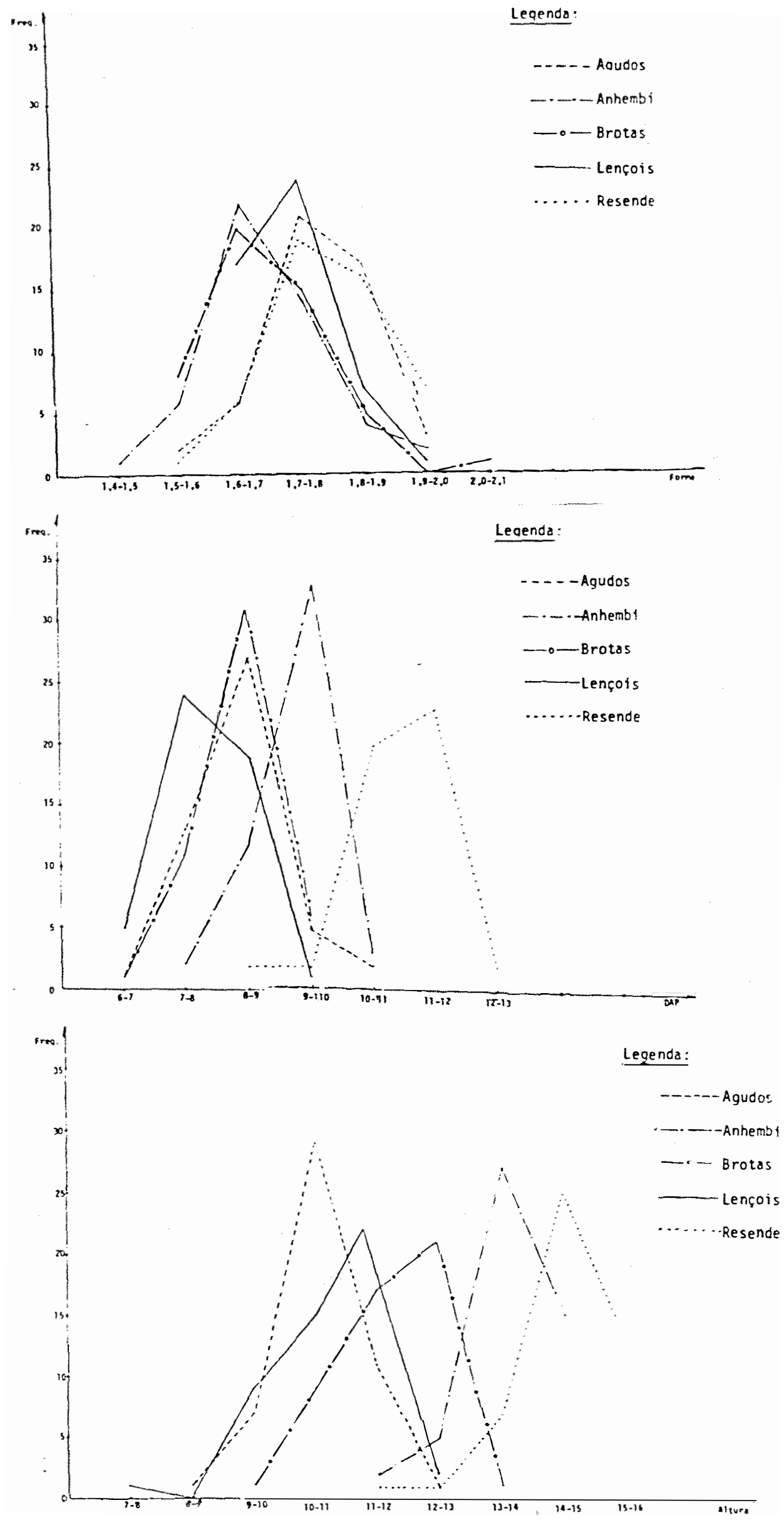

Figura 1. Variação entre médias de progênies para forma do tronco, DAP e altura de plantas, nos cinco 10cals de ensaios, aos dois anos de idade. 
teristicas de crescimento de plantas (altura, DAP e volume cilindrico) do que para a forma do tronco e a sobrevivência de plantas, mostrando que estas ūltimas foram menos afetadas por variações de sítios, nas condições estudadas. A variação relativamente pequena para forma do tronco deveu-se, pro vavelmente, ao caráter subjetivo da avaliação dessa característica, podendo ter havido pequenas variaçóes no critério de atribuição de notas entre locais, muito embora se tenha tido uma boa precisão experimental dentro de cada local. A forma do tronco das árvores tem sido citada como de alta her dabilidade e, portanto, pouco influenciável pelo ambiente, conforme enfatiza SHELBOURNE (1969b), sendo possivelmente, tam bém uma das causas do menor efeito de locais para essa carac terística.

0 efeito da interação de progênies por locais mostrou-se significativo para todas as características estudadas, muito embora essa variação tenha sido, no geral, de menor magnitude do que para locais e para progênies. Essa in teração de progênies por locais, segundo VENCovsky (1978), in clui os dois componentes da interação, ou seja, o devido à diferença na variabilidade entre progênies e o devido à falta de correlação entre os materiais de um local para outro. Para propósitos de seleção de progênies dentro dos ensaios o segundo componente da interação é que seria mais importante, enquanto que para a estimação de variâncias genéticas os dois componentes dessa interação deveriam ser extraídos para a ob tenção das estimativas. 
5.4. Estimação de variâncias genéticas e de coeficientes de herdabilidade para a altura, O DAP e a forma do tronco das ārvores nos cinco locais de ensaios, aos dois anos de idade

As estimativas de variâncias genéticas e nãogenéticas, obtidas a partir dos componentes de variância das anālises da variância individuais e conjuntas, para altura, DAP e forma do tronco das ärvores, nos cinco locais,de ensaios, são expressos na Tabela 10 .

As estimativas de variâncias genéticas entre progênies, obtidas para as três características nos cinco lo cais, mostraram boas precisões, a julgar pelos baixos valores encontrados para os desvios padrões dessas estimativas. Nas anālises individuais, esses desvios padroes, considerados em porcentagem da variância genética entre progênies, va riaram de 4,6\%" (Resende) a $11,4 \%$ " (Brotas) para a altura de plantas; de 4,8\% (Resende) a 12,6\% (Lençōis) para o DAP de plantas e de 3,5\% (Resende) a 4,5\% (Lençóis) para a forma do tronco. Nas análises conjuntas os desvios padrões das variâncias genéticas entre progênies foram equivalentes a $4,9 \%$ para a altura de plantas, $6,5 \%$ para o DAP de plantas e $3,2 \%$ para a forma do tronco. A forma do tronco, apesar de ter si. do avaliada subjetivamente, apresentou o menor erro da estimativa da variância entre progênies e, portanto, maior preci são para as estimativas das variâncias genéticas e das herda bilidades.

As estimativas de variâncias devidas à intera ção de progênies por locais foram superiores às estimativas de variâncias de progênies para a altura e DAP de plantas, e inferiores para a forma do tronco, muito embora elas tenham contribuído pouco para a variância fenotípica total. A inte 
Tabela 10. Estimativas de variâncias genéticas entre progênies $\left(\sigma_{p}^{2}\right)$ e seus respectivos desvios padróes, de variâncias devidas ao erro e de variâncias dentro de parcelas para a altura, o DAP, e a forma, do tronco das ärvores, nos cinco locais de ensaios.

Locais Parâmetros Caracteristicas

\begin{tabular}{|c|c|c|}
\hline $\begin{array}{l}\text { Altura } \\
(\mathrm{m})\end{array}$ & $\begin{array}{l}\text { DAP } \\
(\mathrm{cm})\end{array}$ & $\begin{array}{c}\text { Forma } \\
(\text { notas })\end{array}$ \\
\hline
\end{tabular}

$$
\begin{aligned}
& \sigma^{2^{1}} \\
& s\left(\sigma_{p}^{2}\right)
\end{aligned}
$$$$
0,1268
$$

0,3300

0,0048

0,0121

0,0185

0,00019

Agudos

$$
\text { (\%) }
$$

9,5

5,6

4,0

$\sigma_{\mathrm{e}}^{2}$

0,4137

0,3785

0,0013

$\sigma_{\mathrm{d}}^{2}$

4,2532

5,8263

0,0523

$$
\begin{aligned}
& \sigma_{\mathrm{p}}^{2} \\
& \mathrm{~s}\left(\sigma_{\mathrm{p}}^{2}\right)
\end{aligned}
$$

0,2475

0,0657

0,0057

0,0116

0,0074

0,00021

Anhembi

$$
\text { (\%) }
$$

4,7

11,3

3,7

$\sigma_{\mathrm{e}}^{2}$

0,3088

0,4250

0,0009

$\sigma_{\mathrm{d}}^{2}$

2,3979

1,3679

0,0562

$$
\begin{aligned}
& \sigma_{p}^{2 \prime} \\
& s\left(\sigma_{p}^{2}\right)
\end{aligned}
$$

0,1224

0,1082

0,0054

0,0139

0,0115

0,00023

Brotas

$$
\begin{aligned}
& (\%) \\
& \sigma_{\mathrm{e}}^{2} \\
& \sigma_{\mathrm{d}}^{2}
\end{aligned}
$$

11,4

10,6

4,3

0,9353

0,5664

0,0037

1,6805

2,8990

0,0617 
Tabela 10. (continuação)

Locais Parâmetros

Caracteristicas

\begin{tabular}{ccc}
\hline $\begin{array}{c}\text { A t tura } \\
(\mathrm{m})\end{array}$ & $\begin{array}{c}\text { DAP } \\
(\mathrm{cm})\end{array}$ & $\begin{array}{c}\text { Forma } \\
(\text { notas })\end{array}$ \\
\hline 0,4129 & 0,0999 & 0,0033 \\
0,0219 & 0,0126 & 0,00015
\end{tabular}

Lençóis

(\%)

5,3

12,6

4,6

$\sigma_{\mathrm{e}}^{2}$

0,7656

0,4530

0,0012

$\sigma_{d}^{2}$

2,5988

3,7271

0,0425

$\sigma_{p}^{2^{\prime}}$
$s\left(\sigma_{p}^{2}\right)$

0,3223

0,2558

0,0048

0,0147

0,0123

0,00017

Resende

(\%)

4,6

4,8

3,5

$\sigma^{2}$

0,6432

0,3878

0,0043

$\sigma_{d}^{2}$

4,3430

5,2379

0,0576

$\sigma_{\mathrm{p}}^{2}$

0,0975

0,0543

0,0028

$s\left(\sigma_{p}^{2}\right)$

0,0048

0,0035

0,00009

5 locais

(conjunta)

\begin{tabular}{llll}
$(\%)$ & 4,9 & 6,5 & 3,2 \\
$\sigma_{\mathrm{e}}^{2}$ & 0,6093 & 0,4454 & 0,0023 \\
$\sigma_{\mathrm{d}}^{2}$ & 3,0547 & 3,8116 & 0,0541 \\
$\sigma_{\mathrm{p} 1}^{2}$ & 0,1552 & 0,1161 & 0,0020 \\
\hline
\end{tabular}

$\sigma_{\mathrm{p}}^{2}$ : variância genética entre progênies; $s\left(\sigma_{\mathrm{p}}^{2}\right)$ : erro padrão da estimativa da variância genética entre progênies; (\%) : $s\left(\sigma_{\mathrm{p}}^{2}\right)$ em porcentagem da $\sigma_{\mathrm{p}}^{2} ; \sigma_{\mathrm{e}}^{2}$ : variância entre parcelas; $\sigma_{\mathrm{d}}^{2}$ : variância dentro de parcelas; $\sigma_{\mathrm{pl}}^{2}$ : variância da interação de progênies por locais. 
ração de progênies por locais tem um reflexo importante nas estimativas de herdabilidades ao nível de locais em conjunto, discussão que será feita a seguir.

As estimativas de herdabilidades ao nível de plantas individuais, ao nível de médias de famílias e ao nível de plantas dentro de famílias, obtidas a partir das esti mativas de variâncias genéticas e não-genéticas, são apresen tadas na Tabela 11 .

Os valores encontrados para as estimativas de herdabilidade no sentido restrito ao nível de plantas variaram tanto entre locais como entre características dentro de locais. As herdabilidades obtidas para cada local, a partir das anālises da variância individuais, variaram de $10,6 \%$ (Agudos) a 38,6\% (Lençóis) para a altura de plantas; de ,8,4\% (Lençóis) a 20,2\% (Agudos) para o DAP de plantas e de $28,1 \%$ (Lençöis) a 36,3\% (Anhembi) para a forma do tronco das ärvores. As herdabilidades médias obtidas para os cinco locais foram de $25,2 \%$ para a altura de plantas, $15,5 \%$ para o DAP de plantas e de $31,4 \%$ para a forma do tronco. Esses valores es timados, que mostram uma tendência para maior herdabilidade, na ordem, para a forma do tronco, vindo a seguir a altura de plantas e por fim o DAP de plantas, são coerentes com os observados na literatura para outras espécies florestais (SHEL BOURNE et alii, 1969; MATZIRIS e ZOBEL, 1973; ELDRIDGE, 1972; VAN WYK, 1976, e outros).

As estimativas dessas herdabilidades individuais para cada local foram obtidas não se separando a variância da interação de progênies por locais da variância devida a progênies, sendo, portanto, válidas somente para os locais de ensaios onde as mesmas foram determinadas, conforme colocam ROBINSON e COCKERHAM (1965). A herdabilidade ao nível de 
.81.

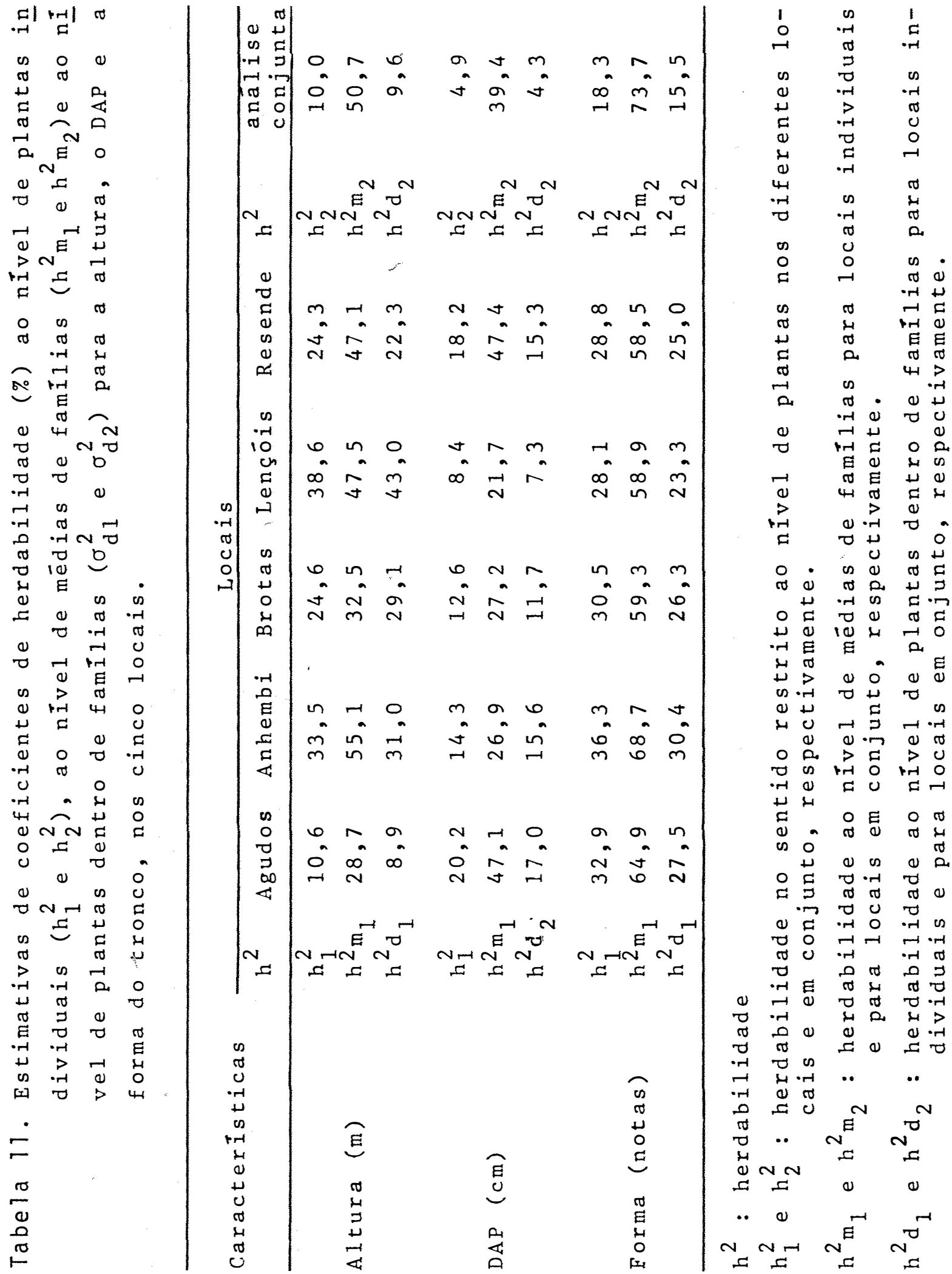


plantas, obtida a partir da anālise conjunta, envolvendo os cinco locais, seria a mais adequada para a seleção indivi dual envolvendo toda a região abrangida pelos ensaios. As herdabilidades obtidas a partir das análises conjuntas para locais, com valores de $18,3 \%$ para a forma do tronco, $10,0 \%$ para a altura de plantas e $4,9 \%$ para o DAP de plantas, foram bem inferiores às médias obtidas dos locais individuais, mos trando que o componente da interação de progênies por locais foi preponderante na redução dos valores das herdabilidades ao nível de locais em conjunto. Essa redução citada foi maior para o DAP de plantas do que para a altura de plantas e que, por sua vez, foi maior do que para a forma do tronco, refletindo a magnitude da interação de progênies por locais para as características. Os dois componentes dessa interação, analisados por VENCOVSKY (1978), não foram separados, porém, devem ser lembrados quando se discute o seu papel na herdabilidade e na seleção. De fato, se o componente devido à não-correlação entre os materiais é mais importante na interação, ter-se-á maior restrição na seleção; se o componente devido à diferença na variabilidade genética do material dentro dos ambientes é mais importante, o maior reflexo será na diminuição da herdabilidade para locais em conjunto. Cer tamente, os dois componentes devem coexistir na maioria dos casos.

As herdabilidades ao nível de médias de famílias, para locais individuais, foram bem superiores às obtidas ao nível de plantas, variando de $28,7 \%$ (Agudos) a $55,1 \%$ (Anhembi) para a altura de plantas, de $21,7 \%$ (Lençóis) a $47,4 \%$ (Resende) para o DAP de plantas e de 58,5\% (Resende) a $68,7 \%$ (Anhembi) para a forma do tronco. Por outro lado, es sas herdabilidades obtidas ao nivel de locais em conjunto ti veram valores também bastante altos e semelhantes às médias 
das herdabilidades individuais nos diversos locais.

As herdabilidades ao nível de plantas dentro de familias, para locais individuais, mostraram magnitudes se melhantes às herdabilidades ao nível de plantas individuais, variando de $8,9 \%$ (Agudos) a 42,9\% (Lençóis) para a altura de plantas, de 7,31\% (Lençóis) a $17,0 \%$ (Agudos) para DAP de plantas e de 23,3\% (Lençóis) a 30,4\% (Anhembi) para a forma do tronco. Essas herdabilidades tiveram também seus valores reduzidos quando estimadas ao nivel de locais em conjunto, da mesma forma que as herdabilidades ao nível de plantas individuais, tendo reflexos na seleção ao nível de plantas dentro de familias para os locais conjuntamente. As herdabi lidades ao nível de plantas dentro de famílias para os locais em conjunto foram equivalentes a $9,6 \%, 4,3 \%$ e $15,5 \%$ para altura, DAP e forma do tronco das árvores, respectivamente.

Para'os três tipos de herdabilidades apresentados, vale ressaltar, a obtida para a forma do tronco, sempre se revelou de maior magnitude que para a altura de plantas e esta, por sua vez, de maior magnitude que para o DAP de plantas. Esse fato vai ao encontro aos resultados obtidos na literatura pela maioria dos autores que trabalharam com outras essências florestais, mostrando que o controle ge nético para essas características tem um comportamento mais ou menos similar para as diferentes espécies. Como na definição da estratégia de melhoramento com as espécies a herdabilidade das características tem um papel fundamental, é bas tante válido o que coloca TODA (1972), no que se réfere ao método de melhoramento que se deve aplicar a cada caracterís tica e em cada ciclo de seleção. As características com her dabilidades notadamente altas podem ser efetivamente melhora das através de seleção massal, enquanto que, para as que a- 
presentam baixas herdabilidades, a seleção por famílias seria muito mais eficiente. Naturalmente, na definição dessa estratégia, ou seja, de como trabalhar com as diferentes características, tem bastante importância o valor econômico das mesmas, o que depende do produto final a que se destina a ma deira.

Apōs essas colocações, que se revestem de fun damental importância para o melhoramento floresta 1 , onde cada ciclo de seleção é normalmente longo, fica evidente a necessidade de se estudarem outras caracteristicas além das en volvidas no presente trabalho. A resistência ao fungo causa dor do cancro (Diaporthe cubensis), a densidade da madeira, o comprimento de fibras, a capacidade de rebrota das touças, etc., seriam as principais caracteristicas que deveriam ser enfocadas, e que complementariam as informações genétiءas bä sicas sobre a espécie.

Pará a obtenção das estimativas dos diversos tipos de herdabilidade apresentados, considerou-se a relação de meios-irmãos para as progênies envolvidas, assim como con siderou-se negligível a ocorrência de endogamia na população-base em estudo, condições indispensáveis preconizadas por VENCOVSKY (1969). Segundo coloca NAMKOONG (1966), com a pre sença de endogamia - ou por ocorrência de autofecundação, ou por restrição no tamanho efetivo da população - o teste de progênie de polinização aberta inflaria as estimativas da va riância genética. Não existem ainda indicações seguras sobre o papel da autofecundação no sistema reprodutivo do Euca lyptus grandis. Segundo PRYOR (1961) e ELDRIDGE (1977), existem evidências de que haja predominância de alogamia nas populações de espécies de eucaliptos, muito embora VAN WYK (1977) relate que uma taxa significativa de autofecundação possa ocorrer nessas espécies. 
Dessa forma, as estimativas obtidas dos parâmetros genéticos da população de Eucalyptus grandis estudada poderão estar superestimadas, se houver ocorrência de endoga mia nessa população. No entanto, a relação entre as herdabi lidades para as características estudadas não é alterada por esse fenômeno, não invalidando, portanto, essa conclusão.

As estimativas de variâncias genéticas aditivas, de coeficientes de variação genética e de relações coeficientes de variação genética e coeficientes de variação ex perimental, para a altura, o DAP e a forma do tronco das árvores, nos cinco locais de ensaios, são expressos na Tabela 12.

As estimativas de variâncias genéticas aditivas foram obtidas a partir das variâncias genéticas entre pro gênies, sendo portanto proporcionais a estas ültimas. Os ex ros padrões das estimativas das variâncias entre progênies são também equivalentes aos das estimativas das variâncias genétí cas aditivas. A apresentação desse parâmetro se justifica mais pelo fato de a variância genética aditiva ser mais padro nizada, possibilitando comparações com outros resultados.

O coeficiente de variação genética, que expressa, em porcentagem da média geral, a quantidade de varia ção genética existente entre as progênies, foi estimado para as caracteristicas nos locais individuais, revelando valores similares para as três caracteristicas. Nas anālises individuais os coeficientes de variação genética variaram de $3,4 \%$ (Agudos) a 5,6\% (Lençóis) para a altura de plantas, de $2,8 \%$ (Anhembi) a 6,9\% (Agudos) para o DAP de plantas e de $3,3 \%$ (Lençóis) a 4,4\% (Anhembi) para a forma do tronco. Os coeficientes de variação genética médios para os cinco locais foram de $4,1 \%, 4,6 \%$ e $4,0 \%$ para a altura, o DAP e a forma do 


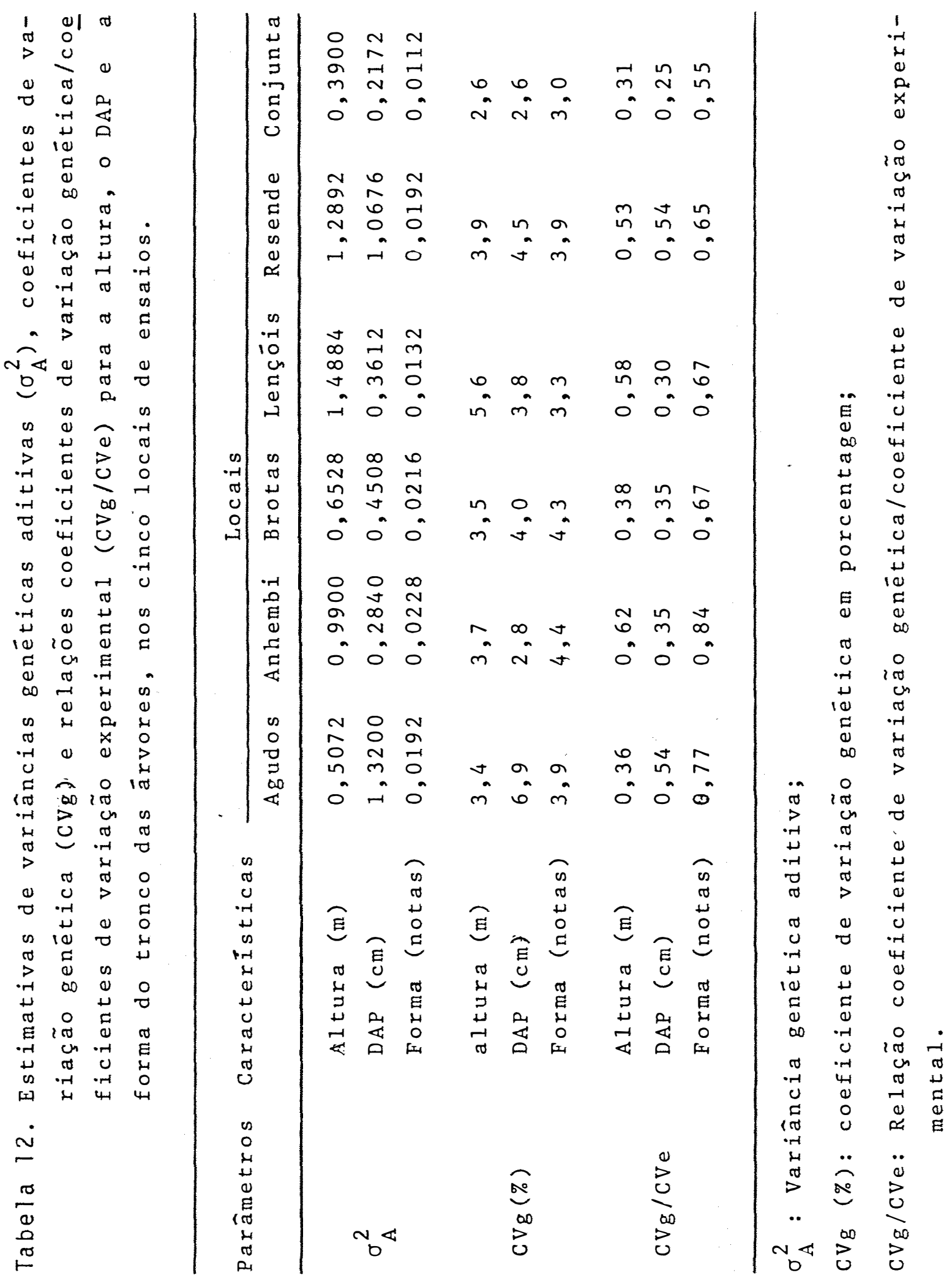


tronco das árvores, respectivamente. Esses valores, quando comparados com os dados de populações panmíticas em geral, mostram razoável variação genética e que pode ser explorada através de seleção. Deve-se ressaltar que não houve tendência de correlações entre esses valores encontrados e as esti mativas de herdabilidades correspondentes.

A relação entre coeficiente de variação genētica e o coeficiente de variação experimental foi estimada para as três características nos cinco locais, mostrando valores mais elevados para a forma do tronco, com média aritmé tica de 0,72, vindo a seguir a altura de plantas com 0,49 e por último o DAP de plantas com 0,42. Segundo VENCOVSKY (19.78), quando essa relação é igual ou maior que 1,0 , em ensaios de progênies de milho, a condição é altamente favorável para a seleção. A julgar pelos valores encontrados, pode-se depreender que a condição mais favorável para a seleção dentro do ensaio seria para a forma do tronco. De fato, o menor erro experimental e a maior herdabilidade associados a essa caracteristica confirmam essa afirmativa.

5.5. Estimação de ganhos genēticos com a seleção entre e dentro de progēnjes para a altura, o DAP e a forma do tronco das ārvores, nos cinco locais de ensaios, aos dois anos de idade

A seleção entre e dentro de progênies,com pos terior desbaste dos individuos inferiores, caracteriza um mé todo de melhoramento denominado "Pomar de Sementes por Mudas" utilizando-se o próprio material de ensaio para a produ ção de sementes melhoradas. Esse método, discutido detalhadamente por NAMKOONG (1966), é de alta importância para as 
espécies de ciclo reprodutivo mais curto e que apresentam di ficuldades na propagação vegetativa, tais como os eucaliptos, conforme enfatiza SHELbOURNE (1969a).

Nesse caso, a seleção teria validade somente quando realizada ao nível de locais, já que ao nível de logais em conjunto a seleção só poderia ser aproveitada através da propagação vegetativa, o que descaracterizaria o méto do citado. Além do mais, no caso da seleção por local individual aproveitar-se-ia também a variância devida à interação de progênies por locais, que tem se mostrado significati va, conforme já discutido anteriormente.

Em função do esquema inicial de instalaçãodos ensaios, com espaçamentos iniciais de 3 x 2 metros, e considerando que a densidade mínima recomendada para produção de sementes florestais está em torno de 50 a 80 árvores por hec tare, existe um 1 imite de seleção dentro dos ensaios de progênies, que estaria entre 3 e $5 \%$ da população original. Para um limite de $3 \%$ de seleção total, podem-se ter diversas combinações de porcentagem para a seleção entre e dentro de progênies. Visando fornecer subsídios para melhor discernimento sobre a estratégia a ser adotada, em termos de prioridade a ser dada para cada característica em estudo, adotou- se uma seleção de $30 \%$ entre famílias e de $10 \%$ dentro de famîlias, que é coerente como que se vem fazendo na prática para instalação dos "Pomares de Sementes por Mudas". As pre dições de ganhos genétidos comparados com a seleção entre e dentro de progênies, para as características independentes, são apresentadas na Tabela 13 .

Os ganhos médios genéticos estimados, a partir das porcentagens de seleção pré-determinadas, mostram va lores médios bastante similares para as três características 


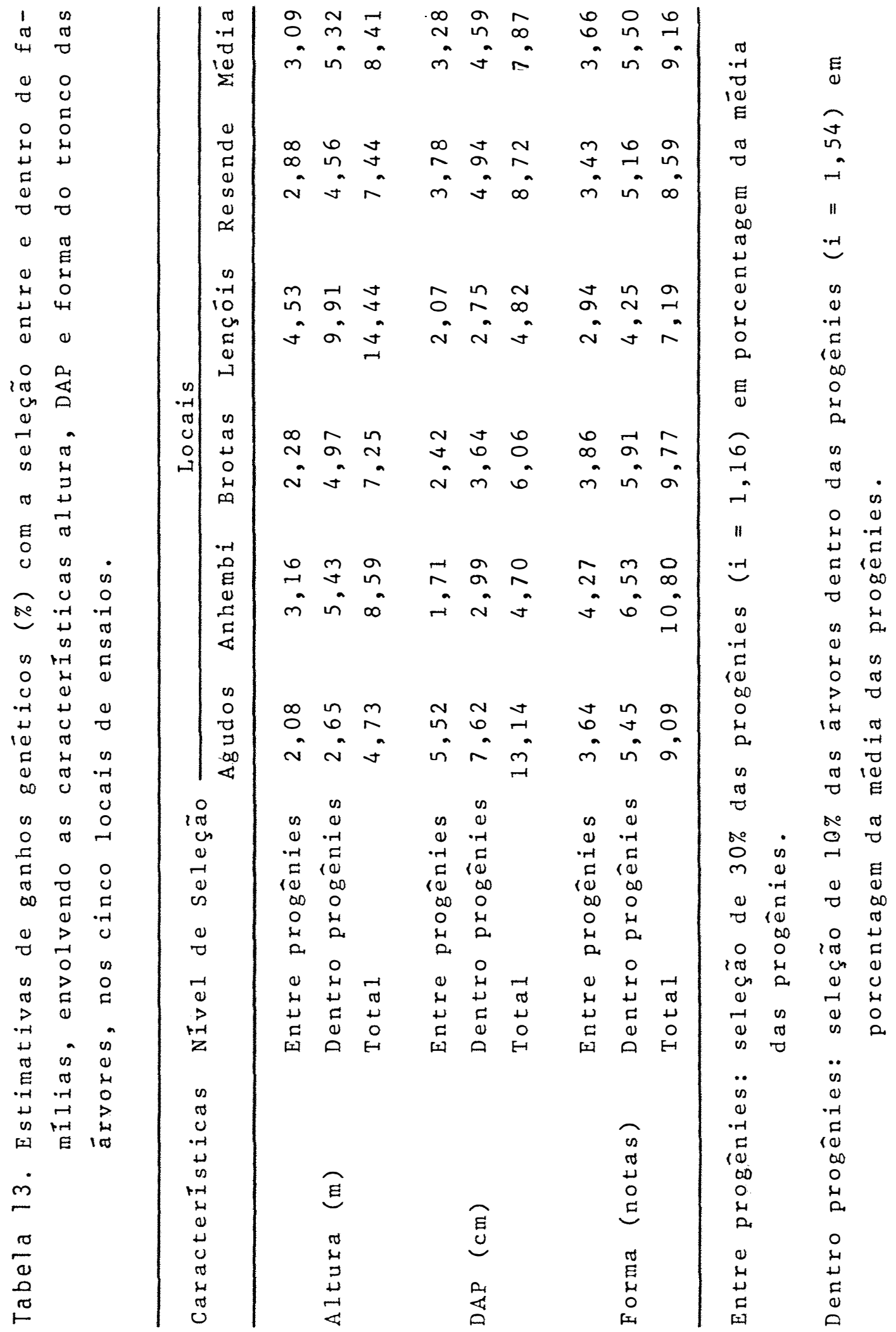


estudadas. A seleção entre progênies dentro dos ensaios revela estimativas de ganhos em média de 3,09\% para a altura de plantas, $3,28 \%$ para o DAP de plantas e de $3,66 \%$ para a forma do tronco. A seleção dentro de progênies, por sua vez, prediz ganhos médios de $5,32 \%$ para altura de plantas, de 4,59\% para DAP de plantas e de 5,50\% para forma do tronoo.0s ganhos totais médios previstos para a seleção combinada, entre e dentro de progênies seriam, portanto, de 8,41\%, 7,87\% e 9,16\% para a altura, o DAP e a forma do tronco, respectiva mente. Deve-se ressaltar que as variações de herdabilidades, principalmente aquelas ao nível de progênies e ao nível de plantas dentro de progênies, diretamente envolvidas nessas prediçães, não foram determinantes na variação dos ganhos es timados.

Os ganhos genéticos esperados com a seleção dentro de progênies foram sempre superiores aos ganhos estimados para a seleção entre progênies, para as três características estudadas, numa proporção em média de $60 \%$ para $40 \%$. Esta também é a relação entre as intensidades de seleção utí lizadas para a seleção dentro e entre progênies. Esse fato faz com que, para o presente caso, o maior determinante para os ganhos previstos na seleção dentro dos ensaios seja a intensidade de seleção utilizada.

Da forma como foram estimados os ganhos genéticos para as três características, percebe-se que esses ganhos previstos não podem ser obtidos simultaneamente para a altura, o DAP e a forma do tronco, já que os mesmos foram de terminados independentemente. Essas informações, como jā en fatizado, servem para a orientação de como proceder na conti nuidade de melhoramento do material genético em questão. As considerações sobre os valores econômicos das características, aliadas aos resultados obtidos acerca das estimativas 
de ganhos para cada uma delas, é que irão permitir a definição de qual ou quais características deverá(ão) ser incluída(s) nessa fase de seleção.

Diante do exposto, pode-se considerar que, em função dos grandes avanços genéticos verificados para a forma do tronco, constatados tanto pelas estimativas de ganhos realizados, como pelas observações visuais da forma do tronco das árvores das progênies, a seleção dentro dos ensaios deveria ser mais centrada nas caracteristicas de crescimento (Altura e DAP de plantas) do que na forma do tronco. Uma ou tra opção seria a de realizar a seleção entre progênies para forma do tronco e a seleção dentro de progênies para as características de crescimento. No entanto, o mais razoável na prática seria conduzir-se a seleção simultânea para as ca racterísticas, dando-se os pesos devidos às mesmas, atravēs de um indice de seleção empírico conforme relatado por KAGEYAMA (1977). O maior aprofundamento da discussão sobre o assunto deve envolver o aspecto de correlação entre as carac terísticas estudadas, que será discutido na seção seguinte deste trabalho.

Uma outra opção em termos de estratégia de me lhoramento seria a seleção das melhores progênies do ensaio, e a volta às árvores originais da população-base que geraram essas progênies. Isso poderia ser efetuado através da coleta de sementes dessas árvores selecionadas, ou então da propagação dessas árvores em áreas propícias para produção de sementes, e que caracterizaria o "Pomar de Sementes Clonal Testado". Nesse caso, a seleção poderia ser efetuada ao nivel de médias de progênies para locais individuais ou então através da seleção marginal, ou envolvendo os locais em conjunto. 
Os resultados da seleção das 15 melhores progênies, por locais individuais e por locais em conjunto, para altura, DAP e forma do tronco das ärvores, são apresentados na Tabela 14 .

A perda percentual em eficiência pela utiliza ção da seleção marginal, ou a seleção pela média dos locais, em relação à seleção por locais individuais, foi, em média bastante similar para as três características, variando subs tancialmente entre os locais. Os valores encontrados para a relação entre os ganhos estimados para a seleção marginal e a seleção por locais variou de $41,3 \%$ a $61,4 \%$, com média de $56,6 \%$, para altura de plantas; de $27,1 \%$ a $80,8 \%$, com média de $55,7 \%$, para DAP de plantas e de $26,7 \%$ a $71,4 \%$, com média de $63,9 \%$, para forma do tronco. Esses resultados sugerem que a seleção por locais seria muito mais eficiente que a se leção marginal, confirmando a existência de uma expressiva interação de progênies por locais. Uma outra opção viável seria a de se agruparem determinados locais com menor expres são dessa interação, e nesses locais se promover a seleção por médias de locais.

A partir dos dados da Tabela 14 pode-se ainda depreender que a seleção das 15 melhores progênies para cada 1 local permite uma estimativa de ganho médio de $6,12 \%$ para ía altura de plantas, ou $7,80 \%$ para o DAP de plantas, ou ainda de $11,88 \%$ para a forma do tronco, em relação a média das pró gênies. Esse ganho, como já colocado, refere-se ao avanço genético que se espera pela utilização de sementes das árvores que geraram as progênies selecionadas nos ensaios. Por outro lado, ao se agruparem essas ārvores através de propaga ção vegetativa, os ganhos estimados para a seleção ao nível de médias de progênies devem ser acrescidos dos ganhos relativos à seleção fenotípica, já relatados no item 5,2, e que 
.93.

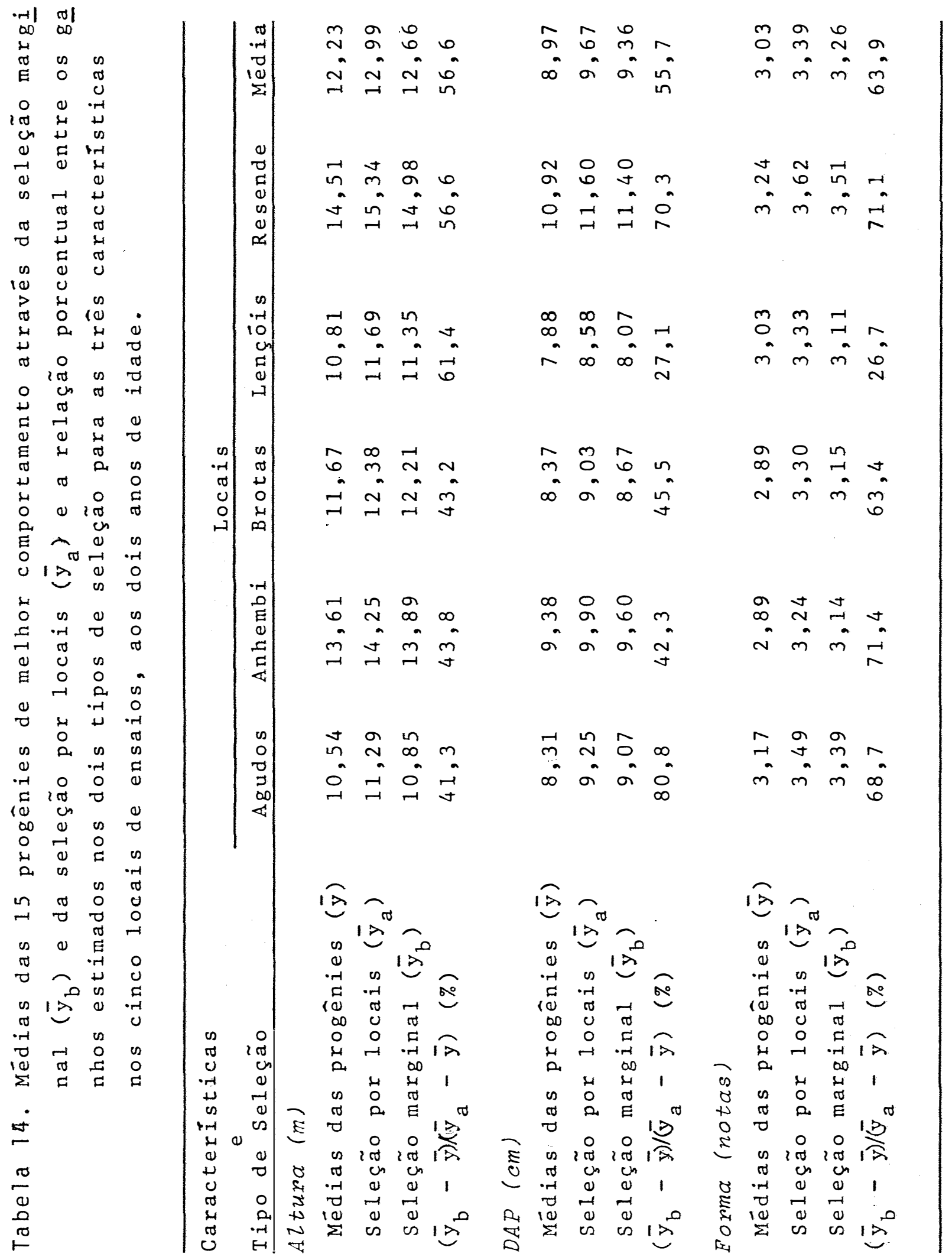


então revelam estimativas de ganhos bem mais expressivas. Nes se caso, os ganhos esperados seriam, em média, da ordem de $21,48 \%$ para altura de plantas, de $19,03 \%$ para DAP de plantas e de $52,9 \%$ para forma do tronco das árvores. Naturalmente, como esses valores de ganhos foram gerados pela somatória de estimativas obtidas por formas diferentes, os erros devem-se acumular, o que sugere cautela na sua utilização, muito embo ra esses dados já sejam muito importantes para que se possa discutir as possibilidades e perspectivas no melhoramento da população de E. grandis em questão.

Como esses ganhos estimados, principalmente os relativos aos obtidos na seleção dentro de progênies, foram considerados independentemente, já que a intensidade de seleção para uma característica restringe a seleção para as outras, é de capital importância que se enfoquem as correlações genéticas como intrínsecas ao processo de seleção. Esse aspecto é abordado no item 5.6 .

5.6. Coeficientes de correlações genēticas e fenotípicas entre as caracteristicas de altura, DAP, volume cilíndrico e forma do tronco das ärvores, nos cinco lo cais de ensaios, aos dois anos de idade

As correlações genéticas aditivas ao nível de plantas e as correlações fenotípicas ao nível de famílias en tre as características altura, DAP, volume cilindrico e forma do tronco das árvores, estimadas para os cinco locais de ensaios, são apresentadas na Tabela 15 .

As estimativas obtidas de correlações genétí cas aditivas ao nível de plantas individuais, apesar de se mostrarem variáveis de local para local, apresentam uma nít 
.95.

Tabela 15. Estimativas de correlações genéticas aditivas ao nível de plantas e de correlações fenotípicas ao nível de médias de progênies entre altura, DAP, vo lume cilindrico e forma do tronco das ärvores,nos cinco locais de ensaios.

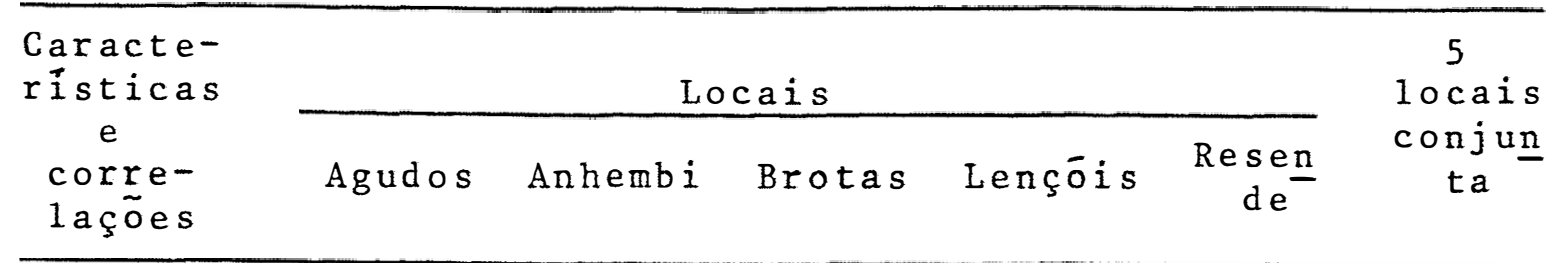

AIt. $x$ DAP

$\begin{array}{lllllll}\mathrm{r}_{\mathrm{A}} & 0,64 & 0,54 & 0,91 & 0,93 & 0,94 & 0,76 \\ \mathrm{r}_{\bar{F}} & 0,53 & 0,50 & 0,89 & 0,85 & 0,77 & 0,74\end{array}$

Alt.x. Vol.

$\begin{array}{lllllll}\mathrm{r}_{\mathrm{A}} & 0,58 & 0,75 & 0,79 & 0,94 & 0,97 & 0,96 \\ \mathrm{r}_{\overline{\mathrm{F}}} & 0,50 & 0,72 & 0,86 & 0,89 & 0,86 & 0,85\end{array}$

DAP $x$ Vo1.

$\begin{array}{lllllll}\mathrm{r}_{\mathrm{A}} & 0,74 & 0,95 & 0,77 & 0,67 & 0,99 & 0,99 \\ \mathrm{r}_{\overline{\mathrm{F}}} & 0,77 & 0,79 & 0,91 & 0,75 & 0,95 & 0,88\end{array}$

Alt. $x$ For.

$\begin{array}{lllllll}r_{A} & -0,17 & 0,01 & 0,07 & -0,07 & 0,20 & 0,29 \\ r_{\bar{F}} & -0,19 & 0,05 & 0,11 & -0,06 & 0,09 & 0,15\end{array}$

DAP $x$ For.

$\begin{array}{lllllll}r_{A} & -0,36 & -0,07 & 0,25 & 0,08 & 0,28 & 0,13 \\ r_{\bar{F}} & -0,31 & -0,16 & 0,03 & 0,04 & 0,16 & 0,03\end{array}$

Vol. x For.

$\begin{array}{lllllll}r_{A} & -0,18 & -0,39 & -0,01 & -0,03 & 0,36 & 0,24 \\ r_{\bar{F}} & -0,23 & -0,12 & -0,02 & -0,04 & 0,19 & 0,12\end{array}$

Alt.: altura das plantas; DAP: DAP das plantas; Vol.: volume cilindrico das plantas; For.: forma do tronco das plantas; ${ }_{A}$ : correlação genética aditiva ao nível de plantas; $r \bar{F}$ : cor relação fenotípica ao nível de médias de progênies. 
da tendência para maior correlação entre determinadas características e para a falta de correlação entre outras. Assim, as características associadas ao crescimento das árvores mos tram entre elas correlações genéticas aditivas, em geral, de alta magnitude, indicando reflexo de uma característica sobre a outra quando se pratica a seleção para uma delas. Essas correlações altas e positivas estão de conformidade com os resultados obtidos pela maioria dos autores, em diferentes espécies florestais, podendo-se destacar os trabalhos re latados por SHELBOURNE et ali $i$ (1969), MATZIRIS e ZOBEL (1973), VAN WYK (1976), SAKAI e MUKAIDE (1967), dentre outros.

As características associadas ao crescimento das ärvores, por sua vez, não se mostraram, correlacionadas com a forma do tronco das árvores, a julgar pelos baixos valores encontrados para as correlações genéticas aditivas ao nível de plantas entre altura, DAP e volume cilíndrico das árvores com a forma do tronco. Esse fato é de suma importân cia, já que em princípio pode-se propor a condução da seleção para as características de crescimento ou de forma do tronco, independentemente, sem a preocupação de interferência de uma sobre a outra, o que dá maior liberdade ou opção para a definição da estratégia a ser seguida na seleção.

As estimativas de correlações fenotípicas ao nível de médias de famílias mostram as mesmas tendências que as correlações genéticas aditivas ao nível de plantas, e com magnitudes semelhantes para os valores encontrados, mostrando, para o caso específico, pouca interferência ambiental na mudança dos dois tipos de correlação estudados. Deve-se con siderar, no entanto, que as correlações obtidas foram em níveis diferentes, uma ao nível de plantas e outra ao nível de médias de progênies, não possibilitando, portanto, compara- 
ções diretas.

As correlações genéticas aditivas ao nível de plantas, obtidas para locais e em conjunto, mostraram as me mas tendências verificadas para essas correlações ao nívelde locais, com valores de 0,76 para altura e DAP, 0,96 para a tura e volume e 0,99 para DAP e volume cilíndrico. A partir desses valores encontrados pode-se visualizar melhor a magni tude das correlações existentes entre as três características de crescimento.

O volume cilíndrico, que é uma característica composta de altura, DAP e sobrevivência de plantas, mostrou-se altamente correlacionado com as duas primeiras. As características de altura e DAP, de maior importância para a definição da estratégia de seleção, em função da maior facilidade e precisão na sua mensuração, mostraram menor correla ção entre si, muito embora seu valor seja relativamente alto e positivo, auxiliando sobremaneira a seleção visando os dois caracteres no processo de seleção.

As caracteristicas de altura, DAP e volume cí lindrico, ao nível de locais em conjunto, não se mostraram correlacionados com a forma do tronco, confirmando os resultados obtidos nas anālises individuais, mostrando uma independência entre as caracteristicas de crescimento e forma do tronco. Esse fato reveste-se de alta importância, já que a seleção para uma delas não trará reflexos negativos à outra, conforme enfatiza FALCONER (1964).

As correlações fenotípicas ao nível de médias de familias, para locais em conjunto, mostraram-se invariavelmente inferiores às obtidas ao nível genético aditivo, confirmando as tendências observadas para locais individuais 
e novamente concordantes com os resultados relatados na 1 ite ratura, conforme se constata nos trabalhos de SHELBOURNE et alii (1969), MATZIRIS e ZOBEL (1973), VAN WYK (1976), entre outros.

Antes de se avaliar a implicação das correlações na seleção por local dentro do ensaio, convém ressaltar que as correlações obtidas através da anālise de variância em látice para a obtenção das covariâncias genéticas e nãogenéticas, apresentaram resultados extremamente variáveis e contraditórios, além de valores frequentemente maiores do que 1,0 , o que indica a existência de erros demasiadamente altos nas estimativas. Isso ocorreu, provavelmente, devido à inclusão das testemunhas na estimativa da covariância dentro de parcelas. A porção dessa covariância correspondente às testemunhas não pode ser separada da covariância dentro de parcelas relativa às progênies, já que a covariância ao nível de plantas não foi determinada. Essa restrição, como já enfatizado na metodologia, induziu à utilização, somente na anālise de covariância, do delineamento em blocos ao acaso, que, embora não tão eficaz, não apresenta aquelas restri çôes citadas.

Retomando a questão da seleção entre e dentro de progênies, mencionada na seção 5.5., pode-se agora abor dar com maior propriedade as vantagens ou não de se atribuir maior peso à seleção para as características de crescimento, em detrimento da seleção para forma do tronco. Em função dos argumentos apresentados naquela seção, aliados à comprovação da alta correlação entre as características de crescimento, a seleção atribuindo-se maior peso para, por exemplo, altura de plantas, deverá refletir-se num avanço bastante significativo também para o DAP e o volume cilíndrico. 
Tal decisão é fundamental, pois representa uma economia de esforços na seleção, conduzindo a ganhos bas tante elevados. Assim, a seleção para apenas uma das características componentes do crescimento, embora não atinja os máximos ganhos genéticos possíveis, pode representar uma alternativa de melhoramento de fundamental importância, espe cialmente quando se comparam os esforços adicionais necessários para a seleção das três características em conjunto com os ganhos adicionais daí advindos.

Em função da inclusão de outras características, que deverão ser convenientemente estudadas, novas opções podem súrgir, impondo novos rumos à estratégia do melho ramento do Eucalyptus grandis na região. 
6. CONCLUSOES

o presente estudo sobre variação genética em progênies de polinização livre de Eucalyptus grandis (Hill) Maiden, em cinco locais, permite as seguintes conclusões:

a. Os dados médios de altura de plantas no primeiro ano e de altura, DAP, volume cilíndrico e sobrevivência no segundo ano, nos cinco locais de ensaios, revelam um potencial expressivo do material genético em teste nas condições ecológicas estudadas.

b. As estimativas de ganhos realizados, na se leção fenotípica das ärvores que geraram as progênies utilizadas nos ensaios, mostraram um avanço genético considerável para a altura de plantas no primeiro ano. Aos dois anos de idade, os ganhos foram mais expressivos, na ordem, para a so brevivência de plantas, a forma do tronco, o volume cilíndri co, a altura e o DAP de plantas, indicando a resposta a um ciclo de seleção fenotípica efetuada.

$$
\text { c. A população-base estudada apresentou varia }
$$


.101.

ções genéticas significativas entre progênies para a altura de plantas no primeiro ano e para a altura, o DAP, o volume cilíndrico e a forma do tronco das árvores no segundo ano,em todos os locais estudados, mostrando um potencial da população que pode ser explorado em termos de seleção e continuidä de do melhoramento com a espécie.

d. Ao nível de locais em conjunto, aos dois anos de idade, foram detectadas variações genéticas entre progênies para todas as características estudadas, exceto pa ra a sobrevivência das plantas. O efeito de locais foi o de maior expressão na variação total, mostrando a resposta dife rencial das progênies, principalmente em relação às condições edäficas.

e. A interação de progênies por locais foi significativa para todas as características estudadas, refle tindo-se na redução das herdabilidades ao nível de locais em conjunto e na perda da eficiência pela utilização da seleção marginal relativamente à seleção por locais.

f. As herdabilidades estimadas no sentido res trito ao nível de plantas, ao nível de médias de famílias e ao nível entre plantas dentro de familias, para locais individuais e em conjunto, mostraram valores de maior magnitude para a forma do tronco, vindo a seguir a altura de plantas e por fim o DAP de plantas, revelando as perspectivas de respostas à seleção dessas características.

g. As estimativas de ganhos genéticos com a seleção entre e dentro de progênies, nos locais individuais, mostraram razoáveis ganhos genéticos para as três caracterís ticas estudadas, revelando a possibilidade de seleção dentro 
de cada ensaio e sua posterior transformação em "Pomares de Sementes por Mudas". Em função dos grandes avanços genéticos verificados para a forma do tronco na seleção fenotipica, a seleção dentro dos ensaios deverá ser centrada nas características de crescimento mais do que na forma do tronco.

h. Os valores das correlações genéticas aditi vas ao nível de plantas e fenotípicas ao nível de médias de progênies seguiram uma mesma tendência, apresentando correla ções positivas e altas entre as características de crescimen to (altura, DAP e volume cilindrico). Por outro lado, entre as caracteristicas de crescimento e de forma do tronco as correlações foram inexpressivas. Isto reforça a proposição de que na seleção dentro dos ensaios deva-se dar maiores pesos às características de crescimento. 
7. SUMMARY

This paper is a study of genetic variation in open pollinated progenies of phenotypically selected trees of Eucalyptus grandis (Hill) Maiden from a Coff's Harbour base population.

The trials were established on five localities: Agudos, Anhembi, Brotas, Lençóis Paulista and Resende, in november and december of 1976. The experimental design utilized was the triple lattice with 64 (8 x 8) treatments, including the progenies from selected trees of the base population, progenies from other populations, commercial control, and a sample of the base population without selection.

The results obtained on the first year revealed an average height growth, in the five localities, of 5.27 meters, varying from 4.24 meters (Brotas) up to 6.11 meters (Resende), showing the potentiality of the genetic material in the studied conditions. The study base population of E. grandis presented, at this age, considerable genetic variation for height in all localities, showing the 
possibility of selection and tree improvement. The genetic variation for plant survival, on the other hand, was less expressive, and varied from a local to another.

The realized gains estimates for the phenotypic selection of the trees that originated the progenies were, on the average, $5.65 \%$ for tree height, on five localities, at the age of one year, wich shows the difference between the material with and without selection since early stages.

The data of height growth at the age of two years, with an average of 12.08 meters on five localities confirm the growth potential of the tested genetic material. The average estimates of the realized gains for the phenotypic selection, at the age of two years, was $6.22 \%$, which was similar to the gains obtained on the first years. These estimates were of $24.37 \%, 13.45 \%, 8.41 \%$ and $1.59 \%$ for survival, stem straightness, cilindric volume and d.b.h., respectively, indicating the genetic advance obtained by the utilization of one cycle of phenotypic selection in the study population.

At the age of two years, and at individual localities level, different genetic variations were detected among progenies for all studied characteristics, although significant genetic variations have been detected for most of the characteristics in the localities. The lattice efficiency values obtained justified the utilization of this experimental design.

At joint localities level, on the second year, genetic variations were detected among progenies for all studied characteristics, but not for plant survival. The effect of locality was significant and very expressive for 
all characteristics studied. The effect of the interaction progenies $x$ localities was also significant for all characteristics, which was reflected on the reduction of the heritabilities and, therefore, on the selection for the localities in conjunction.

The genetic variance among progenies, estimated for height, d.b.h. and stem straightness, showed good precision, considering the low standard deviations. The narrow sense heritabilities at plant level were similar to those obtained within the progenies. These heritabilities were inferior to those obtained at mean progeny level for the study characteristies. The estimates of the different types of heritabilities were greater for stem straightness, followed by height and d.b.h., showing the perspectives of selection response regarding these characteristics.

The genetic gains estimates for selection among and within progeny showed considerable genetic advances for the studied characteristics, revealing the possibility of successful selection within each trial. As a result of the advances achieved in the phenotypic selection for stem straightness, as well as the positive and high correlation among the growth characteristics (height, d.b.h. and cilindric volume), and the absence of correlation between stem straightness and growth, the selection within each trial should be centred more on the growth characteristics than on stem straightness. 


\section{LITERATURA CITADA}

BELL, E.F. e P.P. FERET, 1972. Financial analysis of testor numbers used in establishing second generation forest tree seed orchards. Silvae Genetica, Frankfurt, 21:216220 .

BINGHAM, R.T., J. OLSON, W.A. BEGKER e M.A. MARSDEN, 1969. Breeding blister rust resistant western white pine. Sizvae Genetica, Frankfurt, 18:28-38.

BOGYO, T.P., 1964. Coefficients of variation of heritability estimates obtained from variance analyses. Biometrics, Ra1eigh, 20:123-9.

BURLEY, J.; P.M. BURROWS, F.B. ARMITAGE e R.D. BARNES, 1966. Progeny test designs for Pinus patula in Rodhesia. Silvae Genetica, Frankfurt, 15:166-173.

COCKERHAM, C.C., 1963. Estimation of genetic variances. In: HANSON, W.D. e H.F. ROBINSON, (ed.). Statistical Genetics and Plant Breeding. Nat. Acad. Sci. National Res. Council. p. 53-95. 
COMSTOCK, R.E. e H.F. ROBINSON, 1948. The components of genetic variance in populations of biparental progenies and their use in estimating the average degree of dominance. Biometrics, Raleigh, 4: 254-6.

ELDRIDGE, K.G., 1972. Genetic variation in the growth of Eucalyptus regnans from altitudinal transect of mount Erica, Victoria. Department of primary Industry, Forestry am Timber Bureau. Bulletin 46. 71 p.

ELDRIDGE, K.G., 1977. Genetic improvement of Eucalyptus. In: Third world consultation on forest tree breeding. Canberra, 21-26, Março. Roma, FAO, 12 p.

FALCONER, D.S., 1964. Introduction to quantitative genetics. N. York. The Ronald Press. Co. 365 p.

FARMER, R.E., 1970. Genetic variation among open-pollinated progeny of eastern cotton wood. Silvae Genetica, Frankfurt, 19:149-151.

FIELDING, J.M. e A.G. BROWN, 1960. Variation in the density of the wood of monterey pine from tree to tree. Leaf-Let n? 77 . p. $1-28$.

FRANKLIN, E.C. e G.F. MESKIMEM, 1973. Genetic improvement of Eucalyptus robusta $\mathrm{Sm}$. in Southern Florida. In: BURLEY, J. e D.G. NIKLES, ed. Tropical provenance and progeny research and international cooperation. oxford, Commonwealth Forestry Institute. p. 121-125.

GERALDI, I.0., 1977. Estimação de parâmetros genéticos para caracteres do pendão de milho (Zea mays L.) e perspectivas de melhoramento. Piracicaba, ESALQ/USP, 103 p. (Dis sertação de Mestrado). 
GOGGANS, J.F. e R.J. MEIER, 1973. Heritabilities of growth and crown characteristics of Arizona Cypress. Silvae Genetica. Frankfurt, 22:162-164.

HANOVER, J.W. e B.W. BARNES, 1969. Heritability of height growth in western white pine seedlings. Silvae Genetica. Frankfurt, 18:80-82.

HOLST, M.J. e R.A.H. TEICH, 1969. Heritability estimates in Ontario white spruce. Silvae Genetica. Frankfurt, 18 : 23-27.

KAGEYAMA, P.Y., 197Z. Variação genética entre procedências de Pinus oocarpa schied na região de Agudos - SP. Piraci caba, ESALQ/USP, 83 p. (Tese de Mestrado).

KEIDING, H., 1974. Selection of individual trees. In: FAo/ DANIDA Training Course on Forest Tree Improvement, Rome, FAO, p. 165-175.

KRAUS, J.F., 1973. Estimates of general and specific combining ability for height and rust resistance from single cross of slash pine. Silvae Genetica. Frankfurt, 22: $121-124$.

KRIEBEL, H.B., G. NAMKOONG, e R.A. USANIS, 1972. Analysis of genetic variation in - 1,2 - and 3 year old eastern white pine in incomplete diallel-cross experiments. Silvae Genetica. Frankfurt, 21:44-48.

MATZIRIS, D.I. e B.J. ZOBEL, 1973. Inheritance and correlations of juvenile characteristics in loblolly pine. Silvae GEnetica. Frankfurt, 22:38-45. 
MIRANDA FILHO, J.B., 1978. Princípios de experimentação e anālise estatística. In: PATERNIANI, E. (coord.). MeZhoramento e Produgão de MiZho no Brasiz. Piracicaba, Fundação Cargill. p. 620-650.

MOHN, C.A. e W.K. RANDALL, 1971. Inheritance and correlation of growth characters in Populus deltoides. Silvae Genetica. Frankfurt, 20:182-184.

MORGENSTERN, E.K., 1974. Open pollinated progeny testing in a black spruce breeding program. In: Northeastern Forest Tree Improvement Conference. $8 \mathrm{p}$.

NAMKOONG, G., 1966. Imbreeding effects on estimation of genetic additive variance. Forest Science. Madison, $12: 8-13$.

NAMKOONG, G. e M.T. CONKLE, 1976. Time trends in genetic control of height growth in ponderosa pine. Forest Science. Madison, 22 2 2-12.

NAMKOONG, G., E.B. SNYDER e R. STONECYPHER, 1966. Heritability and gain concepts for evaluating breeding systems such as seedling orchards. Sizvae Genetica. Frankfurt, $\underline{15}: 76-84$.

NAMKOONG, G. e A.E. SQUILLACE, 1970. Problems in estimating genetic variance by shriknande's method. Silvae Genetica. Frankfurt, $19: 74-77$.

NICHOLLS, J.W.P., 1967. Assessment of wood qualities for tree breeding. Silvae Genetica. Frankfurt, 15:18-20. 
NIKLES, D.G., 1973. Biology and genetic improvement of Araucaria cuninghamil Ast. in Queensland, Australia. In: BURLEY, J. e D.G. NIKLES, ed. Selection and Breeding to Improve some Tropical Conifers. Oxford, C.F.I. p. 30434.

PIMENTEL GOMES, F., 1973. Curso de Estatistica Experimental. 5a. imp. São Paulo, Livraria Nobel S/A. 430 p.

PRYOR, L.D., 1961. Inheritance, selection and breeding in Eucalyptus. In: Second World Eucalyptus Conference, são Paulo, vol. 1, 297-304.

QUEIROZ, M.A., 1969. Correlações genéticas e fenotípicas em progênies de meios irmãos de milho (Zea mays L.) e suas implicações no melhoramento. Piracicaba, ESALQ/USP, 71 p. (Dissertação de Mestrado).

ROBINSON, H.F. e C.C. COCKERHAM, 1965. Estimation y significado de los parámetros genéticos. Fitotecnia Latinoamericana. Caracas, 2:23-38.

ROBINSON, H.F., R.B. COMSTOCK e D.H. HARVEY, 1951. Genotypic and phenotypic correlation in corn and their implications in selection. Agronomy Journal. Madison, $43: 282-287$.

RINK, G. e E. THOR, 1976. Silvae Genetica. Frankfurt, $\underline{25}: 17-22$.

SAKAI, K. e S. HATAKEYAMA, 1965. Estimation of genetic parameter in forest tree without raising progeny. Sizvae Genetica. Frankfurt, 12:152-157. 
SAKAI, E. e H. MUKAIDE, 1967. Estimation of genetic, environmental and competitional variances in standing forests. Silvae Genetica. Frankfurt, 16:149-152.

SHELBOURNE, C.J.A., 1969a. Predicted genetic improvement from different breeding methods. In: Second World Consultation on Forest Tree Breeding. Washington, FoFTB, p. 8-16.

SHELBOURNE, C.J.A., 1969b. Breeding for stem straightness in conifers. In: Second World Consultation on Forest Tree Breeding. Washington, FO-FTB 69-3/4, 8 p.

SHELBOURNE, C.J.A. e F.R.M. COCKREM, 1969. Progeny and clonal test designs for New Zealand's tree breeding programs. N.Z. For. Res. Inst. Tree Improvement. Report n? $41.15 \mathrm{p}$.

SHELBOURNE, C.J.A. e R.W. STONECYPHER, 1971. The inheritance of bole straightness in young loblolly pine. Silvae Genetica. Frankfurt, 20:151-156.

SHELBOURNE, C.J.A., B.J. ZOBEL e R.W. STONECYPHER, 1969. The inheritance of compression wood and its genetic phenotypic correlation with six other traits in five-yearold loblolly pine. Silvae Genetica. Frankfurt, 18:43-47.

SLUDER, E.R., 1975. Gains in volume growth and rust resistance to age to in progeny tests of selected slash pines. Silvae Genetica. Frankfurt, 24:6-9.

SMITH, W.J., 1967. The heritability of fibre characteristics and its application to wood quality improvement in forest trees. Silvae Genetica. Frankfurt, 16:41-49. 
SNYDER, E.B., 1966. Lattice and compact family block

designs in forest genetics. In: Joint Proceeding, second Genetic Workshop of the Society of American Foresters and the Seventh Lake States Forest Tree Improvement Conference. St. Paul, Minnessota, US. For. Serv. Res. Pap. NC-6, $12-17$.

SQUILlACE, A.E., J.G.A. LA BASTIDE e C.L.H. VAN VREDEN BURCK, 1975. Genetic variation and breeding of scots pine in the Netherlands. Forest Science. Madison, 21:341-352.

SQUILLACE, A.E., R.T. BINGHAM, G. NAMKOONG e H.F. ROBINSON, - 1967. Heritability of juvenile growth rate and expected gain from selection in western pine. Silvae Genetica. Frankfurt, $16: 1-6$.

STEINHOFF, R.J. e R.J. HOFF, 1971 . Estimates of the heritability of height growth in western white pine based on parent progeny relationships. Silvae Genetica. Frankfurt, 20:141-144.

TODA, R., 1972. Heritability problems in forest genetics. In: IUFRo Genetic Sabrao Joint Symposia. Tokyo. p. 1-9.

VARNELL, R.J., A.E. SQUILLACE e G.W. BENGSTON, 1967. Variation and heritability of fruit fulness in slash pine. Silvae Genetica. Frankfurt, 16125-128.

VAN WYK, G., 1976. Early growth results in a diallel progeny test of Eucalyptus grandis. Silvae Genetica. Frankfurt, 25:126-132.

VAN WYK, G., 1977. Progress with the Eucalyptus grandis breeding programme in the Republic of South Africa. In: Third World Consultation on Forest Tree Breeding. Canberra, FO-FTB-77-3/13;5 p. 
VELO, N. e R. VENCOVSKY, 1974. Variâncias associadas às estimativas de variâncias genéticas e coeficientes de herda bilidade. In: Relatōrio Científico, Departamento Genética, Instituto de Genética. p. 238-248.

VENCOVSKY, R., 1969. Genética quantitativa. In: KERR, W.E. (coord.). Melhoramento e Genética. São Paulo, Edições Melhoramentos. 17-37.

VENCOVSKY, R., 1978. Herança Quantitativa. In: PATERNIANI, E. (coord.). Melhoramento de milho no Brasil. Piracica ba, Fundação Cargill. 122-199.

ZOBEL, B.J., 1961. Inheritance of wood properties in conifers. Silvae Genetica. Frankfurt, 10:65-70. 
.114 .

APENDICES 


\section{Apēndice 1}

Médias de altura de plantas (metros) para as 49 progênies co muns aos cincolocais de ensaios, aos dois anos de idade.

\begin{tabular}{|c|c|c|c|c|c|c|}
\hline \multirow{2}{*}{ Progênie } & \multicolumn{5}{|c|}{ Locais } & \multirow{2}{*}{$\begin{array}{l}\text { Média } \\
\text { Geral }\end{array}$} \\
\hline & Agudos & Anhembi & Brotas & Lençöis & Resende & \\
\hline 1 & 10,42 & 14,75 & 11,84 & 11,12 & 15,36 & 12,70 \\
\hline 2 & 10,46 & 13,38 & 11,60 & 11,51 & 14,50 & 12,29 \\
\hline 3 & 10,72 & 13,86 & 11,87 & 11,78 & 15,65 & 12,78 \\
\hline 4 & 10,01 & 13,69 & 12,22 & 11,99 & 15,03 & 12,59 \\
\hline 5 & 11,32 & 13,61 & 11,40 & 10,28 & 15,02 & 12,33 \\
\hline 6 & 10,16 & 14,31 & 12,10 & 11,12 & 14,86 & 12,51 \\
\hline 7 & 11,11 & 14,11 & 10,91 & 11,40 & 14,22 & 12,35 \\
\hline 8 & 11,50 & 14,26 & 12,14 & 12,15 & 13,39 & 12,69 \\
\hline 9 & 10,46 & 12,13 & 11,36 & 9,96 & 14,27 & 12,04 \\
\hline 10 & 10,40 & 13,25 & 11,29 & 11,21 & 14,22 & 12,07 \\
\hline 11 & 10,66 & 14,14 & 10,08 & 10,67 & 14,70 & 12,05 \\
\hline 12 & 10,19 & 13,46 & 10,73 & 9,20 & 15,11 & 11,74 \\
\hline 13 & 10,07 & 13,62 & 12,32 & 10,67 & 14,71 & 12,28 \\
\hline 14 & 8,67 & 13,51 & 11,84 & 9,98 & 14,60 & 11,72 \\
\hline 15 & 10,35 & 13,46 & 12,04 & 10,57 & 15,69 & 12,42 \\
\hline 16 & 9,74 & 13,39 & 12,25 & 10,85 & 12,55 & 11,76 \\
\hline 17 & 10,18 & 13,79 & 10,58 & 9,69 & 13,30 & 11,51 \\
\hline 18 & 9,93 & 14,09 & 12,05 & 11,48 & 14,06 & 12,32 \\
\hline 19 & 11,80 & 13,86 & 12,00 & 11,18 & 14,19 & 12,61 \\
\hline 20 & 11,24 & 14,34 & 12,48 & 12,22 & 15,05 & 13,07 \\
\hline 21 & 10,75 & 14,27 & 11,97 & 10,74 & 15,17 & 12,58 \\
\hline 22 & 11,06 & 13,57 & 10,40 & 11,76 & 15,06 & 12,37 \\
\hline 23 & 10,94 & 13,10 & 12,28 & 10,92 & 15,63 & 12,57 \\
\hline
\end{tabular}


Apêndice 1. (continuação)

Progênie

Locais

Mēdia

Agudos Anhembi Brotas Lençóis Resende

Geral

\begin{tabular}{|c|c|c|c|c|c|c|}
\hline 24 & 9,83 & 13,75 & 12,59 & 11,29 & 14,20 & 12,33 \\
\hline 25 & 10,37 & 13,99 & 12,09 & 11,65 & 14,23 & 12,47 \\
\hline 26 & 11,04 & 13,80 & 12,31 & 10,22 & 14,94 & 12,46 \\
\hline 27 & 11,02 & 14,43 & 11,41 & 9,88 & 14,13 & 12,17 \\
\hline 28 & 10,10 & 11,94 & 11,69 & 11,35 & 14,71 & 11,96 \\
\hline 29 & 10,88 & 14,02 & 11,81 & 9,38 & 14,69 & 12,16 \\
\hline 30 & 10,70 & 13,02 & 10,96 & 11,53 & 14,18 & 12,08 \\
\hline 31 & 10,69 & 13,85 & 11,09 & 9,16 & 14,68 & 11,89 \\
\hline 32 & 10,13 & 14,15 & 9,94 & 11,14 & 15,88 & 12,25 \\
\hline 33 & 10,38 & 12,85 & 10,90 & 11,84 & 14,17 & 12,03 \\
\hline 34 & 12,29 & 12,88 & 10,83 & 10,88 & 14,94 & 12,36 \\
\hline 35 & 10,55 & 13,33 & 13,13 & 10,73 & 15,22 & 12,59 \\
\hline 36 & 10,30 & 12,52 & 11,18 & 7,83 & 13,17 & 11,00 \\
\hline 37 & 9,11 & 11,03 & 11,68 & 10,22 & 11,76 & 10,76 \\
\hline 38 & 10,01 & 12,72 & 12,43 & 11,24 & 14,34 & 12,15 \\
\hline 39 & 9,81 & 13,66 & 12,20 & 11,48 & 14,76 & 12,38 \\
\hline 40 & 10,92 & 13,28 & 12,29 & 11,28 & 15,09 & 12,57 \\
\hline 41 & 10,92 & 13,83 & 12,01 & 10,90 & 13,36 & 12,20 \\
\hline 42 & 11,12 & 13,27 & 12,16 & 11,59 & 14,81 & 12,59 \\
\hline 43 & 10,15 & 14,28 & 11,40 & 11,65 & 13,97 & 12,29 \\
\hline 44 & 11,71 & 14,43 & 12,08 & 11,04 & 15,92 & 13,04 \\
\hline 45 & 11,32 & 12,90 & 10,47 & 9,60 & 13,69 & 11,60 \\
\hline 46 & 9,91 & 13,59 & 11,72 & 10,35 & 14,10 & 11,93 \\
\hline 47 & 10,82 & 14,12 & 11,04 & 10,22 & 13,63 & 11,97 \\
\hline 48 & 9,88 & 13,78 & 12,43 & $9 ; 94$ & 14,71 & 12,15 \\
\hline 49 & 10,52 & 13,68 & 12,48 & 10,73 & 15,15 & 12,51 \\
\hline & 10,54 & 13,61 & 11,67 & 10,81 & 14,51 & 12,23 \\
\hline
\end{tabular}




\section{APēndice 2}

Mëdias de DAP de plantas (centimetros) para as 49 progênies comuns aos cinco locais de ensaios, aos dois anos de idade.

\begin{tabular}{|c|c|c|c|c|c|c|}
\hline \multirow{2}{*}{ Progênie } & \multicolumn{5}{|c|}{ Locais } & \multirow{2}{*}{$\begin{array}{l}\text { Média } \\
\text { Geral }\end{array}$} \\
\hline & Agudos & Anhembi & Brotas & Lençöis & Resende & \\
\hline 1 & 7,58 & 10,18 & 7,99 & 7,86 & 11,25 & 8,97 \\
\hline 2 & 7,95 & 9,11 & 8,16 & 8,58 & 11,25 & 9,01 \\
\hline 3 & 8,94 & 9,71 & 8,72 & 8,48 & 11,27 & 9,42 \\
\hline 4 & 7,41 & 9,00 & 8,87 & 8,61 & 10,69 & 8,92 \\
\hline 5 & 8,70 & 9,84 & 8,24 & 7,33 & 11,27 & 9,08 \\
\hline 6 & 7,21 & 9,61 & 8,99 & 7,87 & 11,05 & 8,95 \\
\hline 7 & 8,35 & 9,36 & 7,37 & 8,56 & 10,85 & 8,90 \\
\hline 8 & 8,10 & 9,56 & 8,29 & 8,91 & 10,28 & 9,03 \\
\hline 9 & 7,85 & 9,74 & 8,37 & 7,43 & 11,12 & 8,90 \\
\hline 10 & 8,13 & 9,66 & 8,16 & 8,35 & 11,05 & 9,07 \\
\hline 11 & 9,58 & 10,00 & 7,28 & 8,55 & 11,97 & 9,48 \\
\hline 12 & 8,03 & 9,71 & 7,31 & 6,84 & 10,73 & 8,52 \\
\hline 13 & 7,63 & 9,50 & 8,93 & 8,12 & 11,13 & 9,06 \\
\hline 14 & 6,84 & 8,83 & 8,99 & 8,08 & 10,82 & 8,71 \\
\hline 15 & 7,60 & 8,76 & 8,44 & 7,55 & 11,22 & 8,71 \\
\hline 16 & 8,09 & 8,83 & 9,07 & 8,22 & 8,26 & 8,49 \\
\hline 17 & 9,01 & 9,98 & 7,50 & 8,32 & 10,31 & 9,02 \\
\hline 18 & 8,93 & 9,33 & 8,70 & 7,94 & 10,46 & 9,07 \\
\hline 19 & 9,24 & 9,33 & 8,81 & 7,91 & 11,60 & 9,38 \\
\hline 20 & 10,00 & 9,66 & 9,09 & 9,08 & 11,65 & 9,90 \\
\hline 21 & 8,74 & 10,00 & 8,89 & 7,98 & 11,38 & 9,40 \\
\hline 22 & 8,52 & 8,90 & 7,14 & 8,68 & 10,67 & 8,78 \\
\hline 23 & 8,83 & 8,40 & 8,57 & 7,97 & 11,60 & 9,07 \\
\hline
\end{tabular}


Apēndice 2. (continuação)

Progênie

Locais

Média

Agudos Anhembi Brotas Lençóis Resende

Geral

\begin{tabular}{|c|c|c|c|c|c|c|}
\hline 24 & 8,16 & 9,49 & 9,53 & 7,97 & 10,52 & 9,13 \\
\hline 25 & 8,23 & 9,26 & 8,42 & 8,11 & 10,82 & 8,97 \\
\hline 26 & 8,46 & 9,74 & 8,93 & 7,33 & 11,38 & 9,18 \\
\hline 27 & 10,39 & 9,92 & 8,20 & 7,21 & 11,25 & 9,39 \\
\hline 28 & 7,48 & 9,04 & 8,26 & 7,58 & 10,97 & 8,67 \\
\hline 29 & 8,01 & 9,57 & 8,58 & 6,77 & 10,97 & 8,78 \\
\hline 30 & 7,97 & 8,81 & 8,52 & 8,20 & 11,42 & 8,98 \\
\hline 31 & 7,64 & 9,81 & 7,82 & 6,46 & 10,80 & 8,51 \\
\hline 32 & 8,33 & 10,01 & 6,88 & 7,71 & 12,26 & 9,04 \\
\hline 33 & . $\quad 8,18$ & 9,43 & 7,29 & 8,68 & 10,21 & 8,76 \\
\hline 34 & 10,70 & 8,68 & 7,40 & 7,75 & 11,40 & 9,19 \\
\hline 35 & 8,06 & 9,56 & 9,19 & 7,78 & 10,98 & 9,11 \\
\hline 36 & 8,23 & 8,63 & 8,20 & 6,12 & 9,97 & 8,23 \\
\hline 37 & 7,09 & 7,69 & 8,37 & 7,43 & 8,73 & 7,86 \\
\hline 38 & 8,84 & 8,94 & 9,22 & 8,11 & 10,87 & 9,16 \\
\hline 39 & 7,01 & 9,21 & 8,42 & 8,60 & 11,07 & 8,86 \\
\hline 40 & 8,37 & 9,40 & 8,77 & 8,26 & 11,08 & 9,18 \\
\hline 41 & 8,54 & 9,45 & 9,01 & 7,98 & 9,48 & 8,89 \\
\hline 42 & 8,37 & 9,50 & 8,55 & 8,77 & 12,08 & 9,45 \\
\hline 43 & 8,45 & 9,57 & 8,20 & 7,58 & 10,90 & 8,94 \\
\hline 44 & 9,86 & 10,40 & 8,62 & 7,81 & 11,72 & 9,63 \\
\hline 45 & 8,70 & $8 ; 81$ & 7,47 & 6,63 & 10,12 & 8,53 \\
\hline 46 & 7,45 & 8,85 & 8,98 & 7,46 & 10,22 & 8,59 \\
\hline 47 & 8,24 & 9,74 & 7,37 & 7,52 & 11,15 & 8,80 \\
\hline 48 & 6,96 & 9,50 & 8,52 & 7,15 & 10,38 & 8,50 \\
\hline 49 & 8,51 & 9,74 & 8,92 & 7,95 & 11,81 & 9,39 \\
\hline Aia & 8,31 & 9,38 & 8,37 & 7,88 & 10,92 & 8,97 \\
\hline
\end{tabular}


Apêndice 3

Médias de forma do tronco ( $\sqrt{\text { notas }}$ ) para as 49 progênies comuns aos cinco locais de ensaios, aos dois anos de idade.

Progênie
Locais

Agudos Anhembi Brotas Lençóis Resende

Média

Geral

\begin{tabular}{|c|c|c|c|c|c|c|}
\hline 1 & 1,82 & 1,61 & 1,80 & 1,78 & 1,76 & 1,75 \\
\hline 2 & 1,74 & 1,68 & 1,59 & 1,67 & 1,71 & 1,68 \\
\hline 3 & 1,65 & 1,68 & 1,74 & 1,78 & 1,74 & 1,72 \\
\hline 4 & 1,85 & 1,60 & $.1,73$ & 1,80 & 1,71 & 1,74 \\
\hline 5 & 1,54 & 1,56 & 1,56 & 1,66 & 1,63 & 1,59 \\
\hline 6 & 1,81 & 1,79 & 1,80 & 1,82 & 1,76 & 1,80 \\
\hline 7 & 1,82 & 1,74 & 1,60 & 1,79 & 1,83 & 1,76 \\
\hline 8 & 1,71 & 1,72 & 1,81 & 1,84 & 1,74 & 1,76 \\
\hline 9 & 1,80 & 1,75 & 1,71 & 1,75 & 1,80 & 1,76 \\
\hline 10 & 1,74 & 1,66 & 1,77 & 1,74 & 1,77 & 1,74 \\
\hline 11 & 1,76 & 1,69 & 1,75 & 1,69 & 1,97 & 1,77 \\
\hline 12 & 1,85 & 1,66 & 1,67 & 1,80 & 1,80 & 1,76 \\
\hline 13 & 1,81 & 1,69 & 1,71 & 1,77 & 1,82 & 1,76 \\
\hline 14 & 1,72 & 1,65 & 1,70 & 1,70 & 1,81 & 1,72 \\
\hline 15 & 1,92 & 1,91 & 2,01 & 1,84 & 1,98 & 1,93 \\
\hline 16 & 1,81 & 1,72 & 1,53 & 1,64 & 1,81 & 1,70 \\
\hline 17 & 1,51 & 1,55 & 1,55 & 1,82 & 1,59 & 1,60 \\
\hline 18 & 1,79 & 1,70 & 1,64 & 1,82 & 1,92 & 1,77 \\
\hline 19 & 1,73 & 1,67 & 1,68 & 1,80 & 1,89 & 1,75 \\
\hline 20 & 1,85 & 1,70 & 1,72 & 1,75 & 1,83 & 1,77 \\
\hline 21 & 1,91 & 1,65 & 1,64 & 1,75 & 1,74 & 1,74 \\
\hline 22 & 1,78 & 1,82 & 1,70 & 1,75 & 1,75 & 1,76 \\
\hline 23 & 1,88 & 1,70 & 1,69 & 1,70 & 1,88 & 1,77 \\
\hline
\end{tabular}


Apēndice 3. (continuação)

Progênie

Locais

Média

Agudos Anhembi Brotas Lençóis Resende

Geral

\begin{tabular}{|c|c|c|c|c|c|c|}
\hline 24 & 1,80 & 1,71 & 1,67 & 1,64 & 1,68 & 1,70 \\
\hline 25 & 1,68 & 1,70 & 1,68 & 1,79 & 1,89 & 1,75 \\
\hline 26 & 1,81 & 1,86 & 1,79 & 1,71 & 1,87 & 1,81 \\
\hline 27 & 1,69 & 1,67 & 1,67 & 1,72 & 1,71 & 1,69 \\
\hline 28 & 1,80 & 1,84 & 1,63 & 1,63 & 1,83 & 1,75 \\
\hline 29 & 1,66 & 1,57 & 1,63 & 1,78 & 1,77 & 1,68 \\
\hline 30 & 1,81 & 1,70 & 1,70 & 1,82 & 1,84 & 1,77 \\
\hline 31 & 1,81 & 1,73 & 1,79 & 1,77 & 1,93 & 1,81 \\
\hline 32 & 1,90 & 1,71 & 1,69 & 1,61 & 1,86 & 1,75 \\
\hline 33 & 1,78 & 1,47 & 1,59 & 1,65 & 1,95 & 1,69 \\
\hline 34 & 1,70 & 1,66 & 1,67 & 1,90 & 1,69 & 1,72 \\
\hline 35 & 1,89 & 1,80 & 1,81 & 1,70 & 1,92 & 1,82 \\
\hline 36 & 1,78 & 1,83 & 1,88 & 1,69 & 1,85 & 1,81 \\
\hline 37 & 1,77 & 1,71 & 1,72 & 1,71 & 1,80 & 1,74 \\
\hline 38 & 1,79 & 1,72 & 1,68 & 1,75 & 1,81 & 1,75 \\
\hline 39 & 1,75 & 1,67 & 1,59 & 1,67 & 1,65 & 1,67 \\
\hline 40 & 1,80 & 1,76 & 1,78 & 1,75 & 1,77 & 1,77 \\
\hline 41 & 1,81 & 1,72 & 1,61 & 1,75 & 1,77 & 1,78 \\
\hline 42 & 1,77 & 1,60 & 1,82 & 1,75 & 1,79 & 1,75 \\
\hline 43 & 1,94 & 1,80 & 1,72 & 1,62 & 1,88 & 1,79 \\
\hline 44 & 1,70 & 1,66 & 1,73 & 1,69 & 1,82 & 1,72 \\
\hline 45 & 1,76 & 1,70 & 1,66 & 1,71 & 1,67 & 1,70 \\
\hline 46 & 1,78 & 1,56 & 1,52 & 1,70 & 1,66 & 1,64 \\
\hline 47 & 1,89 & 1,67 & 1,68 & 1,80 & 1,80 & 1,77 \\
\hline 48 & 1,80 & 1,65 & 1,64 & 1,62 & 1,71 & 1,68 \\
\hline 49 & 1,89 & 1,94 & 1,87 & 1,96 & 1,92 & 1,92 \\
\hline Média & 1,78 & 1,70 & 1,70 & 1,74 & 1,80 & 1,74 \\
\hline
\end{tabular}




\section{Apēndice 4}

Médias de porcentagem de falhas para as 49 progênies comuns aos cinco locais de ensaios, aos dois anos de idade.

\begin{tabular}{ccc}
\multicolumn{2}{c}{ Locais } & Média \\
\cline { 2 - 4 } Progênie & \multicolumn{1}{c}{ Agudos Anhembi Brotas Lençóis Resende } \\
\hline
\end{tabular}

\begin{tabular}{|c|c|c|c|c|c|c|}
\hline 1 & 24,67 & 14,63 & 9,34 & 9,34 & 4,06 & 12,41 \\
\hline 2 & 29,12 & 14,63 & 19,92 & 14,63 & 16,63 & 18,99 \\
\hline 3 & 4,06 & 9,34 & 12,19 & 12,19 & 4,06 & 8,37 \\
\hline 4 & 16,63 & 9,34 & 9,34 & 14,63 & 11,68 & 12,33 \\
\hline 5 & 23,50 & 14,63 & 9,34 & 9,34 & 13,96 & 14,16 \\
\hline 6 & 9,01 & 4,06 & 14,63 & 9,34 & 4,06 & 8,22 \\
\hline 7 & 34,57 & 12,19 & 9,34 & 19,85 & 4,06 & 16,00 \\
\hline 8 & 18,83 & 9,34 & 12,19 & 14,63 & 4,06 & 11,81 \\
\hline 9 & 21,58 & 9,34 & 25,14 & 17,48 & 4,06 & 15,52 \\
\hline 10 & 13,96 & 17,48 & 19,85 & 9,34 & 4,06 & 12,94 \\
\hline 11 & 21,58 & 14,63 & 9,34 & 33,20 & 4,06 & 16,56 \\
\hline 12 & 21,50 & 14,63 & 4,06 & 30,83 & 9,01 & 16,01 \\
\hline 13 & 24,25 & 14,56 & 12,19 & 30,83 & 4,06 & 17,18 \\
\hline 14 & 18,91 & 4,06 & 14,63 & 31,55 & 4,06 & 14,64 \\
\hline 15 & 11,68 & 4,06 & 17,48 & 27,99 & 4,06 & 13,05 \\
\hline 16 & 16,63 & 9,34 & 17,48 & 17,48 & 13,86 & 14,98 \\
\hline 17 & 25,70 & 14,63 & 17,48 & 58,16 & 21,58 & 27,51 \\
\hline 18 & 21,58 & 4,06 & 12,19 & 14,56 & 9,01 & 12,28 \\
\hline 19 & 34,50 & $22 ; 77$ & 9,34 & 9,34 & 4,06 & 16,00 \\
\hline 20 & 13,96 & 12,19 & 14,63 & 9,34 & 9,01 & 11,83 \\
\hline 21 & 4,06 & 4,06 & 30,35 & 9,34 & 9,01 & 11,36 \\
\hline 22 & 26,45 & 4,06 & 14,63 & 25,62 & 9,01 & 15,95 \\
\hline 23 & 9,01 & 9,34 & 14,63 & 19,85 & 4,06 & 11,38 \\
\hline
\end{tabular}


Apēndice 4. (continuação)

Progênie

Locais

Média

Agudos Anhembi Brotas Lençóis Resende Geral

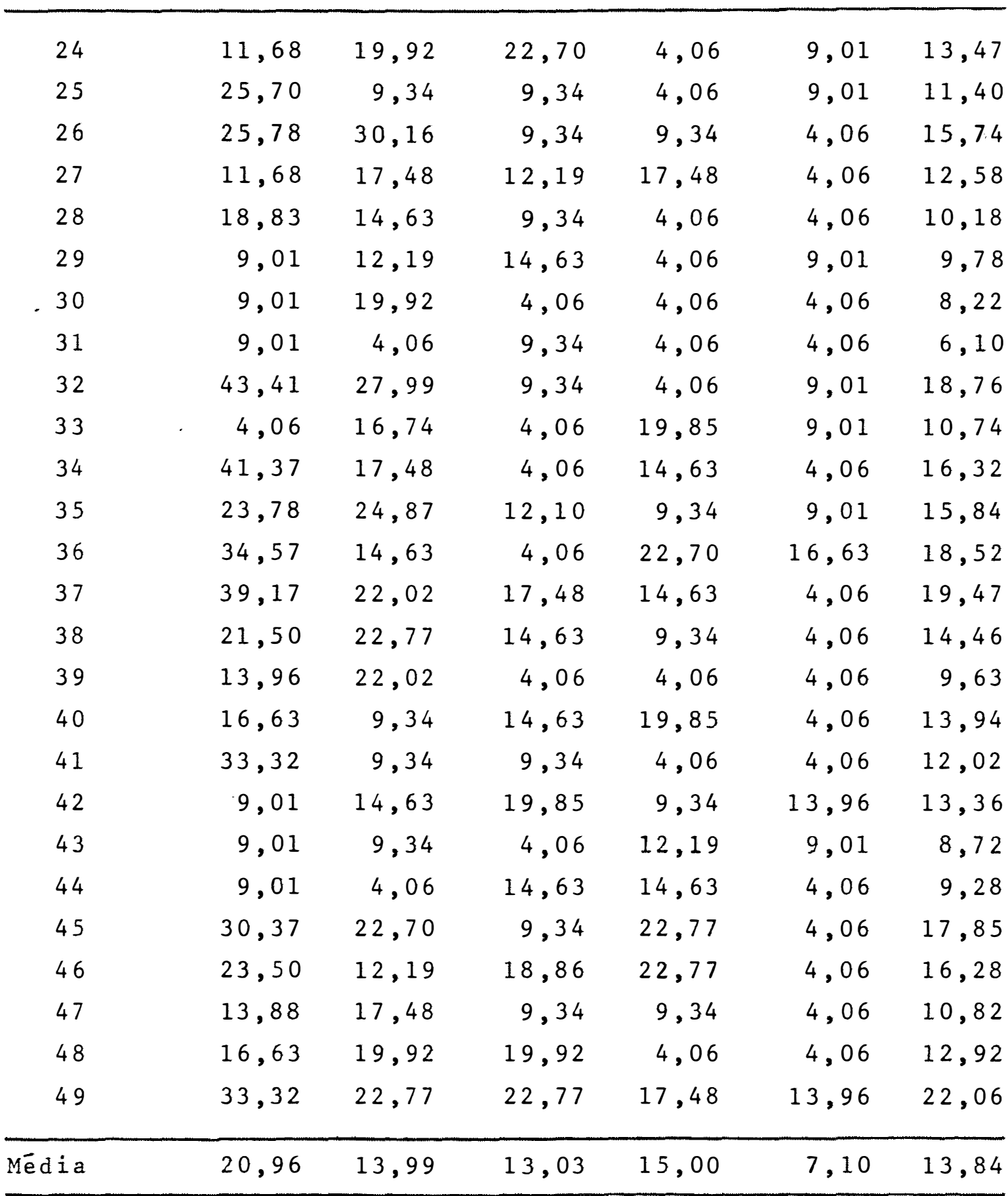




\section{Apēndice 5}

Médias de volume cilindrico ( $\left.\mathrm{m}^{3} / \mathrm{ha}\right)$ para as 49 progênies comuns aos cinco locais de ensaios, aos dois anos de idade.

Progênie

Locais

Média

Agudos Anhembi Brotas Lençóis Resende Geral

\section{1}

2

3

4

5

6

7

8

9

10

11

12

13

14

15

16

17

18

19

20

.21

22

23
76,36

175,40

81,87

143,22

137,07

170,43

74,64

152,59

103,89

162,78

65,67

185,52

$$
80,37
$$

160,28

103,51

168,0

$74,93 \quad 160,54$

99,75

125,58

$92,87 \quad 142,08$

112,65

139,97

123,98

160,80

102,26

102,13

130,10

121,21

82,46

130,60

106,50

162,99

92,28

92,00

85,69

136,16

81,72

107,50

87,87

62,93

70,20

70,20

$264,30143,26$

$234,12136,83$

$266,36165,30$

$215,38145,48$

$240,16 \quad 142,57$

$250,54150,61$

$228,16136,37$

$197,46 \quad 147,69$

$243,50132,65$

$237,64141,04$

$281,27157,56$

$85,80 \quad 156,29$

121,92

94,30

$227,94124,17$

69,37

$241,45136,71$

93,78

67,24
93,63

119,70

46,95

123,81

103,33

140,62

124,12

78,68

123,13

169,01

115,46

141,01

167,55

140,75

120,62

175,68

123,46

$90,25 \quad 187,97 \quad 98,08$

$72,09 \quad 153,35$

73,33

130,49

105,21

$231,66124,91$

$269,58136,24$

$131,60122,07$

$180,39108,88$

$210,49142,08$

$261,59146,24$

$270,42173,87$

$254,47150,85$

$231,16132,08$

$99,64 \quad 131,08 \quad 116,73$
$284,07147,35$ 
Apéndice 5. (continuação)

Progênie
Locais

Agudos Anhembi Brotas Lençóis Resende
Média

Geral

\begin{tabular}{|c|c|c|c|c|c|c|}
\hline 24 & 74,30 & 157,72 & 122,08 & 139,48 & 214,97 & 141,71 \\
\hline 25 & 83,97 & 151,94 & 111,29 & 139,30 & 222,37 & 141,78 \\
\hline 26 & 92,35 & 134,24 & 126,88 & 102,48 & 264,64 & 144,12 \\
\hline 27 & 152,38 & 172,74 & 95,23 & 89,79 & 257,56 & 153,54 \\
\hline 28 & 80,51 & 120,23 & 104,22 & 118,40 & 236,06 & 131,88 \\
\hline 29 & 89,36 & 159,22 & 106,84 & 89,39 & 240,95 & 137,16 \\
\hline 30 & 89,08 & 128,46 & $114 ., 05$ & 142,78 & 258,20 & 146,55 \\
\hline 31 & 95,79 & 183,04 & 94,39 & 80,15 & 244,25 & 139,52 \\
\hline 32 & 53,07 & 146,21 & 81,17 & 121,90 & 311,34 & 142,74 \\
\hline 33 & 102,40 & 123,06 & 84,84 & 132,49 & 193,70 & 127,31 \\
\hline 34 & 120,90 & 125,34 & 83,07 & 113,40 & 270,86 & 142,71 \\
\hline 35 & 79,93 & 134,77 & 137,36 & 115,02 & 242,13 & 141,84 \\
\hline 36 & 75,00 & 130,21 & 107,14 & 53,19 & 159,26 & 104,98 \\
\hline 37 & 40,23 & 77,36 & 107,70 & 105,31 & 137,66 & 93,65 \\
\hline 38 & 85,52 & 127,85 & 131,48 & $130 ; 67$ & 237,32 & 142,57 \\
\hline 39 & 80,41 & 124,87 & 118,80 & 155,94 & 239,25 & 143,86 \\
\hline 40 & 93,20 & 147,75 & 110,59 & 122,17 & 247,20 & 144,18 \\
\hline 41 & 86,77 & 167,23 & 126,22 & 127,66 & 168,77 & 135,33 \\
\hline 42 & 114,46 & 164,62 & 107,44 & 157,48 & 268,94 & 162,59 \\
\hline 43 & 105,45 & 170,20 & 103,32 & 101,87 & 213,81 & 138,93 \\
\hline 44 & 152,93 & 210,79 & 110,65 & 114,70 & 294,75 & 176,77 \\
\hline 45 & 89,48 & 125,54 & 79,35 & 67,83 & 197,52 & 111,95 \\
\hline 46 & 76,36 & 135,83 & 109,95 & 94,94 & 196,25 & 122,67 \\
\hline 47 & 88,22 & 151,69 & 80,04 & 104,45 & 233,43 & 131,57 \\
\hline 48 & 72,48 & 159,89 & 108,24 & 102,64 & 206,82 & 130,02 \\
\hline 49 & 81,72 & 147,11 & 112,86 & 111,77 & 269,30 & 144,55 \\
\hline & 89,78 & 151,50 & 105,72 & 115, & 23 & 1 \\
\hline
\end{tabular}


.125.

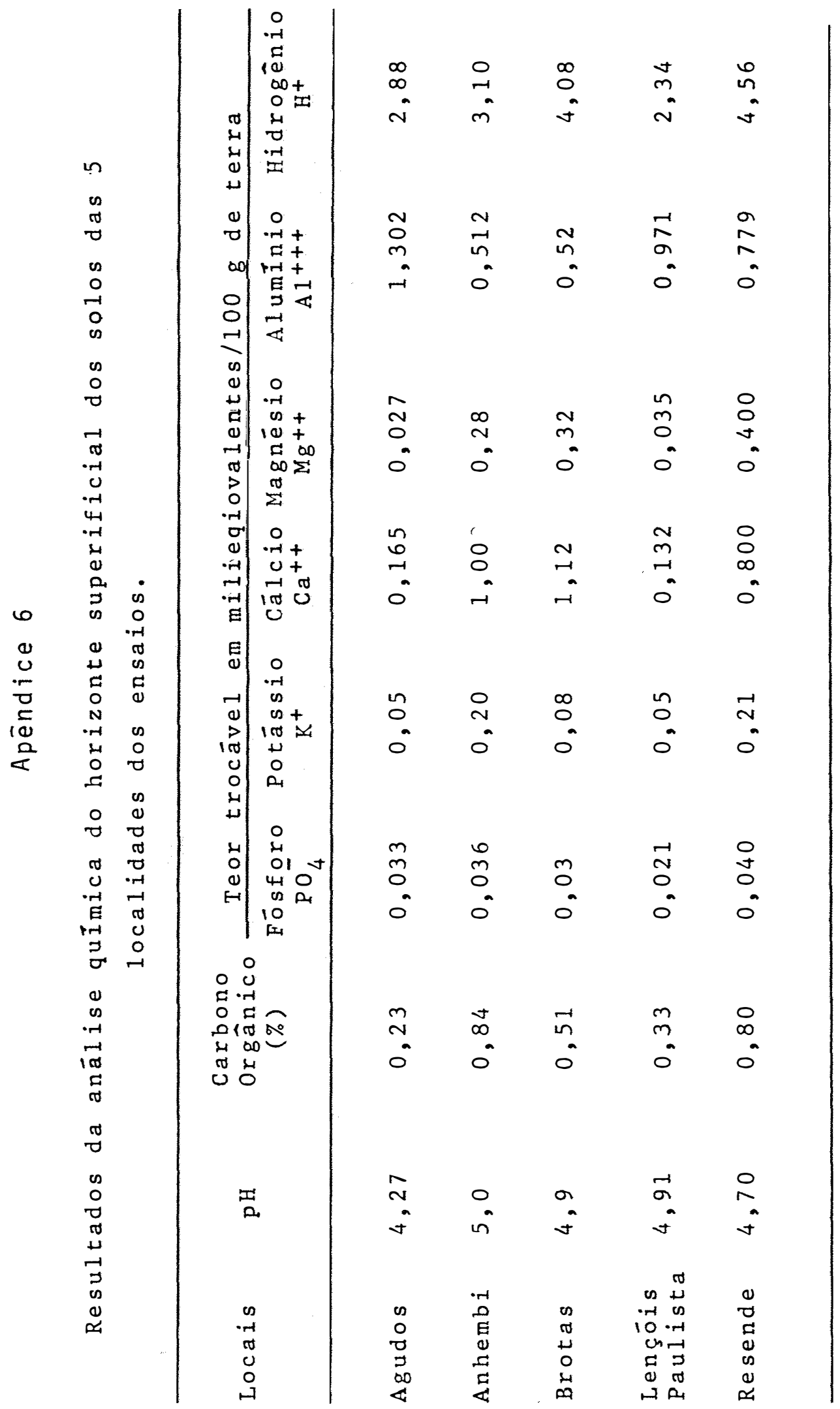

